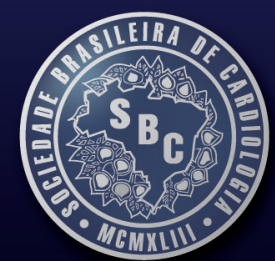

www.cardiol.br

www.arquivosonline.com.br

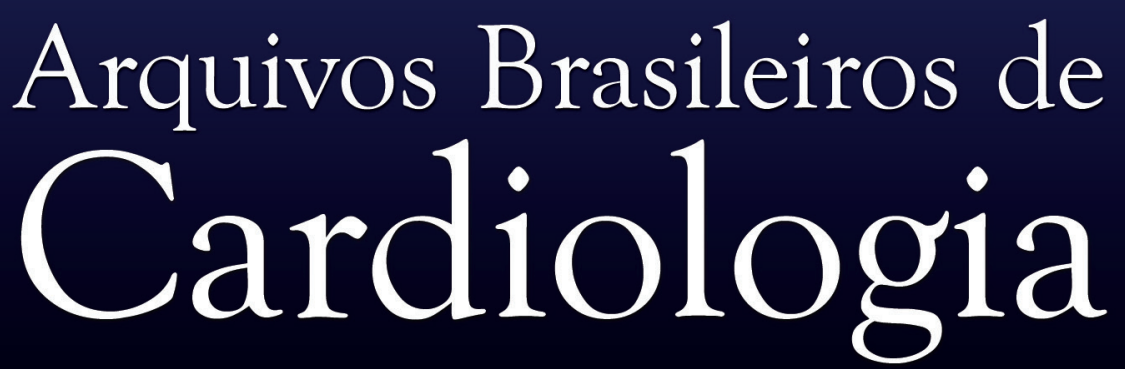

Sociedade Brasileira de Cardiologia •ISSN-0066-782X • Volume 99, N², Supl. 2, Agosto 2012

\title{
I Diretriz Brasileira de Hipercolesterolemia familiar (HF)
}





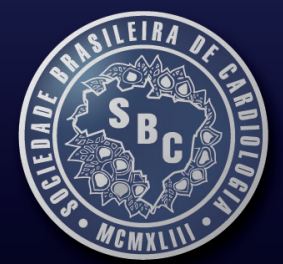

\section{Arquivos Brasileiros de}

www.cardiol.br

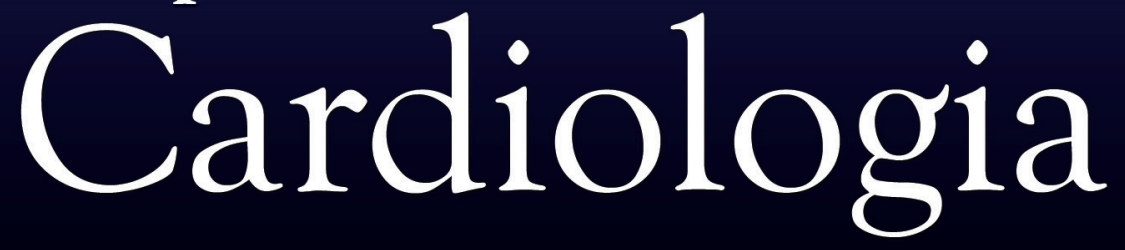

\section{Diretriz Brasileira de}

\section{Hipercolesterolemia Familiar (HF)}

\section{Autores da Diretriz:}

Santos RD, Gagliardi ACM., Xavier HZ, Casella Filho A, Araújo DB.; Cesena FY, Alves RJ, Pereira AC, Lottenberg AM, Chacra APM, Faludi AA, Sposito AC, Ribeiro Filho FF, Fonseca FAH., Giuliano ICB, Catani LH, Bertolami MC, Miname MH, Izar MCO, Monte O, Maranhão RC, Martinez TLR, Machado VA, Rocha VZ, Salgado Filho W 


\section{Arquivos Brasileiros de Cardiologia}

www.arquivosonline.com.br

REVISTA DA SOCIEDADE BRASILEIRA DE CARDIOLOGIA - Publicada desde 1948

Diretor Científico

Luiz Alberto Piva e Mattos

\section{Editor-Chefe}

Luiz Felipe P. Moreira

EDitores Associados

Cardiologia Clínica

José Augusto Barreto-Filho

Cardiologia Cirúrgica

Paulo Roberto B. Evora
CARDiologia INTERVEnCIONISTA

Pedro A. Lemos

Cardiologia Pediátrica/Congênitas

Antonio Augusto Lopes

Arritmias/Marcapasso

Mauricio Scanavacca

Métodos Diagnósticos Não-Invasivos

Carlos E. Rochitte

Pesquisa Básica ou Experimental

Leonardo A. M. Zornoff
Epidemiologia/Estatística

Lucia Campos Pellanda

Hipertensão Arterial

Paulo Cesar B. V. Jardim

Ergometria, Exercício e

Reabilitação Cardíaca

Ricardo Stein

Primeiro Editor (1948-1953)

† Jairo Ramos

\section{Conselho Editorial}

\section{Brasil}

Adib D. Jatene (SP)

Alexandre A. C. Abizaid (SP)

Alfredo José Mansur (SP)

Álvaro Avezum (SP)

Amanda G. M. R. Sousa (SP)

André Labrunie (PR)

Andrei Sposito (DF)

Angelo A. V. de Paola (SP)

Antonio Augusto Barbosa Lopes (SP)

Antonio Carlos C. Carvalho (SP)

Antônio Carlos Palandri Chagas (SP)

Antonio Carlos Pereira Barretto (SP)

Antonio Cláudio L. Nóbrega (RJ)

Antonio de Padua Mansur (SP)

Ari Timerman (SP)

Armênio Costa Guimarães (BA)

Ayrton Klier Péres (DF)

Ayrton Pires Brandão (RJ)

Barbara M. lanni (SP)

Beatriz Matsubara (SP)

Braulio Luna Filho (SP)

Brivaldo Markman Filho (PE)

Bruce B. Duncan (RS)

Bruno Caramelli (SP)

Carisi A. Polanczyk (RS)

Carlos Alberto Pastore (SP)

Carlos Eduardo Negrão (SP)

Carlos Eduardo Rochitte (SP)

Carlos Eduardo Suaide Silva (SP)

Carlos Vicente Serrano Júnior (SP)

Celso Amodeo (SP)

Charles Mady (SP)

Claudio Gil Soares de Araujo (RJ)

Cleonice Carvalho C. Mota (MG)

Dalton Valentim Vassallo (ES)

Décio Mion Jr (SP)

Denilson Campos de Albuquerque (RJ)

Dikran Armaganijan (SP)

Djair Brindeiro Filho (PE)

Domingo M. Braile (SP)

Edmar Atik (SP)

Edson Stefanini (SP)

Elias Knobel (SP)

Eliudem Galvão Lima (ES)

Emilio Hideyuki Moriguchi (RS)

Enio Buffolo (SP)
Eulógio E. Martinez Fo (SP)

Evandro Tinoco Mesquita (RJ)

Expedito E. Ribeiro da Silva (SP)

Fábio Sândoli de Brito Jr. (SP)

Fábio Vilas-Boas (BA)

Fernando A. P. Morcerf (RJ)

Fernando Bacal (SP)

Flávio D. Fuchs (RS)

Francisco Antonio Helfenstein Fonseca (SP)

Francisco Laurindo (SP)

Francisco Manes Albanesi Fo (RJ)

Gilmar Reis (MG)

Gilson Soares Feitosa (BA)

Ínes Lessa (BA)

Iran Castro (RS)

Ivan G. Maia (RJ)

Ivo Nesralla (RS)

Jarbas Jakson Dinkhuysen (SP)

João Pimenta (SP)

Jorge Ilha Guimarães (RS)

Jorge Pinto Ribeiro (RS)

José A. Marin-Neto (SP)

José Antonio Franchini Ramires (SP)

José Augusto Soares Barreto Filho (SE)

José Carlos Nicolau (SP)

José Geraldo de Castro Amino (RJ)

José Lázaro de Andrade (SP)

José Péricles Esteves (BA)

José Teles Mendonça (SE)

Leopoldo Soares Piegas (SP)

Luís Eduardo Rohde (RS)

Luiz A. Machado César (SP)

Luiz Alberto Piva e Mattos (SP)

Lurildo Saraiva (PE)

Marcelo C. Bertolami (SP)

Marcia Melo Barbosa (MG)

Marco Antônio Mota Gomes (AL)

Marcus V. Bolívar Malachias (MG)

Maria Cecilia Solimene (SP)

Mario S. S. de Azeredo Coutinho (SC)

Maurício I. Scanavacca (SP)

Mauricio Wajngarten (SP)

Max Grinberg (SP)

Michel Batlouni (SP)

Nabil Ghorayeb (SP)

Nadine O. Clausell (RS)

Nelson Souza e Silva (RJ)
Orlando Campos Filho (SP)

Otávio Rizzi Coelho (SP)

Otoni Moreira Gomes (MG)

Paulo A. Lotufo (SP)

Paulo Cesar B. V. Jardim (GO)

Paulo J. F. Tucci (SP)

Paulo J. Moffa (SP)

Paulo R. A. Caramori (RS)

Paulo R. F. Rossi (PR)

Paulo Roberto S. Brofman (PR)

Paulo Zielinsky (RS)

Protásio Lemos da Luz (SP)

Renato A. K. Kalil (RS)

Roberto A. Franken (SP)

Roberto Bassan (RJ)

Ronaldo da Rocha Loures Bueno (PR)

Sandra da Silva Mattos (PE)

Sergio Almeida de Oliveira (SP)

Sérgio Emanuel Kaiser (RJ)

Sergio G. Rassi (GO)

Sérgio Salles Xavier (RJ)

Sergio Timerman (SP)

Silvia H. G. Lage (SP)

Valmir Fontes (SP)

Vera D. Aiello (SP)

Walkiria S. Avila (SP)

William Azem Chalela (SP)

Wilson A. Oliveira Jr (PE)

Wilson Mathias Jr (SP)

\section{Exterior}

Adelino F. Leite-Moreira (Portugal)

Alan Maisel (Estados Unidos)

Aldo P. Maggioni (Itália)

Cândida Fonseca (Portugal)

Fausto Pinto (Portugal)

Hugo Grancelli (Argentina)

James de Lemos (Estados Unidos)

João A. Lima (Estados Unidos)

John G. F. Cleland (Inglaterra)

Maria Pilar Tornos (Espanha)

Pedro Brugada (Bélgica)

Peter A. McCullough (Estados Unidos)

Peter Libby (Estados Unidos)

Piero Anversa (Itália) 


\section{Sociedade Brasileira de Cardiologia}

Presidente

Jadelson Pinheiro de Andrade

Vice-Presidente

Dalton Bertolim Précoma

Diretor Administrativo

Marcelo Souza Hadlich

Diretora Financeira

Eduardo Nagib Gaui

Diretor de Relações Governamentais

Daniel França Vasconcelos

Diretor de Comunicação

Carlos Eduardo Suaide Silva

Diretor de Qualidade Assistencial

José Xavier de Melo Filho

Diretor Científico

Luiz Alberto Piva e Mattos

Diretor de Promoção de Saúde

Cardiovascular - SBC/Funcor

Carlos Alberto Machado

Diretor de Relações

Estaduais e Regionais

Marco Antonio de Mattos

Diretor de Departamentos

Especializados

Gilberto Venossi Barbosa

Diretor de Tecnologia da Informação

Carlos Eduardo Suaide Silva

Diretor de Pesquisa

Fernando Bacal

Editor-Chefe Arquivos Brasileiros de Cardiologia

Luiz Felipe P. Moreira

Editor do Jornal SBC

Fábio Vilas-Boas Pinto

Coordenador do Conselho de Projeto Epidemiológico

David de Pádua Brasil
Coordenadores do Conselho de Ações Sociais

Alvaro Avezum Junior

Ari Timerman

Coordenadora do Conselho de Novos

Projetos

Glaucia Maria Moraes Oliveira

Coordenador do Conselho de Aplicação de Novas Tecnologias

Washington Andrade Macie

Coordenador do Conselho de Inserção do Jovem Cardiologista

Fernando Augusto Alves da Costa

Coordenador do Conselho de Avaliação da Qualidade da Prática Clínica e Segurança do Paciente

Evandro Tinoco Mesquita

Coordenador do Conselho de

Normatizações e Diretrizes

Harry Correa Filho

Coordenador do Conselho de Educação

Continuada

Antonio Carlos de Camargo Carvalho

Comitê de Atendimento de Emergência e Morte Súbita

Manoel Fernandes Canesin

Nabil Ghorayeb

Sergio Timerman

Comitê de Prevenção Cardiovascular Antonio Delduque de Araujo Travessa Sergio Baiocchi Carneiro

Regina Coeli Marques de Carvalho

Comitê de Planejamento Estratégico Fabio Sândoli de Brito

José Carlos Moura Jorge

Walter José Gomes

Comitê de Assistência ao Associado

Maria Fatima de Azevedo

Mauro José Oliveira Gonçalves

Ricardo Ryoshim Kuniyoshi

Comitê de Relações Internacionais

Antonio Felipe Simão

João Vicente Vitola

Oscar Pereira Dutra
Presidentes das Estaduais e Regionais da SBC

SBC/AL - Alfredo Aurelio Marinho Rosa

SBC/AM - Jaime Giovany Arnez Maldonado

SBC/BA - Augusto José Gonçalves de Almeida

SBC/CE - Eduardo Arrais Rocha

SBC/CO - Hernando Eduardo Nazzetta (GO)

SBC/DF - Renault Mattos Ribeiro Junior

SBC/ES - Antonio Carlos Avanza Junior

SBC/GO - Luiz Antonio Batista de Sá

SBC/MA - Magda Luciene de Souza Carvalho

SBC/MG - Maria da Consolação Vieira Moreira

SBC/MS - Sandra Helena Gonsalves de Andrade

SBC/MT - José Silveira Lage

SBC/NNE - Aristoteles Comte de Alencar Filho (AM)

SBC/PA - Claudine Maria Alves Feio

SBC/PB - Alexandre Jorge de Andrade Negri

SBC/PE - Silvia Marinho Martins

SBC/PI - Ricardo Lobo Furtado

SBC/PR - Álvaro Vieira Moura

SBC/RJ - Glaucia Maria Moraes Oliveira

SBC/RN - Carlos Alberto de Faria

SBC/RS - Justo Antero Sayão Lobato Leivas

SBC/SC - Conrado Roberto Hoffmann Filho

SBC/SE - Eduardo José Pereira Ferreira

SBC/SP - Carlos Costa Magalhães

SBC/TO - Adalgele Rodrigues Blois

\section{Presidentes dos Departamentos Especializados e Grupos de Estudos}

SBC/DA - Hermes Toros Xavier (SP)

SBC/DCC - Evandro Tinoco Mesquita (RJ)

SBC/DCM - Orlando Otavio de Medeiros (PE)

SBC/DCC/CP - Estela Suzana Kleiman Horowitz (RS)

SBC/DECAGE - Abrahão Afiune Neto (GO)

SBC/DEIC - João David de Souza Neto (CE)

SBC/DERC - Pedro Ferreira de

Albuquerque (AL)
SBC/DFCVR - José Carlos Dorsa Vieira Pontes (MS)

SBC/DHA - Weimar Kunz Sebba Barroso de Souza (GO)

SBC/DIC - Jorge Eduardo Assef (SP)

SBC/SBCCV - Walter José Gomes (SP)

SBC/SBHCI - Marcelo Antonio Cartaxo Queiroga Lopes (PB)

SBC/SOBRAC - Adalberto Menezes Lorga Filho (SP)

SBC/DCC/GAPO - Daniela Calderaro (SP)
SBC/DCC/GECETI - João Fernando Monteiro Ferreira (SP)

SBC/DCC/GEECABE - Luis Claudio Lemos Correia (BA)

SBC/DCC/GEECG - Carlos Alberto Pastore (SP)

SBC/DCP/GECIP - Angela Maria Pontes Bandeira de Oliveira (PE)

SBC/DERC/GECESP - Daniel Jogaib Daher (SP)

SBC/DERC/GECN - José Roberto Nolasco de Araújo (AL) 


\section{Arquivos Brasileiros de Cardiologia}

Volume 99, № 2, Suplemento 2, Agosto 2012

Indexação: ISI (Thomson Scientific), Cumulated Index Medicus (NLM), SCOPUS, MEDLINE, EMBASE, LILACS, SciELO, PubMed

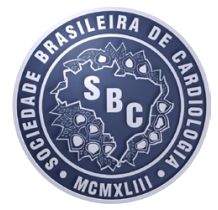

Av. Marechal Câmara, 160 - 3a andar - Sala 330 20020-907 • Centro • Rio de Janeiro, RJ • Brasil Tel.: (21) 3478-2700

E-mail: arquivos@cardiol.br www.arquivosonline.com.br SciElO: www.scielo.br
Departamento Comercial

Telefone: (11) 3411-5500

e-mail: comercialsp@cardiol.br

Produção Editorial

SBC - Núcleo Interno de Publicações
Produção Gráfica e Diagramação SBC - Núcleo Interno de Design

Impressão

Prol Editora Gráfica

Tiragem

11.000 exemplares
AMB

Filiada à Associação Médica Brasileira

Os anúncios veiculados nesta edição são de exclusiva responsabilidade dos anunciantes, assim como os conceitos emitidos em artigos assinados são de exclusiva responsabilidade de seus autores, não refletindo necessariamente a opinião da SBC.

Material de distribuição exclusiva à classe médica. Os Arquivos Brasileiros de Cardiologia não se responsabilizam pelo acesso indevido a seu conteúdo e que contrarie a determinação em atendimento à Resolução da Diretoria Colegiada (RDC) no 96/08 da Agência Nacional de Vigilância Sanitária (Anvisa), que atualiza o regulamento técnico sobre Propaganda, Publicidade, Promoção e informação de Medicamentos. Segundo o artigo 27 da insígnia, "a propaganda ou publicidade de medicamentos de venda sob prescrição deve ser restrita, única e exclusivamente, aos profissionais de saúde habilitados a prescrever ou dispensar tais produtos (...)".

Garantindo o acesso universal, o conteúdo científico do periódico continua disponível para acesso gratuito e integral a todos os interessados no endereço: www.arquivosonline.com.br.

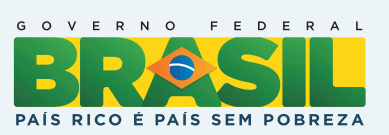

\section{Ministério da Ciência e Tecnologia}

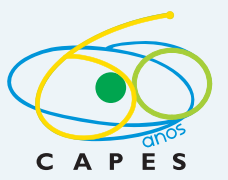

\section{Educação \\ Ministério da}




\section{SUMÁRIO}

3.2. 0 exame físico

3.3. 0 rastreamento e os níveis lipídicos

5.3. Papel dos fatores de risco clássicos na HF: diabetes, tabagismo, hipertensão arterial, SM, AF de DAC precoce, HDL baixo, valores muito elevados de LDL-c, sexo, idade, colesterol não HDL

5.5. Papel de outros fatores no risco cardiovascular da HF: Lp(a), xantoma de tendão de Aquiles, Proteína C-Reativa ultrassensível

5.7. Estratificação de risco habitual não é válida para HF.

5.9. Como fazer a estratificação de risco CV dos pacientes com HF na prática clínica.

5.10. Papel da aterosclerose subclínica na HF: Espessura Íntima-Média das Carótidas (EIMC),

Calcificação da Artéria Coronariana (CAC) e Angiotomografia de Coronárias (TCMD) 


\section{Diretrizes}

6.2. Recomendações nutricionais no tratamento da hipercolesterolemia para portadores de hipercolesterolemia familiar em geral.

página 11

página 11

página 11

página 12

página 12

página 12

página 12

página 12

página 13

página 13

página 13

página 13

página 13

página 13

página 14

6.4. Recomendações.

página 14

página 15

página 15

página 15

página 15

página 15

página 15

página 16

7.3.4. Recomendação

8. Terapias alternativas para tratamento da hipercolesterolemia familiar

página 16

8.1. Bypass ileal

página 16

página 16

página 16

página 17

página 17

página 17

página 17

8.5. Recomendação

. página 17

página 17

página 17

página 18

página 18

página 18

página 18

página 18

página 18

página 20

página 20

página 20 
10. Tratamento de hipercolesterolemia familiar na gravidez. página 21

10.1. Recomendações página 21

10.2. Classificação dos agentes quanto a possíveis efeitos no feto segundo o FDA página 21

11. Perspectivas futuras para o tratamento da hipercolesterolemia familiar página 22

11.1. Inibidor da Microsomal transfer protein página 22

11.2. Inibidor da esqualeno sintase página 22

11.3. Inibidor do Proprotein convertase subtilisin kexin type 9 (PCSK9) página 22

11.4. Análogos de hormônio tireoidiano. página 22

11.5. Oligonucleotídios antissenso (ASO) página 22

11. Referências. página 23 


\title{
(3) \\ I Diretriz Brasileira de Hipercolesterolemia Familiar (HF)
}

\section{Realização}

Sociedade Brasileira de Cardiologia

\section{Coordenador de Normatizações e Diretrizes da SBC}

Harry Corrêa Filho

\section{Coordenação Geral}

\author{
Ana Carolina Moron \\ Antonio Casella Filho \\ Daniel Branco de Araújo \\ Fernando Cesena \\ Hermes Toros Xavier \\ Raul Dias dos Santos Filho \\ Renato Jorge Alves
}

\section{EDITOR}

Raul Dias dos Santos Filho

\section{Membros do Comitê}

Alexandre Costa Pereira; Ana Maria Lottenberg; Ana Paula M. Chacra; André Arpad Faludi; Andrei C. Sposito; Fernando Flexa Ribeiro Filho; Francisco Antonio Helfenstein Fonseca; Isabela de Carlos Back Giuliano; Liane Hülle Catani; Marcelo C. Bertolami; Marcio Hiroshi Miname; Maria Cristina de Oliveira Izar; Osmar Monte; Raul C. Maranhão; Tania L.R. Martinez; Valeria Arruda Machado; Viviane Zorzanelli Rocha; Wilson Salgado Filho

\section{Correspondência:}

Sociedade Brasileira de Cardiologia

Av. Marechal Câmara, 160/330 - Centro - Rio de Janeiro - CEP: 20020-907

e-mail: scb-da@cardiol.br 


\section{Declaração de conflito de interesses}

\begin{tabular}{|c|c|c|c|c|c|c|c|}
\hline $\begin{array}{l}\text { Nomes Integrantes } \\
\text { da Diretriz }\end{array}$ & $\begin{array}{c}\text { Participou de } \\
\text { estudos clínicos el } \\
\text { ou experimentais } \\
\text { subvencionados pela } \\
\text { indústria farmacêutica } \\
\text { ou de equipamentos } \\
\text { relacionados à diretriz em } \\
\text { questão }\end{array}$ & $\begin{array}{l}\text { Foi palestrante } \\
\text { em eventos } \\
\text { ou atividades } \\
\text { patrocinadas } \\
\text { pela indústria } \\
\text { relacionados } \\
\text { à diretriz em } \\
\text { questão }\end{array}$ & $\begin{array}{l}\text { Foi (é) membro } \\
\text { do conselho } \\
\text { consultivo } \\
\text { ou diretivo } \\
\text { da indústria } \\
\text { farmacêutica } \\
\text { ou de equipa- } \\
\text { mentos }\end{array}$ & $\begin{array}{l}\text { Participou } \\
\text { de comitês } \\
\text { normativos } \\
\text { de estudos } \\
\text { científicos } \\
\text { patroci- } \\
\text { nados pela } \\
\text { indústria }\end{array}$ & $\begin{array}{l}\text { Recebeu } \\
\text { auxílio pessoal } \\
\text { ou institucional } \\
\text { da indústria }\end{array}$ & $\begin{array}{l}\text { Elaborou } \\
\text { textos } \\
\text { científicos } \\
\text { em } \\
\text { periódicos } \\
\text { patroci- } \\
\text { nados pela } \\
\text { indústria }\end{array}$ & $\begin{array}{c}\text { Tem } \\
\text { ações } \\
\text { da } \\
\text { indústria }\end{array}$ \\
\hline \multicolumn{8}{|c|}{ Informar o nome da empresa em caso de resposta positiva } \\
\hline Alexandre Pereira & Não & Não & Não & Não & Não & Não & Não \\
\hline Ana Carolina Moron & Não & Não & Não & Não & Não & Não & Não \\
\hline Ana Maria Pita Lottenberg & Não & Não & Não & Não & Não & Não & Não \\
\hline Ana Paula Chacra & Não & Não & Não & Não & Não & Não & Não \\
\hline Andrei Carvalho Sposito & Não & Não & Sim. Merck & Não & Não & Não & Não \\
\hline Antonio Casella Filho & Não & Não & Não & Não & Não & Não & Não \\
\hline Daniel Araujo & Não & Não & Não & Não & Não & Não & Não \\
\hline Fernando Cesena & Não & Não & $\begin{array}{c}\text { Sim. } \\
\text { Astrazeneca }\end{array}$ & Não & Não & Não & Não \\
\hline $\begin{array}{l}\text { Fernando Flexa Ribeiro Filho } \\
\text { (SBEM) }\end{array}$ & Não & Não & Não & Não & Não & Não & Não \\
\hline Francisco Fonseca & Não & Não & Não & Não & Não & Não & Não \\
\hline Hermes T. Xavier & Não & Não & Não & Não & Não & Não & Não \\
\hline Isabela Giuliano & Não & Não & Não & Não & Não & Não & Não \\
\hline Marcelo Bertolami & Não & Não & $\begin{array}{c}\text { Sim. } \\
\text { Astrazeneca e } \\
\text { MSD }\end{array}$ & Não & $\begin{array}{c}\text { Sim. } \\
\text { Astrazeneca, } \\
\text { MSD, } \\
\text { NovoNordisk, } \\
\text { EMS } \\
\text { (Novaquímica), } \\
\text { Bayer }\end{array}$ & $\begin{array}{l}\text { Sim. MSD, } \\
\text { Bayer, } \\
\text { Astrazeneca }\end{array}$ & Não \\
\hline Marcio Hiroshi Miname & Não & Não & Não & Não & Não & Não & Não \\
\hline Maria Cristina Izar & Sim. Genzyme & Não & Não & Não & Não & Não & Não \\
\hline Osmar Monte (SBP) & Não & Sim. MSD & Não & Não & Não & Não & Não \\
\hline Raul Dias dos Santos Filho & Sim. Genzyme, Roche & $\begin{array}{l}\text { Sim. Pfizer, MSD, } \\
\text { AstraZeneca, } \\
\text { Biolab }\end{array}$ & Sim. MSD & $\begin{array}{l}\text { Sim. } \\
\text { Genzyme, } \\
\text { Lilly }\end{array}$ & $\begin{array}{l}\text { Sim. MSD, } \\
\text { Biolab }\end{array}$ & $\begin{array}{l}\text { Sim. MSD, } \\
\text { Astrazeneca, } \\
\text { Pfizer }\end{array}$ & Não \\
\hline Raul Maranhão & Não & Não & Não & Não & Não & Não & Não \\
\hline Renato J. Alves & Não & Não & Não & Não & Sim. Sankyo & Não & Não \\
\hline Tânia Martinez & Não & Não & Não & Não & Não & Não & Não \\
\hline Valéria Arruda Machado & Não & Não & Não & Não & Não & Não & Não \\
\hline Viviane Z. Rocha & Não & Não & Não & Não & Não & Não & Não \\
\hline Wilson Salgado & Não & $\begin{array}{c}\text { Sim. (Sinvastatina/ } \\
\text { Ezetimiba; } \\
\text { Niacina/ } \\
\text { Laropipranto) }\end{array}$ & Não & Não & Não & $\begin{array}{l}\text { Sim. } \\
\text { Ezetimiba }\end{array}$ & Não \\
\hline
\end{tabular}




\section{Diretrizes}

\section{Definição do grau dos níveis de evidência}

\section{Recomendações}

Classe I: Condições para as quais há evidências conclusivas e, na sua falta, consenso geral de que o procedimento é seguro útil/eficaz. Classe II: Condições para as quais há evidências conflitantes e/ou divergência de opinião sobre segurança e utilidade/eficácia do procedimento.

Classe Ila: Peso ou evidência/opinião a favor do procedimento. A maioria aprova.

Classe IIb: Segurança e utilidade/eficácia menos bem estabelecidas, não havendo predomínio de opniões a favor.

Classe III: Condições para as quais há evidências e/ou consenso de que o procedimento não é útil/eficaz e, em alguns casos, pode ser prejudicial.

\section{Evidências}

Nível A: Dados obtidos a partir de múltiplos estudos randomizados de bom porte, concordantes e/ou de metanálise robusta de estudos clínicos randomizados.

Nível B: Dados obtidos a partir de metanálise menos robusta, a partir de um único estudo randomizado ou de estudos não randomizados (observacionais).

Nível C: Dados obtidos de opiniões consensuais de especialistas. 


\section{Siglas utilizadas nos textos e nas tabelas}

\begin{tabular}{|c|c|}
\hline Abreviações & Significado \\
\hline HF & Hipercolesterolemia familiar \\
\hline LDL-C & Lipoproteína de baixa densidade \\
\hline LDLR & Receptor de LDL \\
\hline ApoB & Apolipoproteína B \\
\hline ApoB-100 & Apolipoproteína B-100 \\
\hline PCSK9 & Pró-proteína convertase subutilisina/kexina tipo 9 \\
\hline DAC & Doença arterial coronariana \\
\hline LDLRAP1 & Proteína adaptadora do LDLR tipo 1 \\
\hline CYP7A1 & Colesterol 7-alpha hidroxilase \\
\hline $\mathrm{Mg} / \mathrm{dL}$ & Miligramas/ decilitro \\
\hline OMS & Organização Mundial da Saúde \\
\hline VLDL & Lipoproteína rica em triglicérides \\
\hline IDL & Lipoproteína de densidade intermediária \\
\hline Apo & Apolipoproteína \\
\hline apoE & Apolipoproteína $\mathrm{E}$ \\
\hline FDB & Familial Defective apo B ou defeito familiar de apo B \\
\hline $\mathrm{ARH}$ & Hipercolesterolemia autossômica recessiva \\
\hline ABCG5 & Proteína transportadora de ABC (ATP Binding cassette) \\
\hline EDTA & ácido etilenodiamino tetra-acético \\
\hline PCR & Reação em cadeia de polymerase \\
\hline IC & Intervalo de confiança \\
\hline $\operatorname{Lp}(a)$ & Lipoproteína (a) \\
\hline PCR & Proteína C-reativa \\
\hline CV & Cardiovascular \\
\hline IDF & International Diabetes Federation \\
\hline PA & Pressão arterial \\
\hline $\mathrm{mmHg}$ & Milímetros de mercúrio \\
\hline HAS & Hipertensão arterial sistêmica \\
\hline EIMC & Espessura íntima-média das carótidas \\
\hline CAC & Calcificação das artérias coronarianas \\
\hline TCMD & Angiotomografia de coronárias \\
\hline CT & Colesterol total \\
\hline $\mathrm{HDL}$ & Lipoproteína de alta densidade \\
\hline
\end{tabular}

\begin{tabular}{|c|c|}
\hline Abreviações & Significado \\
\hline AG & Ácidos graxos \\
\hline MUFA & Ácido graxo monoinsaturado \\
\hline SFA & Ácido graxo saturado \\
\hline PUFA & Ácido graxo polinsaturado \\
\hline AGT & Ácido graxo trans \\
\hline FDA & Food and Drug Administration \\
\hline DCV & Doença cardiovascular \\
\hline VCT & Valor calórico total \\
\hline CTT & Cholesterol treatment trialists \\
\hline AAS & Ácido acetil-salicílico \\
\hline g & gramas \\
\hline TG & Triglicérides \\
\hline$n-H D L$ & Partículas não-HDL \\
\hline$\%$ & Porcentagem \\
\hline MTP & Proteína de transferência microssomal de triglicérides \\
\hline HMG Coa & 3-hydroxy-3-methylglutaryl-coenzyme A \\
\hline ASO & Oligonucleotídeos antissenso \\
\hline DNA & Ácido desoxirribonucleico \\
\hline RNA & Ácido ribonucleico \\
\hline NAFLD & Estenose hepática não alcoólica \\
\hline NASH & Esteato-hepatite não alcoólica \\
\hline TNF-alfa & Fator alfa de necrose tumoral \\
\hline IL-6 & Interleucina 6 \\
\hline SAT & Ácido graxo saturado \\
\hline TRANS & Ácido graxo trans \\
\hline MCP-1 & Proteína quimiotática para monócitos \\
\hline VCT & Valor calórico total \\
\hline Anvisa & Agência nacional de vigilância sanitaria \\
\hline CYP7A1 & Colesterol-7-hidroxilase \\
\hline AGI & Ácido graxo insaturado \\
\hline LCAT & Lecitina colesterol acil transferase \\
\hline${ }^{\circ} \mathrm{C}$ & Graus Celsius \\
\hline INMETRO & $\begin{array}{l}\text { Instituto Nacional de Metrologia, Normalização e } \\
\text { Qualidade Industrial }\end{array}$ \\
\hline Kcal & Quilocalorias \\
\hline
\end{tabular}





\section{Carta de Apresentação}

A hipercolesterolemia familiar (HF) é doença grave responsável por 5-10\% dos casos de eventos cardiovasculares em pessoas abaixo de 50 anos. O risco de um portador de HF na forma heterozigótica não tratado de desenvolver doença coronária ou morrer chega a 50\% nos homens e $12 \%$ das mulheres aos 50 anos de idade. Estima-se que, no mundo todo, existam mais de 10.000.000 de indivíduos portadores de HF; no entanto, menos de 10\% destes têm diagnóstico conhecido de HF, e menos de $25 \%$ recebem tratamento hipolipemiante. No Brasil certamente não é diferente, diante da estimativa de que há 250.000-300.000 portadores dessa doença no país. Felizmente o diagnóstico precoce, a triagem em cascata das famílias, já que nessas um em cada 2 familiares pode ser afetado, podem mudar a história natural dessa grave enfermidade. Nós do Departamento de Aterosclerose da SBC temos como dever conscientizar a população, a classe médica e os governantes sobre a importância da HF para saúde do brasileiro e não medir esforços para controla-la de forma adequada. Devemos lembrar que com o fim das patentes de estatinas altamente eficazes em nosso pais o custo do tratamento precoce desses indivíduos certamente caiu de forma expressiva e será possível se realizar prevenção de maneira custo-eficaz. Entretanto para isso é necessário o diagnóstico precoce e acompanhamento constante. Essa diretriz reuniu os maiores especialistas em HF do Brasil, esperamos poder transmitir de forma sucinta as melhores informações disponíveis para melhora da prática médica no Brasil, para prevenção da doença cardiovascular precoce e finalmente alívio para as famílias afetadas pela HF.

Sinceramente,

Prof. Dr. Raul D. Santos Editor 


\section{História natural da hipercolesterolemia familiar}

\subsection{Definição de hipercolesterolemia familiar}

A Hipercolesterolemia Familiar (HF) é uma doença genética do metabolismo das lipoproteínas cujo modo de herança é autossômico codominante e que se caracteriza por níveis muito elevados do colesterol da lipoproteína de baixa densidade (LDL-c), e pela presença de sinais clínicos característicos, como xantomas tendíneos e risco aumentado de doença arterial coronariana prematura'.

O fenótipo clínico de HF é geralmente decorrente de defeitos no gene $L D L R$, que codifica o receptor de $L D L$ (LDL-R) (OMIM\# 143890)², sede de mais de 1.600 mutações descritas até o momento; pode também ser secundário a defeitos no gene $A P O B$, que codifica a apolipoproteína B-100 (Apo B-100) (OMIM\# 144010) ${ }^{3}$, onde a Apo B-100 defeituosa possui menor afinidade pelo LDL-R; ou ainda, quando existe catabolismo acelerado do LDL-R, devido a mutações com ganho de função no gene pró-proteína convertase subutilisina/ kexina tipo 9 (PCSK-9), que codifica a proteína NARC-1 (OMIM\# 603776) ${ }^{4}$, que participa do catabolismo do LDL-R.

Todas essas condições são associadas a níveis elevados de LDL-c. O fenótipo clínico é muito semelhante entre as três formas mais comuns de HF, porém os defeitos do gene $A P O B$ são mais comuns entre algumas populações europeias (1:300 a 1:700 na Europa central) $)^{5}$, enquanto mutações do gene PCSK-9 não têm uma frequência estabelecida e são infrequentes em nosso meio. A HF possui penetrância de quase $100 \%$, o que significa que a metade dos descendentes em primeiro grau de um indivíduo afetado serão portadores do defeito genético e irão apresentar níveis elevados de LDL-c desde o nascimento e ao longo de suas vidas, sendo homens e mulheres igualmente afetados. Os heterozigotos possuem metade dos receptores de LDL funcionantes.

\subsection{História da HF}

As primeiras observações sobre a doença foram feitas pelo patologista Harbitz6, que em meados do século XVIII relatou pela primeira vez casos de morte súbita em portadores de xantomas. Em 1938, Müller ${ }^{7}$ descreveu a HF como uma entidade clínica e observou que a associação de hipercolesterolemia, xantomas e manifestações de DAC eram achados comuns em algumas famílias e herdados como um traço dominante. Cerca de 50 anos mais tarde, Brown e Goldstein ${ }^{8-10}$, ao estudarem pacientes e culturas de células, elucidaram a complexa via da síntese endógena do colesterol e identificaram o defeito na internalização da LDL ligada ao seu receptor. Em 1983, esse gene foi clonado e mapeado no braço curto do cromossomo $19^{11}$, sendo denominado então gene do receptor da lipoproteína de baixa densidade, ou gene LDLR em $1989^{12}$.

Mutações no gene $L D L R$ reduzem o número ou comprometem a função dos LDL-R na superfície dos hepatócitos, resultando em elevações significativas dos níveis de LDL-c e ocasionando a deposição de colesterol nos tecidos. Na maioria dos casos, o modo de herança é autossômico dominante, mas pode ter modo de herança autossômico recessivo. As formas recessivas (muito raras) podem ser devidas a mutações no gene que codifica a proteína adaptadora do LDL-R (LDLRAP1) ${ }^{13,14}$, à deficiência de colesterol 7-alfa hidroxilase (CYP7A1) ${ }^{15}$, ou por defeitos nos transportadores ABCG5/G8, como ocorre na sitosterolemia ${ }^{16}$.

Entre as formas dominantes, Khachadurian ${ }^{1}$ observou uma relação dose-efeito com o número de alelos mutados e diferenciou as formas heterozigóticas das homozigóticas em indivíduos de origem libanesa acometidos por HF, pelo grau das manifestações clínicas.

O ponto de partida para se considerar a possibilidade diagnóstica de HF é a concentração de LDL-c $\geq 190$ mg/dL em adultos ${ }^{17,18}$. Sinais clínicos, como a presença de algum grau de arco corneal, ocorre em 50\% dos indivíduos com HF entre 31-35 anos. Já o arco corneal completo está presente em $50 \%$ dos portadores de HF aos 50 anos $^{19}$. Não existe, no entanto, correlação entre o grau do arco corneal e as manifestações de DAC. Espessamento dos tendões ocorre em $63 \%$ dos portadores de HF; alterações na ecogenicidade dos tendões estão presentes em $90 \%$ dos portadores de HF; xantomas são detectados em $68 \%$ dos portadores de HF com mutações do gene $L D L R^{20}$.

\subsection{HF como problema de saúde mundial}

A HF é uma das doenças monogênicas herdadas mais comuns na população geral. A frequência da HF na sua forma heterozigótica é de cerca de 1:500 indivíduos, sendo muito rara na forma homozigótica, onde se estima uma frequência de 1:1.000.000 de indivíduos afetados ${ }^{21}$. Entretanto, a HF é mais prevalente em algumas populações, devido a um efeito "fundador". Esses são os sul-africanos (1:100), libaneses $(1: 170)$, franco-canadenses $(1: 270)$ e finlandeses ${ }^{22-24}$.

A HF é um problema de saúde mundial reconhecido pela Organização Mundial de Saúde $(\mathrm{OMS})^{25}$. Estima-se que no mundo todo existam mais de 10.000 .000 de indivíduos portadores de HF; no entanto, menos de 10\% desses têm diagnóstico conhecido de $\mathrm{HF}$, e menos de $25 \%$ recebem tratamento hipolipemiante ${ }^{25}$. Um dado preocupante é a alta incidência de doença aterosclerótica prematura (em homens abaixo de 55 anos e em mulheres abaixo de 65 anos), especialmente à custa da Doença Arterial Coronariana (DAC) prematura, reduzindo a expectativa de vida em muitas famílias de portadores de $\mathrm{HF}^{26}$.

A HF é responsável por cerca de 5\%-10\% dos casos de DAC em indivíduos abaixo dos 55 anos $^{27}$. Sem tratamento 50\% dos homens heterozigotos desenvolverão DAC antes dos 50 anos e 100\%, aos 70 anos; entre as mulheres heterozigóticas, 12\% terão alguma manifestação de DAC aos 50 anos e $74 \%$, aos 70 $\operatorname{anos}^{28}$. Cerca de $85 \%$ dos homens e $50 \%$ das mulheres com HF heterozigótica terão um evento cardiovascular antes dos 65 anos de idade. Entretanto, a expressão clínica da DAC em portadores de HF é heterogênea quanto à idade de aparecimento e sua gravidade. As manifestações de DAC tendem a se apresentar com maior frequência em algumas famílias, mas diferenças marcantes entre indivíduos podem ocorrer ${ }^{29}$, mesmo entre aqueles oriundos de famílias que possuem a mesma mutação no gene $L D L R$, sugerindo que fatores ambientais e outros fatores genéticos desempenhem um papel modulando o desenvolvimento de aterosclerose na $\mathrm{HF}^{30}$. 
Estudos de seguimento de longo prazo em pacientes com HF mostram que a principal causa de morte entre os portadores de HF é a DAC ${ }^{26}$. Além disso, cerca de 200 mil mortes por DAC que ocorrem anualmente em todo o mundo poderiam ser evitadas com tratamento apropriado ${ }^{31}$. Acreditase que o uso de hipolipemiantes possa aumentar a expectativa de vida desses indivíduos em 10-30 anos ${ }^{25}$.

Embora não existam grandes estudos clínicos de intervenção com hipolipemiantes com seguimento de longo prazo para análise de desfechos cardiovasculares em portadores de HF, alguns grupos utilizaram desfechos substitutos para avaliar a efetividade da redução de LDL-c na evolução da aterosclerose coronária, das lesões aórticas, do espessamento médio-intimal carotídeo, da função endotelial, modificações da cintilografia de perfusão miocárdica, ou de biomarcadores inflamatórios, demonstrando de modo geral, melhora nesses parâmetros com reduções expressivas do LDL-c revisto por Civeira ${ }^{17}$, em 2004. Consistente com esses achados, o uso crescente de fármacos hipolipemiantes, especialmente de estatinas, mostrou em uma corte seguida por 8,5 anos que o início precoce do tratamento hipolipemiante reduz em $80 \%$ o risco de DAC na HF e que, indivíduos acima de 55 anos com HF, que receberam tratamento hipolipemiante ao longo de suas vidas tiveram as mesmas taxas de infarto do miocárdio que seus pares da população geral sem HF, não se observando aumento de mortalidade por causa não cardiovascular relacionada ao tratamento hipolipemiante ${ }^{32}$. Outro estudo em uma corte de indivíduos sul-africanos com HF homozigótica demonstrou retardo na ocorrência de morte e maior sobrevida com a terapia hipolipemiante ${ }^{33}$.

Em crianças com HF, existe disfunção endotelial e aumento da espessura médio-intimal das artérias carótidas, preditor de aterosclerose prematura na vida adulta. O tratamento hipolipemiante por dois anos nas crianças portadoras de HF induziu regressão significativa na aterosclerose carotídea, sem afetar o crescimento, maturação sexual, níveis hormonais, enzimas hepáticas ou musculares ${ }^{34}$.

Pelas razões expostas, a identificação de indivíduos portadores de HF e de seus familiares, e a instituição precoce de terapia hipolipemiante e sua manutenção ao longo da vida são aspectos importantes na prevenção da doença cardiovascular prematura e do risco de morte nessa população.

\section{Metabolismo lipídico na hipercolesterolemia familiar}

A homeostase do colesterol no organismo depende do equilíbrio entre a síntese hepática e absorção intestinal desse composto, de um lado, e a sua excreção, especialmente pelas vias biliares, de outro. Quando há desequilíbrio dessa equação, como acontece na hipercolesterolemia familiar, o colesterol acumulado forma depósitos como os xantomas e placas de ateroma. A entrada e a saída do colesterol corpóreo são reguladas por sistema de feedback em que o aumento do conteúdo e absorção do colesterol da dieta determina a diminuição da síntese pelo fígado. Ao contrário das gorduras alimentares, que são absorvidas pelo intestino quase completamente, a absorção do colesterol é parcial, e quando a quantidade do composto na dieta aumenta, a absorção diminui proporcionalmente.

No homem, a maior parte do colesterol presente no plasma compõe a fração lipoproteína de baixa densidade (LDL). Em indivíduos normolipidêmicos, por volta de $70 \%$ do colesterol estão contidos nas LDL. As LDL são o produto de degradação das VLDL, lipoproteínas ricas em triglicérides que, na superfície dos capilares, sofrem lipólise continuada, pela ação da lipase lipoproteica. Nessa cascata de degradação, em paralelo com a perda dos triglicérides, o conteúdo de colesterol vai proporcionalmente aumentando nas partículas lipoproteicas até chegar ao produto final, as LDL. Nessa, o conteúdo de triglicérides é apenas residual e o colesterol, especialmente na forma esterificada, constitui a maior parte dos lipídios constituintes da lipoproteína.

Parte substancial dos produtos de degradação das VLDL, os remanescentes de VLDL e as IDL, lipoproteínas de densidade intermediária, é removida pelos tecidos antes de sofrer catabolismo completo, ou seja, antes de chegar ao produto final, as LDL. Uma proporção menor das LDL não é produto de degradação das VLDL, mas é sintetizada pelo fígado já em forma de LDL.

As LDL são removidas da circulação para o interior das células por receptores da membrana celular que reconhecem a apolipoproteína (apo) B100, a única proteína existente nas LDL. Remanescentes e IDL são removidos também por esses receptores, mas de forma bem mais rápida que a LDL. Isso se dá porque essas partículas, além da apo B100, têm apo E na superfície, e a apo E tem afinidade bem maior pelos receptores do que a apo B100.

Na hipercolesterolemia familiar ocorrem defeitos genéticos afetando o receptor da LDL e que resultam em diminuição da endocitose da lipoproteína ${ }^{17}$. A existência da endocitose da LDL mediada por receptor e os defeitos que resultam em deficiência da função dos receptores e em hipercolesterolemia foram descritas por Brown e Goldstein ${ }^{9}$ na década de 1970. As várias centenas de polimorfismos no gene do receptor podem afetar tanto a estrutura do receptor que liga a apo B100 da LDL quanto outros domínios da proteína e até mesmo a recirculação dos receptores que normalmente são reciclados após a endocitose, voltando à membrana celular. Defeitos na apo B100, bem mais raros do que os do receptor da LDL (LDL-R), também são causa de hipercolesterolemia grave, mas a designação hipercolesterolemia familiar refere-se aos defeitos do receptor ${ }^{3}$. Há também casos de hipercolesterolemia familiar em razão de mutações com ganho de função no gene pró-proteína convertase subutilisina/ kexina tipo 9 (PCSK-9) ${ }^{4}$, que codifica a proteína NARC-14, que participa do catabolismo do LDL-R. Assim descrita, a hipercolesterolemia familiar é um defeito de remoção das LDL da circulação. Como as partículas da LDL circulam por mais tempo nos pacientes com hipercolesterolemia familiar, estão mais sujeitas a oxidação e outras transformações químicas. Isso resulta na captação aumentada da LDL modificada pelos macrófagos, deflagrando mecanismos pró-aterogênicos.

Os estudos de Müller ${ }^{7}$, na Noruega, e Khachadurian"1 do Líbano, na década de 1960, foram pioneiros para o estabelecimento da hipercolesterolemia familiar como doença 


\section{Diretrizes}

de caráter autossômico monozigótico e dominante. Na forma heterozigótica, metade dos receptores está comprometida e a outra metade é normal, enquanto na forma homozigótica todos os receptores estão afetados.

\section{Diagnóstico clínico da hipercolesterolemia familiar}

Os critérios clínicos e laboratoriais para o diagnóstico da Hipercolesterolemia Familiar (HF) são arbitrários e baseiam-se nos seguintes dados:

- sinais clínicos de depósitos extravasculares de colesterol;

- $\quad$ taxas elevadas de LDL-c ou colesterol total no plasma;

- $\quad$ história familiar de hipercolesterolemia e/ou doença aterosclerótica prematura;

- $\quad$ identificação de mutações e polimorfismos genéticos que favoreçam o desenvolvimento da HF.

Alguns critérios diagnósticos têm sido propostos na tentativa de uniformizar e formalizar o diagnóstico de HF, como por exemplo, os da Dutch Lipid Clinic Network (Dutch MEDPED, ver tab. 1) ${ }^{35}$, os do US Make Early Diagnosis Prevent Early Death Program (USA MEDPED) ${ }^{36}$ e os do Simon Broome Register Group ${ }^{37}$.

Tabela 1 - Critérios diagnósticos da HF (baseado nos critérios da Dutch Lipid Clinic Network [Dutch MEDPED ${ }^{35}$ ])

\begin{tabular}{|c|c|}
\hline Parâmetro & Pontos \\
\hline \multicolumn{2}{|l|}{ História familiar } \\
\hline $\begin{array}{l}\text { Parente de } 1^{\circ} \text { grau portador de doença vascular/ } \\
\text { coronária prematura (homem }<55 \text { anos, } \\
\text { mulher }<60 \text { anos) OU }\end{array}$ & 1 \\
\hline \multicolumn{2}{|l|}{$\begin{array}{l}\text { Parente adulto de } 1^{\circ} \text { ou } 2^{\circ} \text { grau com colesterol } \\
\text { total }>290 \mathrm{mg} / \mathrm{dL}^{*}\end{array}$} \\
\hline $\begin{array}{l}\text { Parente de } 1^{\circ} \text { grau portador de xantoma } \\
\text { tendinoso e/ou arco corneano OU }\end{array}$ & 2 \\
\hline \multicolumn{2}{|l|}{$\begin{array}{l}\text { Parente de } 1^{0} \mathrm{grau}<16 \text { anos com colesterol } \\
\text { total }>260 \mathrm{mg} / \mathrm{dL}^{*}\end{array}$} \\
\hline \multicolumn{2}{|l|}{ História clínica } \\
\hline $\begin{array}{l}\text { Paciente portador de doença arterial coronária prematura } \\
\text { (homem }<55 \text { anos, mulher }<60 \text { anos) }\end{array}$ & 2 \\
\hline $\begin{array}{l}\text { Paciente portador de doença arterial cerebral ou periférica } \\
\text { prematura (homem }<55 \text { anos, mulher }<60 \text { anos) }\end{array}$ & 1 \\
\hline \multicolumn{2}{|l|}{ Exame físico } \\
\hline Xantoma tendinoso & 6 \\
\hline Arco corneano $<45$ anos & 4 \\
\hline \multicolumn{2}{|l|}{ Nível de LDL-c (mg/dL) } \\
\hline$\geq 330 \mathrm{mg} / \mathrm{dL}$ & 8 \\
\hline $250-329 \mathrm{mg} / \mathrm{dL}$ & 5 \\
\hline $190-249 \mathrm{mg} / \mathrm{dL}$ & 3 \\
\hline $155-189 \mathrm{mg} / \mathrm{dL}$ & 1 \\
\hline \multicolumn{2}{|l|}{ Análise do DNA } \\
\hline $\begin{array}{l}\text { Presença de mutação funcional do gene do } \\
\text { receptor de LDL, da apoB100 ou da PCSK9* }\end{array}$ & 8 \\
\hline \multicolumn{2}{|l|}{ Diagnóstico de HF: } \\
\hline certeza se & $>8$ pontos \\
\hline provável se & 6 - 8 pontos \\
\hline possível se & $3-5$ pontos \\
\hline
\end{tabular}

* Modificado do Dutch MEDPED1 adotando um critério presente na proposta do Simon Broome Register Group3
Esta diretriz recomenda a utilização de critérios simples para a suspeita diagnóstica de HF e para a decisão de se iniciar o tratamento (ver adiante). Um algoritmo baseado no Dutch MEDPED ${ }^{35}$ pode ser empregado para melhor precisão diagnóstica, embora não esteja disponível até o momento uma validação para a população brasileira.

\subsection{A anamnese}

Dada a alta prevalência de HF na população geral e o seu grande impacto nas taxas de doença cardiovascular e mortalidade, toda a anamnese deve incluir a pesquisa de histórico familiar de hipercolesterolemia, uso de medicamentos hipolipemiantes e doença aterosclerótica prematura, incluindo a idade de acometimento.

A possibilidade de HF é sempre reforçada na presença de história familiar de hipercolesterolemia e/ou doença aterosclerótica prematura.

\subsection{0 exame físico}

A pesquisa pelos sinais clínicos da HF (xantomas, xantelasmas e arco corneano) deve fazer parte do exame físico rotineiro e poderá ser complementada por exames subsidiários, como o ultrassom de tendão, em casos selecionados.

De uma forma geral, esses sinais clínicos não são muito sensíveis, mas podem ser bastante específicos. Ou seja, embora não haja necessidade de sua presença para o diagnóstico da HF, esses sinais, quando identificados, sugerem fortemente essa etiologia.

Os xantomas tendinosos (Figura 1 e Figura 2) são mais comumente observados no tendão de Aquiles e nos tendões extensores dos dedos, mas também podem ser encontrados nos tendões patelar e do tríceps. Eles devem ser pesquisados não só pela inspeção visual, mas também pela palpação. São praticamente patognomônicos de HF, mas ocorrem em menos de 50\% dos casos $^{38}$. Podem ser encontrados também xantomas planares intertriginosos, especialmente na HF forma homozigótica (Figura 2).

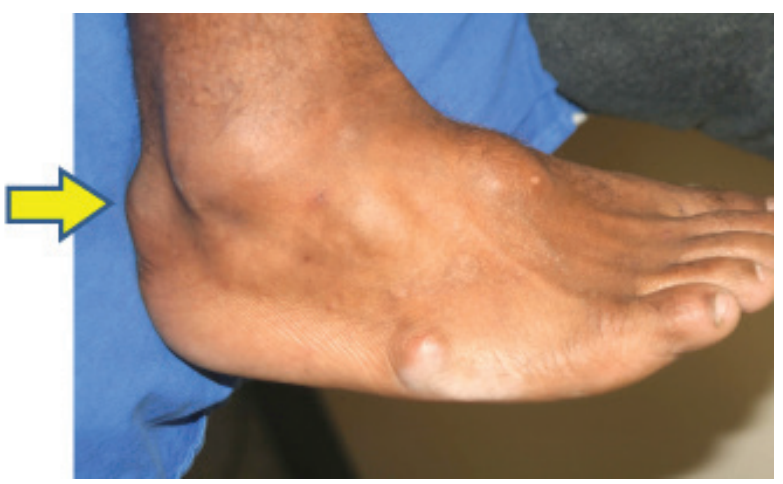

Fig. 1 - Xantoma no tendão de Aquiles em portador de HF Homoizgótica. 


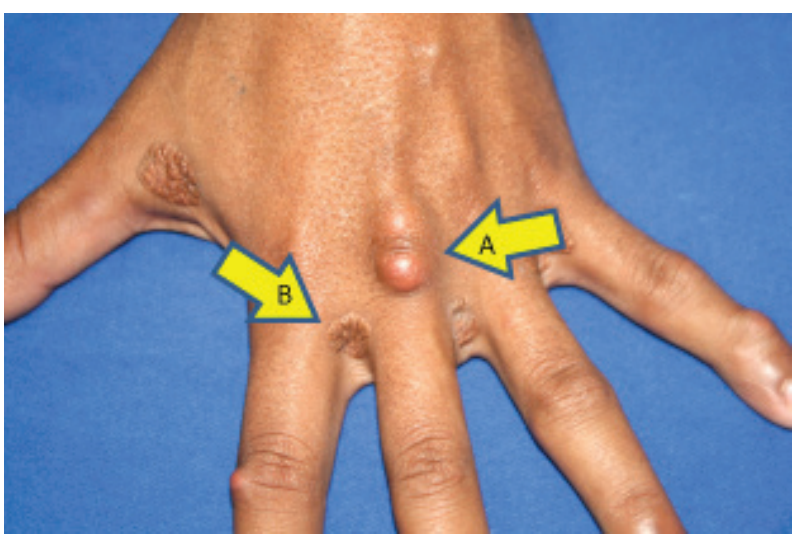

Fig. 2 - Xantoma tendionoso (A) em região dorsal da mão e xantomas planares intertriginosos (B) em portador de HF homozigótica.

Os xantomas tuberosos amarelo-alaranjados e os xantelasmas de pálpebras não são específicos de HF e devem ser valorizados quando encontrados em pacientes com idade em torno de 20-25 anos.

A presença de arco corneano, parcial ou total, sugere HF quando observada antes dos 45 anos de idade (Fig. 3).

Portadores da forma homozigótica da HF podem apresentar também sopro sistólico ejetivo decorrente de estenose da valva aórtica e da região supra-aórtica.

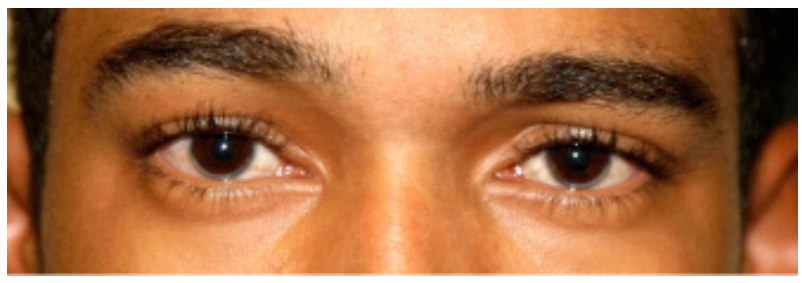

Fig. 3 - Arco corneano em portador de HF homozigótica.

\subsection{0 rastreamento e os níveis lipídicos}

A coleta de sangue para determinação de níveis de colesterol total e LDL-c visando rastrear a HF é de fundamental importância para o diagnóstico do maior número possível de casos e, consequentemente, para reduzir o impacto da HF sobre a morbimortalidade cardiovascular na população geral. Esse rastreamento pode ser realizado por meio de dois métodos: o chamado rastreamento universal e o rastreamento em cascata.

\subsubsection{Rastreamento universal}

Todas as pessoas acima dos 10 anos de idade devem ser submetidas a análise do perfil lipídico. A obtenção dos lípides plasmáticos também deve ser considerada a partir dos 2 anos de idade nas seguintes situações:
- quando houver história familiar de doença aterosclerótica prematura (homens $<55$ anos ou mulheres < 65 anos) e/ou de dislipidemia;

- $\quad$ se a própria criança apresentar xantomas ou arco corneano, fatores de risco (hipertensão arterial, diabete melito, fumo, obesidade) ou doença aterosclerótica.

A periodicidade recomendada para a determinação dos lípides plasmáticos é motivo de debate. De uma forma geral, se o perfil lipídico for normal, mas existirem outros critérios de possível HF, como história familiar de doença aterosclerótica precoce ou hipercolesterolemia significativa, o exame pode ser repetido após um ano. Na ausência desses fatores, o exame pode ser repetido em até cinco anos. Outros dados, como idade, presença de outros fatores de risco para aterosclerose, grau de controle dos fatores de risco, hábitos de vida e eventual uso de medicamentos que possam interferir com o metabolismo lipídico podem ser considerados para individualizar a periodicidade das dosagens lipídicas.

O diagnóstico de HF deve sempre ser suspeitado em adultos ( $\geq 20$ anos) com valores de LDL-c $\geq 190 \mathrm{mg} / \mathrm{dL}$.

$\mathrm{Na}$ população geral, a probabilidade de HF é de aproximadamente $80 \%$ na presença de LDL-c $\geq 250 \mathrm{mg} / \mathrm{dL}$ em indivíduos $\geq 30$ anos, ou LDL-colesterol $\geq 220 \mathrm{mg} / \mathrm{dL}$ em indivíduos entre 20-29 anos, ou LDL-C $\geq 190 \mathrm{mg} / \mathrm{dL}$ em indivíduos $<20$ ano $^{36}$.

O diagnóstico de HF é também mais provável em portadores de LDL-c $\geq 190 \mathrm{mg} / \mathrm{dL}$ em famílias caracterizadas por uma distribuição bimodal do LDL-C, nas quais alguns membros apresentam níveis tipicamente baixos (LDL-C $<130 \mathrm{mg} / \mathrm{dL}$ ), enquanto outros (os afetados por HF) apresentam taxas tipicamente $\geq 190 \mathrm{mg} / \mathrm{Dl}^{38}$.

Antes de se fazer o diagnóstico de HF, no entanto, devem ser afastadas causas secundárias de hipercolesterolemia, incluindo hipotireoidismo e síndrome nefrótica.

Deve também ser ressaltado que a presença de hipertrigliceridemia não exclui o diagnóstico de HF.

Por fim, deve-se considerar que a determinação do perfil lipídico está sujeita a uma série de variações relacionadas tanto ao método e procedimentos utilizados como a fatores intrínsecos do indivíduo como estilo de vida, uso de medicações e doenças associadas. Dessa forma, a confirmação de uma alteração laboratorial com nova amostra, idealmente colhida com intervalo mínimo de uma semana após a primeira coleta, aumenta a precisão diagnóstica.

\subsubsection{Rastreamento em cascata}

O rastreamento em cascata envolve a determinação do perfil lipídico em todos os parentes de primeiro grau (pai, mãe e irmãos) dos pacientes diagnosticados como portadores de HF. As chances de identificação de outros portadores de HF a partir de um caso-índice são: 50\% nos familiares de primeiro grau, $25 \%$ nos de segundo grau e $12,5 \%$ nos de terceiro grau ${ }^{38}$.

À medida que novos casos vão sendo identificados, novos parentes vão sendo recomendados para o rastreamento. 


\section{Diretrizes}

Essa é considerada a forma mais custo-eficaz para a identificação de portadores de HF

\subsection{Recomendações*}

- Sinais clínicos de HF e história familiar de doença aterosclerótica precoce e/ou dislipidemia devem ser pesquisados em todos os indivíduos (Classe I, Nível de evidência C).

- O perfil lipídico deve ser obtido em todos os indivíduos acima dos 10 anos de idade (Classe I, Nível de evidência C).

- A determinação do perfil lipídico deve ser considerada a partir dos 2 anos de idade na presença de fatores de risco, sinais clínicos de HF ou doença aterosclerótica, bem como na presença de história familiar de doença aterosclerótica prematura e/ou de dislipidemia (Classe I, Nível de evidência C).

- O perfil lipídico deve ser obtido em todos os parentes de primeiro grau dos indivíduos diagnosticados como portadores de HF (Classe I, Nível de evidência C).

\section{Diagnóstico genético da hipercolesterolemia familiar}

Classicamente, a Hipercolesterolemia Familiar (HF) foi descrita como doença de herança autossômica dominante ${ }^{1}$, caracterizada por elevação do colesterol total e do LDL-C, causada por mutações no gene que codifica o receptor da LDL ou nos genes codificadores da apo B e da pró-proteína convertase subtilisina/kexina 9 (PCSK9 $)^{4}$.

O defeito primário na hipercolesterolemia familiar é uma mutação no gene específico do receptor para LDL plasmático ${ }^{4}$. Localizado na superfície das células hepáticas e de outros órgãos, o receptor se liga ao LDL e facilita sua captação, realizada por endocitose mediada pelo próprio receptor. A LDL é degradada nos lisossomos e o colesterol é liberado na célula para uso metabólico. Quando os receptores de LDL são defeituosos, o nível de remoção de LDL do plasma diminui, e o nível plasmático de LDL aumenta em proporção inversa ao número de receptores funcionais presentes ${ }^{17}$.

Em pacientes heterozigotos, um gene defeituoso para o receptor de LDL é herdado de um dos pais e um gene normal, do outro. Como dois genes funcionais são necessários para manter o nível plasmático normal de LDL-c, a ausência de um gene funcional causa um aumento no nível de LDL para aproximadamente duas vezes o normal já na infância ${ }^{21}$.

Os pacientes homozigotos herdam dois genes defeituosos, consequentemente os receptores de LDL não têm funcionalidade e os pacientes têm uma hipercolesterolemia grave $(650 \text { a } 1.000 \mathrm{mg} / \mathrm{dL})^{21}$.

O gene que codifica o receptor humano para LDL compreende aproximadamente 45 mil pares de bases de DNA e se localiza no cromossomo 19. O gene está dividido em 18 éxons e 17 íntrons. Há uma forte correlação entre os domínios estruturais na proteína (receptor de LDL) e a sequência dos éxons no gene. O receptor de LDL é uma proteína composta de 839 aminoácidos, contendo vários domínios funcionais.
A produção é finamente regulada por um mecanismo de retroalimentação sofisticado que controla a transcrição do gene $L D L R$ em resposta a variações no conteúdo intracelular de esterois e da demanda celular de colesterol ${ }^{21}$.

Existem mais de 1.600 mutações do gene $L D L R$ documentadas como causadoras de HF até o momento. Essas representam cerca de 85\%-90\% dos casos de HF. Um grande número de mutações no $L D L R$ foi catalogado em todo o mundo e os recursos de listagem podem ser pesquisados $^{39-41}$.

A HF é mais comumente atribuível a mutações (incluindo deleções, missense, nonsense e inserções) no gene $L D L R$, resultando em receptores de LDL com reduções funcionais (parcial a completa) em sua capacidade de remover LDL-C da circulação. Os pacientes podem ser receptor negativos, expressando pouca ou nenhuma atividade do receptor de LDL, ou receptor defeituoso, levando à expressão de isotipos de $L D L R$ com afinidade reduzida para LDL na superfície dos hepatócitos ${ }^{42-47}$.

Há cinco principais classes de defeitos no gene $L D L R^{45,46}$.

- Classe I: receptor de LDL não é sintetizado.

- Classe II: receptor de LDL não é devidamente transportado do retículo endoplasmático para o aparelho de Golgi e há menor expressão na superfície celular.

- Classe III: o receptor de LDL não se liga corretamente ao LDL na superfície da célula graças a um defeito em qualquer apolipoproteína (apo) B-100 (R3500Q) ou no receptor de LDL.

- Classe IV: proteínas transportadoras ligam-se normalmente à $L D L$, mas não se situam nas depressões revestidas e, portanto, a LDL não é internalizada.

- Classe V: o receptor de LDL não é reciclado de volta para a superfície celular.

A hipercolesterolemia devida à mutação no gene $A P O B$ é referida como Familial Defective apo $B$ ou defeito familiar da apo B (FDB) ${ }^{48,49}$. A FDB é declaradamente menos grave do que a HF típica causada por mutações no $L D L R^{50,51}$. A mutação mais comum no gene $A P O B$ é a substituição Arg35000Gln, correspondendo a 5\%-10\% dos casos de HF nas populações do norte da Europa, sendo, porém, rara em outras populações ${ }^{52}$.

Outra etiologia para o fenótipo HF é hipercolesterolemia autossômica dominante atribuível ao aumento da atividade de PCSK9, também chamada HF3, onde mutações com ganho de função levam a maior degradação do receptor de $\mathrm{LDL}^{52,53}$. Essa é a causa menos comum de HF, representando menos de $5 \%$ dos $\operatorname{casos}^{52}$.

O gene causal, se $L D L R, A P O B$, ou $P C S K 9^{54}$, não pode ser determinado clinicamente, sendo necessário teste genético para sua verificação.

Hipercolesterolemia autossômica recessiva (ARH) tem sido atribuída a expressão reduzida da proteína adaptadora do receptor de LDL tipo 1 (LDLRAP1), que facilita a associação de receptores de LDL com clatrina nas fendas revestidas da superfície celular ${ }^{13,55,56}$. 
Outros formas raras de $\mathrm{ARH}$ incluem sitosterolemia ou fitosterolemia, em razão de mutações em dois genes adjacentes e com orientações opostas (ABCG5 e ABCG8) que codificam proteínas transportadoras da família ABC (ATP binding cassete) denominadas esterolina-1 e esterolina- $2^{57}$; deficiência de colesterol 7-alfa hidroxilase (CYP7A1), que é a enzima da primeira etapa na síntese de ácidos biliares, resultando em colesterol intra-hepático aumentado e expressão reduzida de receptores de LDL na superfície do hepatócito. A deficiência de CYP7A1 é a menos comum das condições autossômicas recessivas que podem causar graves hipercolesterolemias ${ }^{56}$.

O colesterol elevado hereditário pode incluir outras formas de hipercolesterolemia, tais como a disbetalipoproteinemia (tipo III de Friedrickson), hiperlipidemia familiar combinada, hipercolesterolemia por polimorfismos no gene $A P O E$, bem como hipercolesterolemia poligênica, além de outras variantes em genes ainda não identificados, que podem mimetizar a $\mathrm{HF}^{58,59}$, mas que não são o foco desta Diretriz.

\subsection{Metodologias para diagnóstico genético}

Pelo grande número de mutações possíveis, o método de diagnóstico genético deve incluir o sequenciamento da região codificadora do gene $L D L R$, polimorfismos do gene $A P O B$ e $P C S K 9^{60,61}$.

Sumariamente, para o estudo genético é efetuada coleta de sangue periférico em tubo contendo EDTA, obtendo-se o DNA genômico de leucócitos. As regiões de interesse do(s) gene(s) em estudo são amplificadas por meio da reação em cadeia da polimerase (PCR). Os produtos de amplificação obtidos pela PCR são analisados por meio de eletroforese e submetidos a digestão por enzimas de restrição, no caso da APOB e PCSK9, e comparados com sequências-padrão, ou sequenciados, no caso do gene $L D L R$.

\subsection{Rastreamento em cascata}

O rastreamento em cascata para HF geralmente não é necessário para diagnóstico ou tratamento clínico, mas pode ser útil quando o diagnóstico é incerto e para diagnóstico de familiares de um indivíduo afetado.

Identificação de uma mutação causal pode fornecer uma motivação adicional para alguns pacientes iniciarem o tratamento adequado, e o teste genético é padrão de referência para o diagnóstico de certeza de HF. Pode ser particularmente útil nos casos de familiares com diagnóstico clínico equivocado ou apenas com nível de LDL-c sugestivo de HF. Testes genéticos também podem ser importantes para a identificação de uma mutação causal em famílias recémidentificadas ou com forte suspeita de HF.

Além disso, quando encontrada a mutação, o teste fornece uma resposta simples e definitiva para o diagnóstico da HF, sendo assim ferramenta definitiva para a presença de hipercolesterolemia como traço familiar ${ }^{59}$.

Os testes genéticos, no entanto, têm limitações. Entre os pacientes hipercolesterolêmicos com diagnóstico de HF possível, a taxa de identificação de uma mutação causal por meio do teste genético é de $50 \%$ ou menos, enquanto em pacientes com HF definitiva, a taxa de identificação da mutação pode ser tão alta quanto $86 \%{ }^{59,60}$.
É importante ressaltar que um teste genético negativo não exclui a HF. Além disso, indivíduos com LDL-c elevado permanecem em alto risco e devem ser tratados de acordo com diretrizes aceitas, independentemente dos resultados dos testes genéticos.

A estratégia mais custo-efetiva para diagnóstico de HF é o rastreamento de mutações em parentes de primeiro grau de indivíduos onde uma mutação causal para HF tenha sido identificada ${ }^{28,61}$. Os indivíduos diagnosticados como HF por meio de teste genético passam a ser os casos-índice, sendo a partir desses rastreados os parentes de primeiro grau, e subsequentemente os demais parentes (segundo e terceiro graus) numa abordagem genética combinada à análise do perfil lipídico dos familiares suspeitos e de uma anamnese dirigida e exame físico, pesquisando-se os achados clínicos típicos da HF (arco corneal precoce, xantomas tendíneos, xantelasmas). Isso é referido como rastreamento genético em cascata ${ }^{62}$. Pode-se, no entanto, como primeira abordagem, realizar o teste genético, onde se busca a mesma alteração do caso-índice. Há 50\% de probabilidade de detecção em parentes de primeiro grau; $25 \%$ de probabilidade em parentes de segundo grau; e 12,5\% de probabilidade em parentes de terceiro grau ${ }^{4}$.

Estudos mostram que muito poucos indivíduos com HF são diagnosticados. Em qualquer população, estimase que aproximadamente $20 \%$ dos pacientes com HF são diagnosticados e menos de $10 \%$ dos pacientes com $\mathrm{HF}$ recebem tratamento adequado ${ }^{4}$. O rastreamento em cascata aumenta o número de diagnósticos e diminui a idade com que o indivíduo é diagnosticado, havendo maior chance de tratamento precoce e diminuição do risco cardiovascular global.

Marks e cols. ${ }^{28}$ analisaram a custo-efetividade do rastreamento em cascata de indivíduos com hipercolesterolemia familiar. Foi determinado o custo incrementado por ano de vida adquirida de $£ 3.300$ por vida/ano adquirido. Em outro estudo ${ }^{60}$, o resultado mostrou que o programa de rastreamento em cascata foi o mais custo-efetivo na Dinamarca e o custo por vida/ano foi de $\$ 8.700$. Ambos os estudos mostram uma estimativa de custos menor que o gasto com prevenção secundária em indivíduos não portadores de $\mathrm{HF}^{61}$. Portanto, o rastreamento em cascata para indivíduos com HF pode ser considerado como altamente custo-efetivo ${ }^{28}$.

\subsection{Recomendações}

1. O diagnóstico genético (análise dos genes $L D L R, A P O B$ e $P C S K 9)$ é padrão de referência para diagnóstico de Hipercolesterolemia Familiar (HF), e, quando disponível, deve ser oferecido para pacientes com diagnóstico provável ou definitivo (certeza) para HF com o objetivo de viabilizar rastreamento familiar em cascata de maneira mais custo-efetiva. O oferecimento do teste genético para casos em que o diagnóstico de HF é possível deve ser analisado caso a caso ${ }^{62}$.

2. O melhor método para diagnóstico genético de HF é o sequenciamento da região codificadora do gene $L D L R$, e de hot-spots nos genes APOB e PCSK9, associado à pesquisa de microdeleções no gene $L D L R$ em casos em que uma mutação não seja identificada. A realização do teste genético deve ser realizada por equipe 


\section{Diretrizes}

especializada e oferecida dentro de um contexto de aconselhamento genético, compreendendo informações pré- e pós-teste e encaminhamento para tratamento específico.

3. O rastreamento em cascata é custo-efetivo e deve ser realizado em todos os pacientes e familiares em primeiro grau de pacientes com diagnóstico de HF. O rastreamento em cascata mais custo-efetivo é o que utiliza informação genética de indivíduos afetados, no qual uma mutação causadora da doença tenha sido identificada. No entanto, o rastreamento clínico/ bioquímico deve ser realizado mesmo quando a realização de teste genético não é possível ${ }^{63,64}$.

\section{Estratificação de risco cardiovascular}

\subsection{Epidemiologia do risco cardiovascular na HF}

A associação entre Hipercolesterolemia Familiar (HF) heterozigótica e Doença Arterial Coronariana (DAC) está bem estabelecida $^{65,66}$. Existe um risco cumulativo na ausência de terapia hipolipemiante de doença coronariana fatal e não fatal na proporção de $50 \%$ em homens de 50 anos, e de $30 \%$ em mulheres de 60 anos $^{67,68}$. No estudo do Simon Broome Register Group ${ }^{69}$, realizado no período de 1980 até 1995, houve um aumento do risco relativo de morte por doença coronariana de 50 vezes para homens (intervalo de confiança 95\% - IC95: 17-105) e de 125 vezes para mulheres (IC95: 15-140) na faixa etária de 20-39 anos ${ }^{69}$.

É importante enfatizar que mesmo com o advento das estatinas para diminuição do LDL-c, as taxas de eventos cardiovasculares em homens e mulheres portadores de HF sem manifestação prévia de doença coronariana nas faixas etárias dos 15 aos 66 anos de idade são, respectivamente, 3\% e 1,6\% ao ano70. No mesmo estudo, portadores de DAC estabelecida apresentaram taxas anuais médias de eventos cardiovasculares de $15 \%$ para os homens e $14 \%$ para as mulheres ${ }^{70}$.

As taxas anuais de mortalidade para portadores de DAC foram, respectivamente, $1,6 \%$ para homens e $0,5 \%$ para mulheres $^{70}$. Apesar disso, o tratamento com estatinas em HF apresenta claros benefícios, como demonstra a coorte de HF estudada por Versmissen e cols. ${ }^{32}$, em que o grupo tratado com estatina apresentou uma redução de $76 \%$ do risco de doença coronariana, comparado ao grupo sem estatina ("hazard ratio" $0,24, p<0,001)$. Contudo, é importante frisar que, a despeito dos níveis elevados de colesterol e elevado risco relativo de DAC, o comportamento clínico da aterosclerose nos pacientes com HF pode ser variável em curto-médio prazo, e alguns indivíduos desenvolvem eventos clínicos tardiamente em sua vida ${ }^{71}$.

Esse fato foi bem demonstrado na coorte de 526 portadores de HF do Simon Broome Register Group ${ }^{71}$, com 2.234 pessoas-ano de seguimento, onde foi observada maior taxa ajustada de mortalidade por DAC na faixa etária de 20-29 anos em comparação a faixas etárias mais velhas, ou seja, alguns HF apresentam evento coronariano muito precocemente e outros desenvolvem muito tardiamente ou mesmo não irão morrer de doença cardiovascular. Dessa forma, a estratificação de risco nessa população é muito importante, dada sua implicância em custo-benefício no manejo e tratamento desses pacientes ${ }^{17}$.

\subsection{Recomendações}

O risco cardiovascular na hipercolesterolemia familiar está aumentado e estratificação de risco cardiovascular deve ser estimulada a ser realizada (Classe I, Nível de evidência A).

\subsection{Papel dos fatores de risco clássicos na HF: diabetes,} tabagismo, hipertensão arterial, SM, AF de DAC precoce, HDL baixo, valores muito elevados de LDL-c, sexo, idade, colesterol não HDL

Os fatores de risco clássicos para DAC na HF também apresentam importância na estratificação de risco dessa população. O estudo de Simon Broome Register Group já havia demonstrado maior risco cardiovascular dos homens em relação às mulheres. Esse fato foi confirmado no estudo de coorte holandês de Jansen e cols. ${ }^{72}$, em que encontraram risco quase três vezes maior de os homens apresentarem evento cardiovascular em comparação às mulheres ${ }^{72}$. A associação de tabagismo com HF também apresenta forte relação com o desenvolvimento de DAC, e estudo prévio mostra uma chance 1,8 vez maior para os tabagistas ${ }^{73}$.

O diabete melito é um fator de risco tão importante, que diretrizes atuais consideram sua presença como já indicativo de alto risco cardiovascular, até mesmo com metas mais agressivas de tratamento. O estudo de Lloyd Jones e cols. ${ }^{74}$ avaliando o life time risk de diabéticos mostrou que homens com diabetes apresentam uma chance de $67 \%$ de desenvolverem um evento cardiovascular ao longo de sua vida e as mulheres, de $57 \%{ }^{74}$. O diabetes para a população HF também apresenta um peso importante. O estudo de Kastelein e cols. ${ }^{75}$ mostrou um risco 2,2 vezes maior de doença cardiovascular nos HF diabéticos. A hipertensão arterial também confere maior risco na população HF (risco 1,4 vez maior de evento cardiovascular) e deve ser corretamente diagnosticada e tratada ${ }^{75}$.

O histórico familiar de doença coronariana precoce (homens com $<55$ anos e mulheres com $<65$ anos) é um fator encontrado com maior frequência na população HF e também deve ser valorizado como fator de risco.

O HDL-c baixo é considerado como fator de risco importante na população não HF. Existem evidências de que o HDL-c baixo também pode estar associado a maior risco de DAC nos HF17,72. Estudos epidemiológicos prévios já demonstravam a associação do colesterol alto com doença cardiovascular. Na população HF, a elevação do colesterol ocorre basicamente à custa do LDL-c; dessa forma, valores muito elevados de LDL-c também devem ser considerados importante fator de risco nesses indivíduos.

\subsection{Recomendação}

Os fatores de risco clássicos também apresentam papel importante na HF e devem ser pesquisados de forma ativa. (Classe I, Nível de evidência B).

5.5. Papel de outros fatores no risco cardiovascular da HF: Lp(a), xantoma de tendão de Aquiles, Proteína C-Reativa ultrassensível

A lipoproteína (a) ou Lp(a) é uma lipoproteína composta pela partícula de LDL com ligação covalente entre a apolipoproteína (a) e a apolipoproteína B-100. 
A apolipoproteína (a) apresenta forte homologia com o plasminogênio. Níveis elevados de Lp(a) podem teoricamente aumentar o risco cardiovascular pelo efeito protrombótico/antifibrinolítico da apolipoproteína (a) e pela deposição da $\mathrm{Lp}(\mathrm{a})$ no espaço subintimal. Alguns estudos e metanálises mostram a associação da $\mathrm{Lp}(\mathrm{a})$ com aumento do risco cardiovascular em população não $\mathrm{HF}^{76,77}$. Outros estudos mostram associação de valores elevados da Lp(a) com risco cardiovascular na HF, porém existem dificuldades relacionados a metodologia ${ }^{78}$.

\subsection{Recomendação}

A dosagem rotineira de Lp(a) na HF pode ser considerada (Classe Ilb, Nível de evidência C).

O xantoma de tendão de Aquiles é um sinal peculiar da hipercolesterolemia familiar, e faz parte do critério diagnóstico dessa doença. Cerca de $30 \%$ a $50 \%$ dos HF heterozigóticos com diagnóstico genético apresentam xantoma tendinoso. Estudo de Civeira e cols. ${ }^{79}$ já havia demonstrado que HF com xantomas apresentam maior prevalência de doença cardiovascular prematura em comparação aos sem xantomas (36,7\% versus 13,8\%, p = $0,001)^{79}$. A metanálise de Oosterveer e cols. ${ }^{80}$ encontraram um risco 3 vezes maior de os HF portadores de xantoma tendinoso evoluir com doença cardiovascular ${ }^{80}$.

O xantoma de tendão de Aquiles parece estar relacionado a risco cardiovascular mais alto na $\mathrm{HF}$, por ser baseado apenas no exame físico, deve ser estimulado sua pesquisa (Classe IIA, Nível de evidência B).

A associação da proteína C-reativa com doença cardiovascular na HF é baseada em estudos pequenos de sua associação com aterosclerose subclínica e com resultados controversos $^{81,82}$.

Não existem evidências para dosagem rotineira de PCR na HF (Classe IIB, Nível de evidência C).

\subsection{Estratificação de risco habitual não é válida para HF}

Os escores de risco clínicos amplamente utilizados para estratificação, tais como o escore de Framingham ${ }^{83}$, PROCAM (Prospective Cardiovascular Münster Study) $^{84}$, Reynolds ${ }^{85,86}$, entre outros, não foram elaborados para pacientes portadores de HF. A IV Diretriz Brasileira de Dislipidemia e Prevenção da Aterosclerose ${ }^{87}$ recomenda o escore de Framingham para estratificação de risco e, dessa forma, guiar metas terapêuticas. O escore de Framingham na HF frequentemente subestima o risco. Por exemplo, suponhamos um homem de 50 anos, portador de HF, colesterol total de $390 \mathrm{mg} / \mathrm{dL}$, LDL-c de $310 \mathrm{mg} / \mathrm{dL}$, triglicérides $150 \mathrm{mg} / \mathrm{dL}$, HDL-c de $50 \mathrm{mg} / \mathrm{dL}$, PA: 110 × $70 \mathrm{mmHg}$, sem anti-hipertensivos, não tabagista, apresenta um risco calculado em 10 anos de $8 \%$, ou seja, baixo risco ${ }^{83}$. Sabemos que esse paciente submetido de longa data a esse nível de colesterol não pode ser abordado como de baixo risco cardiovascular.

\subsection{Recomendação}

Não usar o escore de Framingham ou outros escores de risco clínicos na HF (Classe Ilb, Nível de evidência B).
5.9. Como Fazer a estratificação de risco CV dos pacientes com HF na prática clínica (Tabela 2 e 3)

Todos os pacientes portadores de HF deverão ser considerados de alto risco cardiovascular pelo menos em longo prazo (Classe I, Nível de evidência B). Os fatores de risco tradicionais também apresentam impacto na evolução dessa população e deverão ser identificados. Podemos considerar como mais alto risco (Classe I, Nível de evidência B) colocar como valores de corte da idade para histórico familiar de DAC precoce $<55$ e $<65$ anos, apenas ${ }^{17,88}$ :

Tabela 2 - *Modificado do Dutch MEDPED ${ }^{1}$ adotando um critério presente na proposta do Simon Broome Register Group ${ }^{3}$

Pacientes portadores de HF com qualquer uma dessas características deve ser considerado de muito alto risco

\begin{tabular}{ll}
\hline $\begin{array}{l}\text { Doença coronariana ou doença } \\
\text { cardiovascular estabelecida }\end{array}$ & $\begin{array}{c}\text { História prévia de infarto agudo } \\
\text { do miocárdio, acidente vascular } \\
\text { encefálico, doença arterial periférica, } \\
\text { revascularização miocárdica, angina } \\
\text { estável ou instável, ataque isquêmico } \\
\text { transitório, estenose carotídea maior } \\
\text { que 50\%, aneurisma de aorta }\end{array}$ \\
\hline Tabagistas & Parentes de primeiro ou segundo graus \\
com início da doença antes dos 45 \\
coronariana prematura
\end{tabular}

Tabela 3 - Fatores de risco em indivíduos com HF

\begin{tabular}{|c|c|}
\hline Fator de risco & $\begin{array}{c}\text { Se mais de } 2 \text { fatores de risco estiverem } \\
\text { presentes, recomenda-se intensificar } 0 \\
\text { tratamento }\end{array}$ \\
\hline Idade & $\begin{array}{l}\text { Homem com mais de } 30 \text { anos } \\
\text { Mulher com mais de } 40 \text { anos }\end{array}$ \\
\hline LDL-c basal & $>250 \mathrm{mg} / \mathrm{dL}$ \\
\hline Sexo & Sexo masculino \\
\hline Tabagismo & Tabagismo atual \\
\hline $\begin{array}{l}\text { História familiar de doença } \\
\text { arterial coronariana prematura }\end{array}$ & $\begin{array}{c}\text { Parentes de primeiro grau: } \\
\text { Homem }<55 \text { anos } \\
\text { Mulheres }<65 \text { anos }\end{array}$ \\
\hline Síndrome metabólica & $\begin{array}{l}\text { Considerar os critérios da International } \\
\text { Diabetes Federation (IDF) }\end{array}$ \\
\hline HDL-c baixo & $\begin{array}{c}\mathrm{HDL}-\mathrm{c}<40 \mathrm{mg} / \mathrm{dL} \text { para homens e } \\
50 \mathrm{mg} / \mathrm{dL} \text { para mulheres }\end{array}$ \\
\hline Hipertensão arterial sistêmica & $\begin{array}{c}\mathrm{PA}>140 \times 90 \mathrm{mmHg} \text { ou tratamento } \\
\text { medicamentoso da HAS }\end{array}$ \\
\hline Aumento de lipoproteína(a) & Níveis $\geq 60 \mathrm{mg} / \mathrm{dL}$ \\
\hline Exame físico & Xantoma de tendão \\
\hline
\end{tabular}




\section{Diretrizes}

5.10. Papel da aterosclerose subclinica na HF: Espessura Íntima-Média das Carótidas (EIMC), Calcificação da Artéria Coronariana (CAC) e Angiotomografia de Coronárias (TCMD)

\subsubsection{Calcificação da Artéria Coronariana (CAC)}

Diversos estudos demonstraram a correlação entre CAC e eventos coronarianos em pacientes sem eventos cardiovasculares prévios. Raggi e cols. ${ }^{89}$, em seguimento de 632 pacientes assintomáticos por período de $32 \pm 7$ meses, relataram ocorrência de 19 eventos relacionados a DAC e 8 mortes, e desses eventos, 70\% ocorreram em pacientes com CAC no último quartil (> 400 Agatston). A ausência de CAC estava associada a uma taxa de eventos de $0,11 \%$ por ano quando comparada com $4,8 \%$ por ano com um escore $>$ 400. Kondos e cols. ${ }^{90}$, em 2003, haviam demonstrado em seguimento de $37 \pm 12$ meses, com 8.855 pacientes, que a CAC foi marcadora de eventos cardíacos e sua presença fornecia informação adicional a idade e outros fatores de risco, em pacientes previamente assintomáticos. Existem evidências de que a CAC poderia agregar valor aos fatores de risco tradicionais e mesmo ao escore de Framingham na estratificação de risco dos pacientes de prevenção primária. Arad e cols. ${ }^{91}$ avaliaram o escore de cálcio em 4.613 pacientes assintomáticos entre 50 e 70 anos, e seguiram essa população por 4,3 anos. Nesse período, ocorreram 119 eventos cardiovasculares. Os autores demonstraram que a CAC foi preditora de risco independentemente dos fatores de risco tradicionais e foi melhor que o escore de Framingham na predição de eventos (área sob a curva ROC-"receiver operating characteristic" de 0,79 versus $0,69, p=0,0006$ ). Uma metanálise publicada em 2004 por Pletcher e cols. ${ }^{92}$ demonstra um relação linear entre valor de CAC e evento coronariano. O consenso sobre CAC da American Heart Association $^{93}$ de 2007 coloca que a CAC pode ser utilizada em pacientes de risco médio (risco em 10 anos de 10\%-20\%) como forma de aprimorar sua estratificação de risco.

A avaliação de CAC na população de HF no Brasil já havia sido estudada por Santos e cols. ${ }^{94}$ em mulheres e por Martinez e cols. ${ }^{81}$ em homens e mulheres, ambos os estudos demonstrando maior prevalência e gravidade da CAC em portadores de HF em relação a controles normolipidêmicos.

\subsubsection{Angiotomografia de Coronárias (TCMD)}

A capacidade da TCMD em diferenciar placas com composições diferentes pode tornar esse método capaz de auxiliar na detecção de tipos de placa associados a eventos cardiovasculares ${ }^{95-97}$. Um exemplo dessa análise foi feito em trabalho de Pundziute e cols. ${ }^{98}$, onde, em seguimento médio de 16 meses de 100 pacientes com doença coronariana conhecida ou suspeita submetidos a TCMD, a presença de placas mistas foi uma das variáveis associadas a evento cardiovascular. De fato, a informação de composição de placa fornecida pela TCMD pode agregar valor na estratificação de risco dos pacientes, partindo do conhecimento prévio de que placas pouco obstrutivas, por serem mais frequentes que as obstrutivas, são as que mais estão relacionadas a evento isquêmico agudo ${ }^{99-101}$. Daí também parte o conceito de "placa vulnerável". Esse termo foi originalmente utilizado por Little $\mathrm{e}^{102}$ ao relatar que a placa culpada por um infarto ou angina instável não necessariamente deveria provocar obstrução da luz coronariana antes de provocar o evento. Uma placa aterosclerótica apresentaria duas características importantes: primeiro, pode ser obstrutiva; segundo, pode ser "vulnerável" à medida que pode ser trombogênica se exposta a um estímulo desencadeante ${ }^{102}$. Uma lesão não necessitaria ser obstrutiva para ser trombogênica e também nem todas as lesões obstrutivas seriam trombogênicas. A revascularização miocárdica cirúrgica e a angioplastia percutânea tratam apenas as lesões obstrutivas, portanto não necessariamente estariam prevenindo um infarto agudo do miocárdio, e, desse modo, o tratamento da doença arterial deveria ser feito visando todo o território vascular.

A angiotomografia de coronárias foi avaliada na população HF no estudo de Miname e cols. ${ }^{103}$. Os autores encontraram maior carga de aterosclerose subclínica comparada a controles normolipidêmicos, representados por maior número de pacientes com placas (48\% vs. $14 \%, p=0,0005)$, com estenose ( $19 \%$ vs. $3 \%, p=0,015)$, segmentos com placas $(2,05 \pm 2,85$ vs. $0,43 \pm 1,33, p=0,0016)$ e escore de cálcio $(55 \pm 129 \text { vs. } 38 \pm 140, p=0,0028)^{103}$.

\subsubsection{Espessura Íntima-Média das Carótidas (EIMC)}

Atualmente, a EIMC pode ser aferida por aparelhos de ultrassom de alta resolução ${ }^{104}$. A EIMC está associada a fatores de risco cardiovasculares, prevalência de doença cardiovascular, incidência de doença cardiovascular e grau de aterosclerose em diferentes sítios arteriais. A progressão da EIMC pode ser revertida ou atenuada com intervenção em fatores de risco, em associação com redução de eventos cardiovasculares ${ }^{105}$. Esses achados colocam a EIMC como potencial marcador substituto de aterosclerose.

A EIMC já foi estudada na população HF em nosso meio por Martinez e cols. ${ }^{81}$, demonstrando maior valor da EIMC no grupo HF em relação aos controles. A EIMC foi utilizada na população HF como um marcador substituto de aterosclerose para avaliação de progressão de aterosclerose com medicação hipolipemiante ${ }^{75,106}$

\subsection{Recomendação}

Existem evidências de maior prevalência de gravidade de aterosclerose subclínica na população HF. Contudo, ainda não existem evidências para a pesquisa rotineira de aterosclerose subclínica nos HF. Isso pode auxiliar na estratificação de risco (Classe Ilb, Nível de evidência C).

\subsection{Papel da prova de isquemia na HF}

Considerar a realização de prova de isquemia miocárdica (teste ergométrico) para HF assintomáticos de mais alto risco acima de 20 anos e de menor risco acima de 30 anos.

Estudos prospectivos têm mostrado que as principais causas de morte em portadores de HF são doenças relacionadas com aterosclerose $^{31,107}$. 
Identificação precoce de doença arterial coronariana é, portanto, de fundamental importância na prevenção de eventos cardiovasculares ou morte, especialmernte em individuos portadores de HF de mais alto risco, em especial os assintomáticos.

Para essa identificação, testes indutores de isquemia miocárdica como o teste ergométrico ou testes de estresse cardiológico avaliados por ecocardiografia ou cintilografia constituem armamento diagnóstico precoce importante.

\subsection{Recomendação}

Como a HF é uma doença que acomete desde o nascimento, e aterosclerose pode evoluir rapidamente nesses indíviduos, deve-se considerar a realização dessas provas de isquemia miocárdica (especialmente o teste ergométrico, por ser de baixo custo e fácil realização) para portadores de HF assintomáticos de mais alto risco acima de 20 anos, e homens acima de 30 anos e mulheres acima de 45 anos com classificação de menor risco, cada 3 a 5 anos (Classe Ilb, Nível de Evidência C) ${ }^{17}$, sequencialmente como na figura 4.

\section{Recomendações nutricionais no tratamento da hipercolesterolemia familiar}

Medidas dietoterápicas e relacionadas a mudanças de estilo de vida devem ser sempre recomendadas para a prevenção da doença cardiovascular ${ }^{24}$. Entretanto, geralmente em razão das elevadas concentrações de LDL-c decorrentes dos defeitos genéticos que caracterizam a Hipercolesterolemia Familiar (HF), essas têm menor impacto sobre os lípides e possivelmente sobre a evolução da aterosclerose do que na população em geral. No entanto, recomendações dietéticas podem produzir benefícios sobre a colesterolemia, os triglicérides, a parede vascular, o ajuste do peso, o controle de outras doenças concomitantes como o diabete melito e a hipertensão arterial, e deve ser incentivada a todos os portadores de hipercolesterolemia, especialmente as crianças $^{108}$.

\subsection{Recomendações nutricionais no tratamento da hipercolesterolemia para crianças}

Recomenda-se que uma alimentação equilibrada seja iniciada após os dois anos de idade ${ }^{109}$. Isso tem por objetivo alcançar os níveis lipídicos ideais preconizados pela Diretriz Brasileira sobre Dislipidemias e Prevenção da Aterosclerose ${ }^{24}$. Embora em crianças e adolescentes que apresentam a forma familiar de hipercolesterolemia, a resposta à orientação dietética seja pequena, ela se fundamenta na adoção de padrões alimentares adequados, de acordo com o desvio lipídico apresentado, mantendo-se a ingestão de vitaminas e a quantidade de calorias necessárias para o desenvolvimento e crescimento da criança ou adolescente. Para tanto, devem ser avaliados os hábitos individuais e familiares. Para melhor conduzir a orientação dietética, torna-se valiosa a colaboração do pediatra e do nutricionista ${ }^{110}$.

\subsection{Recomendações nutricionais no tratamento da hipercolesterolemia para portadores de hipercolesterolemia familiar em geral}

\subsection{Influências da dieta sobre a concentração plasmática de lípides plasmáticos}

\subsubsection{Colesterol alimentar}

Apesar da associação entre consumo de colesterol e doença coronariana no tratamento da hipercolesterolemia, sabe-se que o colesterol alimentar exerce pouca influência

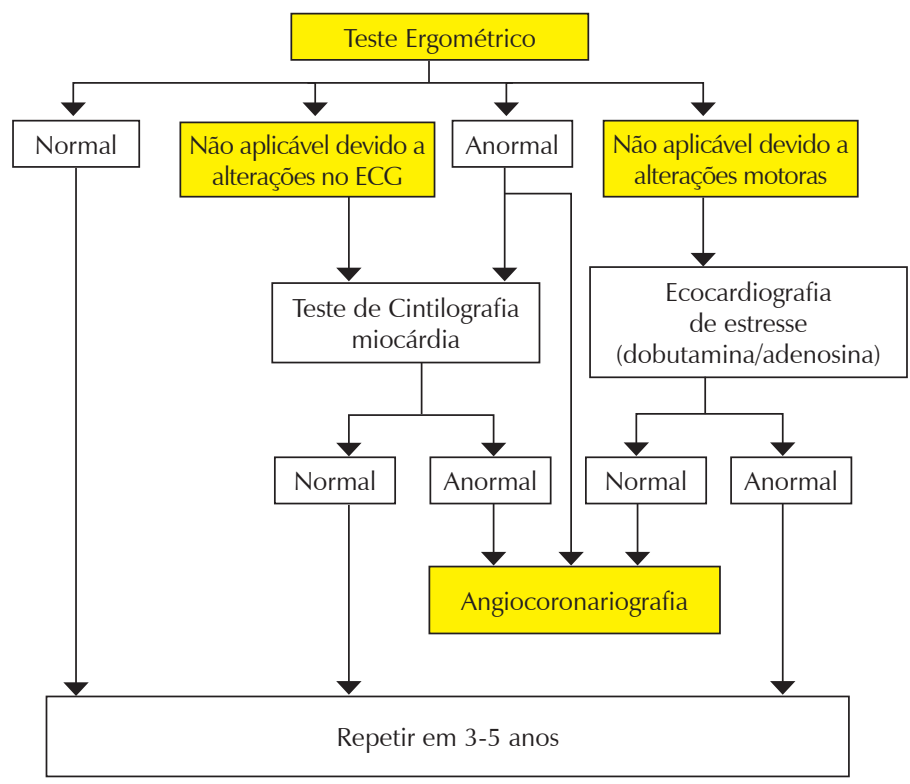

Fig. 4 - Recomendações para testes de pesquisa de isquemia miocárdica em portadores de hipercolesterolemia familiar. 
sobre a concentração plasmática de colesterol e aterosclerose precoce, já que aproximadamente $56 \%$ do colesterol da dieta é absorvido ${ }^{111}$. Os ácidos graxos (saturados e trans) exercem maior influência sobre a colesterolemia ${ }^{111,112}$.

Em razão da controvérsia sobre efeito colesterolemizante do colesterol alimentar, diversas diretrizes ${ }^{24,113}$ recomendam a restrição de gorduras totais e do colesterol da dieta, objetivando a redução e o controle do colesterol e de LDL-c plasmáticos.

\subsection{2. Ácidos graxos saturados (SFA)}

Entre os vários componentes dietéticos, são os ácidos graxos trans que mais aumentam LDL-C, seguidos dos ácidos graxos saturados, que também aumentam HDL-c e não alteram a relação $\mathrm{CT} / \mathrm{HDL}$, se comparados ao consumo de carboidratos. O consumo de 1\% do VCT de SFA está associado com aumento de 1,3 a 1,7 mg/dL no LDL-c e 0,4 a 0,5 mg/dL de HDL-c ${ }^{111,114}$, ocorrendo o inverso quando a ingestão de gordura saturada é reduzida.

Diferentes SFA podem ter efeitos diversos no perfil lipídico e fatores de risco cardiovascular. Metanálise recente ${ }^{115}$ mostrou que, se comparado a carboidratos, o ácido graxo (AG) láurico (C12:0) é o que mais aumenta o LDL-C, seguido do mirístico (C14:0) e do palmítico (C16:0). Já o esteárico pode provocar pequena redução no LDL-c. No tocante ao HDL-c, na mesma comparação com carboidratos, os AG láurico, mirístico e palmítico aumentam em maior \% o HDL-C, enquanto o esteárico provoca um pequeno aumento no HDL-c. O efeito dos ácidos graxos é comparado com outros nutrientes, no caso citado com carboidratos ${ }^{115}$. Portanto, ao se analisar os efeitos desses AG, deve-se verificar qual nutriente foi substituído pelo AG em questão.

\subsection{3. Ácidos graxos monoinsaturados (MUFA)}

Os ácidos graxos monoinsaturados possuem uma dupla ligação na cadeia carbônica, e o mais comum encontrado na natureza é o oleico (C18:1), série $\omega-9$, com maior concentração no óleo de oliva.

O conceito mais aceito é de que o consumo de MUFA não afeta significativamente os níveis de colesterol total circulantes, enquanto o consumo de SFA aumenta os níveis de colesterol ${ }^{116}$. Em uma metanálise de 14 estudos controlados entre 1983 e 1994, dietas ricas em óleos ricos em MUFA versus PUFA mostraram efeitos similares sobre o LDL-c e o HDL-C, enquanto os PUFA proporcionaram um discreto efeito redutor sobre os triglicerídeos ${ }^{117}$. Dessa forma, a substituição de SFA por MUFA reduz o LDL-c de forma semelhante à substituição por PUFA. Dados epidemiológicos mostram que populações que vivem no Mediterrâneo possuem menor risco de desenvolver doenças cardiovasculares, em virtude do tipo de alimentação adotada, em que a principal fonte de gordura é o azeite de oliva associado ao alto consumo de cereais, vegetais e frutas ${ }^{118}$.

\subsection{4. Ácidos graxos poli-insaturados}

Os ácidos graxos poli-insaturados são representados pelas séries do Ômega-6, e em elevadas quantidades podem provocar pequenas reduções nas concentrações séricas de HDL- ${ }^{119}$. Já os ácidos graxos Ômega-3 podem diminuir as concentrações de triglicerídeos (efeito secundário à redução da síntese de VLDL-c), sendo recomendado o consumo de duas a três porções de peixes/semana ${ }^{120}$. O poli-insaturado mais abundante, pertencente à série $\omega$-6, é o ácido linoleico (C18:2), seguido do araquidônico (C20:4), presentes especialmente nos óleos de milho e girassol. As principais fontes de linolênico, série $\omega$-3, são linhaça, soja e canola. Os ácidos graxos linoleico e linolênico são essenciais ao homem, pois as células dos mamíferos não têm a capacidade de inserir uma dupla ligação (dessaturar) antes do carbono 9 da cadeia dos ácidos graxos. Os ácidos graxos eicosapentenoico (C20:5) e docosa-hexenoico (C22:6), série $\omega-3$, são encontrados na gordura dos peixes de águas frias e profundas. Não são essenciais aos humanos, pelo fato de serem sintetizados a partir do ácido linoleico.

\subsection{5. Ácidos graxos trans}

Os ácidos graxos são denominados trans quando os hidrogênios ligados aos carbonos de uma insaturação encontram-se em lados opostos ${ }^{121}$. Estão presentes na dieta oriundos de gorduras parcialmente hidrogenadas, de óleos refinados, da carne, leite e derivados de animais ruminantes. Segundo Larqué e cols. ${ }^{122}$, os alimentos contendo gordura parcialmente hidrogenada contribuem com cerca de $80 \%$ a 90\% da ingestão diária de AGT. Para alimentos provenientes de animais ruminantes essa contribuição é bem menor, sendo estimada em torno de $2 \%$ a $8 \%$. Os óleos refinados apresentam níveis razoavelmente pequenos (1,0\%-1,5\%) de AGT, mas a reutilização, especialmente no preparo de alimentos fritos, pode tornar significativa a sua contribuição na ingestão diária de AGT ${ }^{123,124}$.

$\mathrm{O}$ alto consumo de ácidos graxos trans, provenientes de alimentos industriais, está associado ao aumento de doença arterial coronariana ${ }^{125}$. A causa mais provável é a sua ação sobre as lipoproteínas, da mesma maneira que as gorduras saturadas, as gorduras trans aumentam a concentração de LDL-c. A redução de HDL-c representa um aumento significativo da relação LDL/HDL. A principal fonte de gordura trans na dieta é a vegetal hidrogenada, utilizada industrialmente na produção de biscoitos, bolachas recheadas, empanados, sorvetes cremosos, tortas e alimentos comercializados em restaurantes fast-food. Embora esses ácidos graxos sejam abundantes nas margarinas duras, representam apenas $10 \%$ do consumo de gorduras trans, sendo os alimentos industrializados a maior fonte.

\subsubsection{Fibra alimentar}

O alto consumo de fibra alimentar está associado com diminuição significante nas taxas de prevalência de doença cardiovascular, acidente vascular cerebral e doença vascular periférica; além disso, os fatores de risco hipertensão, diabetes, obesidade e dislipidemia são menos frequentes em pessoas que têm alto consumo de fibra alimentar ${ }^{126}$. Uma revisão feita por Brown e cols. ${ }^{127}$ mostrou que fibras solúveis diminuem concentrações de colesterol total e LDL-c. O consumo de aproximadamente $3 \mathrm{~g}$ de fibra solúvel está associado com diminuição de $5 \mathrm{mg} / \mathrm{dL}$ nas concentrações de colesterol total e LDL-c, o que pode predizer uma redução na incidência de doença cardiovascular por volta de $4 \%$. 
Como resultado de dados acumulados, em 1997 o FDA autorizou a reivindicação de saúde para a associação entre fibras solúveis provenientes de aveia e psyllium, e desenvolvimento de doença cardiovascular quando consumidas como parte de uma dieta pobre em colesterol e gordura saturada. A literatura suporta o uso do psyllium para diminuir níveis de LDL-c. Doses $>7$ a $8 \mathrm{~g} /$ dia podem reduzir níveis de $\mathrm{LDL}$ por volta de $5 \%{ }^{128}$.

\subsubsection{Fitosterol}

Os fitosteróis são compostos naturais com estrutura semelhante ao colesterol. O mecanismo clássico de ação dos fitosteróis é o deslocamento do colesterol da fase micelar. $\mathrm{Na}$ dieta, as micelas mistas têm uma capacidade limitada de incorporar esteróis. A competição entre fitosteróis e colesterol reduz o conteúdo de colesterol nas micelas e, consequentemente, diminui seu transporte para a membrana de borda em escova do intestino. Fora da fase micelar, o colesterol não é mais solúvel, formando cocristais com fitosteróis, sendo, então, excretado juntamente com os fitosteróis não absorvidos ${ }^{129}$. Com isso, observam-se efeitos na diminuição do colesterol, especialmente LDL-c, ocasionados por fitosteróis ${ }^{130}$. O consumo diário de dois gramas de fitosteróis sob a forma de margarinas enriquecidas reduz a absorção de colesterol em aproximadamente $30 \% 40 \%$, o que ocasiona uma redução média no LDL-c de $8,8 \%{ }^{131}$. No entanto, essa redução nas concentrações de LDL-c pode variar com a concentração basal de LDL-c do indivíduo, do meio em que o fitosterol está inserido (margarinas, iogurtes, leite) e da frequência de consumo (uma ou várias vezes ao dia ${ }^{131}$. A suplementação com fitosteróis é uma opção para diminuição do LDL-c em crianças com HF que ainda não podem receber tratamento farmacológico ${ }^{132}$.

\subsubsection{Dietas ricas em carboidratos}

Sabe-se há alguns anos que dieta rica em carboidratos aumenta os níveis plasmáticos de triglicérides, quando comparada com dietas com alta porcentagem de gordura. Essas dietas podem reduzir as concentrações de HDL-c e são pouco eficazes sobre o LDL-C ${ }^{133}$.

\subsubsection{Soja}

O efeito do consumo de alimentos a base de soja sobre as concentrações de LDL-c é controverso ${ }^{128,134,135}$. As controvérsias nos resultados podem ser explicadas em parte pelos diferentes métodos empregados nos estudos, tais como: diferentes doses de soja são utilizadas em cada estudo, concentração de isoflavona varia nos suplementos e nos diferentes estudos, a substituição de proteína animal por soja pode ser viés, já que produtos animais são ricos em gordura saturada, conhecidamente aterogênica.

\subsubsection{Ovo}

O ovo é um alimento com baixo custo e uma excelente fonte de vários nutrientes, tais como folato, riboflavina, selênio, colina e vitaminas A, DE, Ke B12, além de sais minerais (ferro, fósforo, cálcio, magnésio, sódio, potássio, cloro, iodo, manganês, enxofre, cobre e zinco), proteína de alta qualidade e lipídeo, que tornam biodisponíveis importantes nutrientes, como luteína e zeaxantina, associadas com a prevenção da degeneração macular, além de fonte de gorduras saturadas e colesterol. Vale lembrar que lípides, minerais e vitaminas estão presentes quase que totalmente na gema, sendo a clara constituída especialmente pelas proteínas. Um ovo contém de 50 a 250 mg de colesterol, dependendo do tamanho. O impacto do consumo de ovos sobre a colesterolemia depende da capacidade do organismo em absorver colesterol. Acredita-se que entre $75 \%-85 \%$ da população sejam pouco sensíveis às concentrações de colesterol na dieta, ou seja, o impacto do consumo de alimentos ricos em colesterol como os ovos sobre o LDL-c é muito pequeno ${ }^{136}$. Certamente o alto consumo de gordura saturada por certas populações tem impacto muito maior sobre a colesterolemia, e o ovo pouco acrescentará ao risco de doença cardiovascular ${ }^{137,138}$.

Deve-se ter cuidado na forma de preparo do ovo: quando frito ou mexido, há adição de gorduras, aumentando calorias e, dependendo do tipo de gordura, elevando o colesterol.

\subsubsection{Chocolate}

Originário da América do Sul, o chocolate é o produto obtido a partir da mistura de derivados de cacau (Theobromacacao $L$.), massa (ou pasta ou liquor) de cacau, cacau em pó e/ou manteiga de cacau com outros ingredientes. A gordura do chocolate, derivada do cacau, é constituída por dois ácidos graxos saturados, o ácido palmítico e o esteárico, e o ácido oleico monoinsaturado, em adição de uma pequena quantidade (menos do que 5\%) de outros ácidos graxos ${ }^{139}$.

Embora seja conhecido que o consumo de gorduras saturadas aumente os níveis de colesterol, o consumo regular de manteiga de cacau e chocolate rico em cacau (chocolate escuro) não se relaciona a esse aumento ${ }^{140}$. As quantidades de ácido graxo esteárico são responsáveis pelo efeito neutro sobre o metabolismo do colesterol. Deve-se ter cuidado, no entanto, com chocolate confeccionado com leite, pois pode conter grande quantidade de ácidos graxos mirístico e láurico, conhecidamente hipercolesterolêmicos.

\subsubsection{Coco e óleo de coco}

O coco e o óleo de coco (Coco nucifera) são importantes fontes naturais de gorduras saturadas, especialmente de ácido láurico (C12:0). Em respeito à dislipidemia, sabe-se que gorduras sólidas saturadas ricas em ácido láurico resultam em perfil lipídico mais favorável do que uma gordura sólida rica em ácidos graxos trans ${ }^{111,141}$. Entretanto, em relação aos demais tipos de gorduras saturadas, especialmente ácido mirístico e palmítico, o ácido láurico apresenta maior poder em elevar tanto o LDL-c como o HDL-c ${ }^{115}$. Apesar disso, esse efeito parece não ser a causa do aumento da prevalência de DCV de acordo com estudos realizados na Ásia, onde o óleo de coco representa até $80 \%$ da gordura consumida em algumas regiões ${ }^{142,143}$.

No Brasil, um ensaio clínico realizado com mulheres normolipidêmicas com baixo consumo de gordura saturas, e com 12 semanas de duração, mostrou redução da relação LDL:HDL, aumento do HDL-c e redução da circunferência 
abdominal no grupo que utilizou óleo de $\operatorname{coco}^{144}$. Apesar dos potenciais benefícios do óleo de coco no HDL, os estudos experimentais comprovam o efeito hipercolesterolêmico do coco e seus subprodutos, como o recente estudo com cobaias que comparou óleo de coco com azeite de oliva e óleo de girassol. O grupo tratado com óleo de coco apresentou aumento significativo da fração não HDL e triglicérides ${ }^{145}$.

\subsection{Recomendações}

\begin{tabular}{|c|c|c|}
\hline Recomendações & $\begin{array}{l}\text { Grau de } \\
\text { recomendação }\end{array}$ & $\begin{array}{l}\text { Nível de } \\
\text { evidência }\end{array}$ \\
\hline $\begin{array}{l}\text { O consumo de colesterol alimentar deve } \\
\text { ser }<300 \text { mg/dia para auxiliar controle da } \\
\text { colesterolemia. }\end{array}$ & I & $A$ \\
\hline $\begin{array}{l}\text { O consumo de ácidos graxos saturados } \\
\text { deve se }<7 \% \text { do Valor Calórico Total } \\
\text { (VCT) para controle da colesterolemia. }\end{array}$ & I & A \\
\hline $\begin{array}{l}\text { O alto consumo de ácido palmítico e } \\
\text { mirístico aumenta o colesterol total e o } \\
\text { LDL colesterol. }\end{array}$ & I & $A$ \\
\hline $\begin{array}{l}\text { A adequação do consumo de ácidos } \\
\text { graxos saturados auxilia no controle do } \\
\text { LDL-c. }\end{array}$ & I & $A$ \\
\hline $\begin{array}{l}\text { O consumo de ácidos graxos } \\
\text { monoinsaturados deve ser }<20 \% \text { do } \\
\text { VCT, juntamente com dieta rica em frutas, } \\
\text { vegetais, grãos e carnes magras e laticínios } \\
\text { desnatados, que se relacionam com menor } \\
\text { concentração plasmática de LDL-c. }\end{array}$ & I & A \\
\hline $\begin{array}{l}\text { O consumo de ácidos graxos poli- } \\
\text { insaturados deve ser }<10 \% \text { do VCT. }\end{array}$ & $\|$ & B \\
\hline $\begin{array}{l}\text { O consumo de ácidos graxos trans eleva } \\
\text { o colesterol total e o LDL- c e reduz o } \\
\text { HDL-c. }\end{array}$ & I & $A$ \\
\hline $\begin{array}{l}\text { O consumo de chocolate rico em cacau } \\
\text { não está relacionado ao aumento do } \\
\text { colesterol. }\end{array}$ & $\|$ & $A$ \\
\hline
\end{tabular}

Não se recomenda coco e óleo de coco para tratamento de hipercolesterolemia sendo necessários estudos adicionais para orientar seu uso em demais alterações metabólicas

$\begin{aligned} & \text { O consumo de ovo ou alimentos ricos } \\ & \text { em colesterol tem pouca influência sobre } \\ & \text { níveis de lipídeos plasmáticos; no entanto, } \\ & \text { recomenda-se consumo moderado de } \\ & \text { alimentos fontes de colesterol. }\end{aligned}$
$\begin{aligned} & \text { O consumo diário de } 2 \mathrm{~g} \text { de fitosterol está } \\ & \text { relacionado à diminuição do LDL-c. }\end{aligned}$

\section{Tratamento farmacológico da hipercolesterolemia familiar heterozigótica}

Diversos estudos randomizados demonstraram que reduzir a concentração de LDL-colesterol (LDL-c) plasmático com estatinas resulta na diminuição da morbimortalidade da doença cardiovascular aterosclerótica ${ }^{146}$. Destacam-se os dados obtidos de uma autêntica metanálise prospectiva realizada pelo Cholesterol Treatment Trialists (CTT) Collaborators ${ }^{147}$. O CTT incluiu a análise de 90.056 indivíduos de 14 estudos randomizados para o uso de estatinas no período de cinco anos. Encontrou-se que para cada $1 \mathrm{mmol} / \mathrm{L}$ de redução do LDL-c (39 mg/dL) houve uma diminuição proporcional de mortalidade de causa coronariana em $19 \%$ no período analisado de cinco anos, projetando uma redução esperada de $38 \%$ em dez anos. Isso significa aproximadamente que para cada $1 \mathrm{mg}$ de LDL-c reduzido com o uso de estatina, podemos obter uma diminuição de $1 \%$ na mortalidade cardiovascular aterosclerótica em dez anos.

Considerando o potencial benefício de reduções maiores no LDL-c possibilitando crescente diminuição na morbimortalidade, o CTT realizou nova metanálise comparando a incidência de eventos cardiovasculares entre grupos de pacientes em uso de doses mais elevadas de estatinas versus pacientes com doses menos intensas ${ }^{148}$. Foram obtidos dados prospectivos de $170 \mathrm{mil}$ participantes de 26 grandes estudos com duração mínima de dois anos. A redução adicional de 1,0 mmol/L no LDL-C (39 mg/dL) com o emprego de estatinas mais potentes em altas doses resultou em diminuição de eventos cardiovasculares em relação ao grupo tratado com menor intensidade, na mesma proporção encontrada nos estudos de estatina versus placebo, mesmo naqueles com LDL-C basal menor que $2 \mathrm{mmol} / \mathrm{L}(76 \mathrm{mg} / \mathrm{dL}$ ) em tratamento menos intenso. Reduções de LDL-c de 80 e 120 mg/dL resultaram na diminuição dos eventos ateroscleróticos maiores, respectivamente, em $40 \%$ e 50\%. Portanto, apesar de existirem nas Diretrizes tradicionalmente diferentes metas de tratamento de LDL-C, os dados do CTT permitem concluir a importância de sempre ser tentada uma redução substancial do LDL-c com a terapia hipolipemiante utilizada.

Apesar de não haver um estudo específico randomizado controlado de redução da colesterolemia em portadores de HF, há evidência na literatura de que esses indivíduos se beneficiam da redução do $L D L-C^{32}$. A coorte de HF estudada por Versmissen e cols. ${ }^{32}$ com mais de dois mil pacientes seguida por dez anos mostrou que o grupo tratado com estatina apresentou uma redução de $76 \%$ do risco de doença coronariana (IC95\% 0,18 a 0,30 $p<0,001)$, comparado ao grupo sem estatina. Isso foi associado à diminuição relativa do LDL-c de 44\%, o que correspondeu à redução absoluta de 124 mg/ dL. Nesse estudo, as taxas de infarto do miocárdio ao final do seguimento foram similares às da população normal. É importante enfatizar que em razão do alto risco de eventos cardiovasculares da população com Hipercolesterolemia Familiar (HF) e considerando todas as evidências do benefício da redução do LDL-c para redução da morbimortalidade por doença cardiovascular, não seria ético realizar um estudo controlado por placebo nessa população nos dias de hoje. 


\subsection{Metas de LDL-c no tratamento farmacológico da HF}

Indivíduos portadores de HF apresentam risco elevado de doença coronariana ao longo da vida, podendo desenvolvê-la precocemente, de modo que o tratamento farmacológico deve ser iniciado mais cedo e mantido em longo prazo para reduzir consistentemente a incidência de eventos cardiovasculares e mortalidade ${ }^{149,150}$. Assim sendo, pessoas com HF requerem um seguimento regular e atento ao longo de suas vidas para o controle da colesterolemia.

A indicação do tratamento farmacológico ocorre para concentrações de LDL-c $\geq 190 \mathrm{mg} / \mathrm{dL}$ de forma isolada em indivíduos sem manifestação prévia de doença cardiovascular, após aplicação de medidas de estilo de vida saudável. Da mesma forma, indivíduos com LDL-c $\geq 160 \mathrm{mg} / \mathrm{dL}$, mas que apresentem outros fatores de risco, também deverão ser tratados. Considerando os elevados valores de colesterolemia basais presentes na HF, uma redução de pelo menos $50 \%$ obtida com o tratamento medicamentoso é considerada de real valor terapêutico ${ }^{1}$. Entretanto, os pacientes com HF em maior risco necessitam intensificação do esquema de tratamento para alcançar maiores reduções de LDL-c.

São considerados portadores de HF de maior risco aqueles com manifestação clínica de aterosclerose coronariana ou equivalente cerebrovascular e/ou periférico; pacientes diabéticos com HF; indivíduos com HF tabagistas; presença de dois ou mais fatores de risco coronarianos clássicos associados à HF (ver Capítulo 5 desta Diretriz); antecedente de Doença Arterial Coronariana (DAC) muito precoce em parentes de primeiro grau: pai ou irmão com DAC abaixo de 45 anos e mãe ou irmã com DAC abaixo de 55 anos e presença de lipoproteína(a) elevada (> $60 \mathrm{mg} / \mathrm{dL}$ ). Em portadores de HF sem tais características, a intensificação do tratamento farmacológico pode ser considerada se o LDL-c permanece $>160 \mathrm{mg} / \mathrm{dL}$ ou se a redução inicial de $50 \%$ no LDL-c não foi atingida.

\subsection{Recomendação}

Portadores HF devem ter reduções de pelo menos 50\% no LDL-c (Classe I, Nível de evidência A). Reduções maiores podem ser necessárias dependendo dos valores de LDL-C e do risco de eventos cardiovasculares (Classe I, Nível de evidência B).

\subsection{Tratamento farmacológico}

\subsubsection{Estatinas}

A HF heterozigótica se manifesta com somente 50\% dos receptores de LDL em funcionamento, apresentando em geral boa resposta ao uso de estatinas que aumentam significativamente a expressão desses receptores ao determinarem o bloqueio da síntese intracelular do colesterol. As estatinas utilizadas devem ser de alta potência como a atorvastatina (10-80 $\mathrm{mg}$ ) e a rosuvastatina (10-40 mg), tituladas para se obter redução $\geq$ a $50 \%$ a partir dos níveis basais ${ }^{1,149,150}$, sendo difícil alcançar tal meta com o uso isolado da sinvastatina. Estatinas de menor potência, como fluvastatina, pravastatina e lovastatina, geralmente são inapropriadas para os portadores de HF. De um modo geral, as estatinas são bem toleradas e possuem um bom perfil de segurança ${ }^{151-153}$. Os potenciais efeitos adversos das estatinas com relação a miopatia e elevação de enzimas hepáticas nos portadores de HF, evidentemente, são os mesmos encontrados em outros pacientes tratados mais intensivamente. As estatinas menos potentes, como fluvastatina e pravastatina, podem ter melhor tolerância e menor risco de miopatia grave, mas possuem menor capacidade de reduzir níveis elevados de LDL-c $\mathrm{C}^{154,155}$. Alguns pacientes não toleram estatinas. Nesses casos, deve-se tentar outra estatina ou tentar doses reduzidas dessas em combinação com outros hipolipemiantes, como ezetimiba, niacina ou colestiramina ${ }^{150}$. Como última opção para o uso de estatina em pacientes intolerantes, embora haja poucos estudos, em geral de curto prazo com pequeno número de pacientes e que avaliaram apenas tolerabilidade ou eficácia e não desfechos clínicos, pode ser tentada a tomada em dias alternados ${ }^{156,157}$. Para pacientes que não podem usar estatina está indicada a terapia combinada de niacina, ezetimiba e/ ou colestiramina.

\subsubsection{Recomendação}

Estatinas potentes em doses adequadas são a primeira escolha para redução do LDL-c em portadores de HF (Classe I, Nível de Evidência A). Em intolerantes a estatinas pode-se tentar doses reduzidas em combinação com outros hipolipemiantes, como ezetimiba, niacina (ou ácido nicotínico), ou colestiramina (Classe I, Nível de Evidência B). Para pacientes que não podem usar estatina está indicada a terapia combinada de niacina, ezetimiba e/ou colestiramina (Classe IIA, Nível de Evidência B).

\subsubsection{Terapia adjuvante às estatinas}

A maior parte dos portadores de HF tolera doses máximas das estatinas mais potentes (atorvastatina e rosuvastatina), com segurança e boa tolerância. $\mathrm{O}$ fato é que, em razão das concentrações muito elevadas de LDL-c na HF, frequentemente é necessária a adição de um ou mais hipolipemiantes que não a estatina para alcançar as metas desejadas ${ }^{25,158}$.

A colestiramina no estudo Lipid Research Clinics ${ }^{159}$ reduziu a incidência de infarto do miocárdio em 19\%. Portanto, a colestiramina pode ser utilizada como coadjuvante às estatinas na HF. A colestiramina é apresentada em envelopes de 4 gramas. A posologia inicial é de $4 \mathrm{~g}$ ao dia, podendose atingir no máximo $24 \mathrm{~g} / \mathrm{dia}$. Posologias superiores a 16 g são dificilmente toleradas. Os principais efeitos colaterais relacionam-se ao aparelho digestivo (plenitude gástrica, náuseas), interferindo na motilidade intestinal e causando obstipação, meteorismo, além da exacerbação de hemorroidas preexistentes. O fármaco diminui a absorção de vitaminas lipossolúveis (A, D, K, E) e de ácido fólico, sendo eventualmente necessária a suplementação desses elementos. A colestiramina deve ser utilizada uma hora antes ou três horas após a ingestão de outros medicamentos, para não diminuir a absorção desses. A colestiramina é fármaco útil em crianças com menos de 8 anos que ainda não podem receber estatinas. 


\section{Diretrizes}

\subsubsection{Recomendação}

A colestiramina pode ser utilizada como terapia adjuvante às estatinas para maior redução do LDL-c quando essas em uso isolado não são suficientes (Classe I, Nível de Evidência B).

A ezetimiba, por sua vez, tem um mecanismo específico de inibir a absorção do colesterol ao nível do enterócito e, portanto, não interfere na absorção de outros agentes ${ }^{24,158}$. A redução do afluxo do colesterol a partir do intestino para o fígado resulta em aumento compensador da expressão de receptores hepáticos de LDL e aumento da captura das partículas de LDL-c circulantes. Entretanto, em razão do aumento da síntese intracelular de colesterol que tenta compensar a diminuição do seu aporte ao hepatócito, a redução final da colesterolemia com o uso da ezetimiba (isolada ou em associação à estatina) fica em torno de 15\% a $20 \%$, mas que ainda assim tem grande significado na redução de eventos cardiovasculares. O uso da ezetimiba em associação à sinvastatina mostrou eficácia em reduzir eventos cardiovasculares, além de segurança em portadores de insuficiência renal crônica não dialítica no estudo SHARP ${ }^{160}$. A redução dos eventos ateroscleróticos maiores foi proporcional à queda do LDL-c e foi similar aos dados obtidos pela metanálise do $\mathrm{CTT}^{147}$ com uso isolado de estatinas.

A ezetimiba pode ser utilizada como terapia adjuvante às estatinas para redução adequada do LDL-c e prevenção da doença cardiovascular em portadores de HF (Classe I, Nível de Evidência B).

A niacina reduz o afluxo de ácidos graxos para o fígado e como consequência levando a menor produção de VLDL-C, precursora do LDL-C, diminuindo assim a concentração dessas partículas circulantes. Seu uso tem excelente nível de evidência científica iniciado desde há aproximadamente 20 dias após o estudo Coronary Drug Project ${ }^{161}$, onde foi constatada redução de eventos em $27 \%$ após acompanhamento por 15 anos. Combinada com estatinas ou em tripla associação com estatinas e bloqueadores de absorção, a niacina reduziu a progressão anatômica da aterosclerose e os principais desfechos cardiovasculares ${ }^{162-165}$. A tolerabilidade é um fator limitante no uso da niacina, mesmo na forma de liberação estendida, por sua ação em receptores de prostaglandina na derme resultando em vasodilatação por vezes intensa e rubor facial ou prurido. Esse frequente efeito colateral motiva a titulação paciente e progressiva da niacina partindo de doses de 500 mg no primeiro mês, seguindo aumentos progressivos a cada quatro ou oito semanas até a dose máxima tolerada possível, não ultrapassando $2 \mathrm{~g}$ diários.

A tomada única no período noturno visa a minimizar a sensação do eventual flushing que, desse modo, poderia não ser percebido durante o sono. Para os pacientes em uso do AAS 300 mg é recomendado o uso desse uma hora antes da niacina pelo potencial benefício como inibidor de prostaglandina. Recentemente sua associação com inibidor específico de prostaglandina, o laropipranto, melhorou a tolerância, possibilitando maior uso desse tão importante fármaco hipolipemiante ${ }^{166}$. Nesse caso, a titulação pode ser tentada de maneira mais rápida, iniciando-se com $1 \mathrm{~g}$ à noite no primeiro mês e aumentando para a dose plena de $2 \mathrm{~g}$ do segundo mês em diante, em caso de boa tolerância.
No caso do uso da combinação niacina/laropipranto, não há necessidade de uso de aspirina previamente à ingestão da niacina. Outros fármacos como monascus, ácidos graxos Ômega-3 e vitaminas antioxidantes não foram testadas em portadores de HF, logo, não são indicadas.

A niacina pode ser utilizada como terapia adjuvante às estatinas para redução adequada do LDL-c em portadores de HF (Classe I, Nível de Evidência B). Para controle da hipercolesterolemia e redução dos eventos cardiovasculares em portadores de HF, esta Diretriz contraindica o uso de fibratos, ácidos graxos Ômega-3, monascus e vitaminas antioxidantes em razão da total falta de evidência de benefício dessas substâncias (Classe III, Nível de Evidência C).

\section{Terapias alternativas para tratamento da hipercolesterolemia familiar}

Terapias alternativas não farmacológicas podem ser tentadas em casos de Hipercolesterolemia Familiar (HF) refratários ao tratamento medicamentoso, como: cirurgia de bypass ileal, plasmaférese e transplante hepático.

\subsection{Bypass ileal}

Estudo utilizando cirurgia de by-pass ileal diminuiu LDL-c em $38 \%$ e eventos cardiovasculares em $30 \%$ em portadores de hipercolesterolemia grave ${ }^{167}$. Já em portadores de HF, um estudo com apenas 11 pacientes mostrou queda do LDL-C em aproximadamente $20 \%$. Esses estudos foram realizados antes do advento das estatinas e da ezetimiba. O valor do bypass ileal no tratamento da HF e prevenção da doença cardiovascular na vigência da terapia farmacológica atual é desconhecido $^{168}$.

\subsection{Recomendação}

Embora o estudo $\mathrm{POSCH}$ tenha mostrado redução de eventos cardiovasculares com o bypass ileal, não se recomenda de rotina esse procedimento em portadores de HF refratária ao tratamento farmacológico (Classe IIB, Nível de evidência $\mathrm{C}$ ).

\subsection{Plasmaférese e LDL-aférese}

O LDL-c pode ser removido de forma intensa do plasma por meio de plasmaférese ou LDL-aférese. Atualmente, as técnicas disponíveis para LDL aférese são:

- Imunoadsorção. Adsorção pelo sulfato de dextran celulose. Sistema extracorpóreo de precipitação da LDL pela heparina (sistema HELP).

- Adsorção direta de lipoproteínas utilizando filtro de hemoperfusão (DALI).

Classicamente, a aférese pode ser realizada em portadores de HF homozigótica; contudo, pode ser alternativa também para HF heterozigóticos graves refratários ao tratamento farmacológico. Pequenos estudos mostram além da redução do LDL-c e Lp(a), regressão de xantomas e lesões coronarianas anatômicas ${ }^{169,170}$. 


\subsubsection{Indicações para LDL aférese}

1. Aférese de LDL é uma terapia medica aprovada pela Food and Drug Administration dos Estados Unidos ${ }^{171}$ para pacientes que não respondem ao tratamento de LDL-c ou que têm doenças sintomáticas crônicas.

2. Em pacientes que após seis meses não apresentam resposta adequada ao tratamento medicamento otimizado, a LDL-aférese é indicada de acordo com essas normas:

- pacientes com HF homozigótica funcional com colesterol LDL > $300 \mathrm{mg} / \mathrm{dL}$ (ou colesterol não HDL $>330 \mathrm{mg} / \mathrm{dL}$ ).

- pacientes com HF heterozigótica funcional com colesterol LDL > $300 \mathrm{mg} / \mathrm{dL}$ (ou colesterol não HDL $>330 \mathrm{mg} / \mathrm{dL}$ ) e com zero ou 1 fator de risco.

- pacientes com HF heterozigótica funcional com colesterol LDL > $200 \mathrm{mg} / \mathrm{dL}$ (ou colesterol não HDL $>230 \mathrm{mg} / \mathrm{dL}$ ) com dois ou mais fatores de risco ou lipoproteína (a) > $50 \mathrm{mg} / \mathrm{dL}$.

- pacientes de HF heterozigótica funcional com colesterol LDL > $160 \mathrm{mg} / \mathrm{dL}$ (ou colesterol não HDL colesterol > $190 \mathrm{mg} / \mathrm{dL}$ ) com DC estabelecida e outras doenças cardiovasculares ou diabetes.

\subsubsection{Recomendações para uso de aférese e prevenção da doença cardiovascular}

Embora a plasmaférese e LDL-aférese sejam eficazes em reduzir as concentrações de LDL-c, e em alguns pequenos estudos seu uso ter demonstrado regressão de xantomas e da aterosclerose angiográfica, não há evidências de estudos randomizados controlados de que a aférese reduza o risco de eventos cardiovasculares ou prolongue a vida em portadores de HF homozigóticos. Da mesma forma, seu custo-eficácia é discutível. Considerando esses fatos, esta Diretriz coloca a aférese como alternativa de tratamento para casos graves e refratários, porém como Classe IIB Nível de Evidência C.

\subsection{Transplante hepático}

O transplante hepático pode ser uma alternativa para pacientes HF refratários ao tratamento farmacológico ${ }^{172}$. Esse estaria indicado especialmente nos HF homozigóticos. Entretanto, deve-se sempre discutir com pacientes e familiares para que sejam esclarecidos os riscos e os benefícios do procedimento.

\subsection{Recomendação}

O transplante hepático pode ser uma alternativa para casos de HF refratária ao tratamento farmacológico, especialmente nos portadores de forma homozigótica (Classe IIB, Nível de evidência C).

\section{Hipercolesterolemia familiar - na criança}

\subsection{Triagem}

Em nível populacional, deve haver a triagem do perfil lipídico de crianças a partir dos 2 anos de idade, segundo os critérios descritos a seguir. Antes disso, os casos devem ser analisados individualmente, segundo doenças concomitantes, terapêuticas e história familiar.

Devemos triar o perfil lipídico em criança entre 2 e 10 anos, quando:

- Tenham pais ou avós com história de doença arterial isquêmica em homens com menos de 55 anos, e em mulheres com menos de 65 anos.

- Tenham pais com colesterol total superior a $240 \mathrm{mg} / \mathrm{dL}$.

- Apresentem outros fatores de risco, como hipertensão arterial sistêmica, obesidade, tabagismo, diabete melito, nascidos pequenos para a idade gestacional, dieta rica em gorduras saturadas e/ou ácidos graxos trans.

- Utilizem drogas ou sejam portadoras de doenças que cursam com dislipidemia (síndrome da imunodeficiência humana, hipotireoidismo, doença de Cushing etc.).

- Possuam manifestações clínicas de dislipidemias (xantomas, xantelasma, arco corneal, dores abdominais recorrentes, pancreatites).

Acima de 10 anos, toda criança deve ter dosado, ao menos uma vez, seu colesterol total, independentemente da presença de fatores de risco (Classe Ila, Nível B)

\subsection{Valores de referência}

Os valores de referência para lípides e lipoproteínas em crianças e adolescentes estão descritos na tabela 41 (Classe Ila, Nível B).

Tabela 4 - Valores de referência para lípides e lipoproteínas em crianças e adolescentes ${ }^{2}$

\begin{tabular}{lccc}
\hline Parâmetro & Aceitável & Limítrofe & Alto (p95) \\
\hline CT & $<170$ & $170-199$ & $>200$ \\
\hline LDL-C & $<110$ & $110-129$ & $>130$ \\
\hline n-HDL-C & 123 & $123-143$ & $>144$ \\
\hline TG $(0-9 a)$ & $<75$ & $75-99$ & $>100$ \\
\hline TG $(10-19 a)$ & $<90$ & $90-129$ & $>130$ \\
\hline HDL-C & $>45$ & $35-45$ & $<35$ \\
\hline Apo A1 & $>120$ & $110-120$ & $>110$ \\
\hline Apo B & $<90$ & $90-109$ & $<$ \\
\hline
\end{tabular}




\section{Diretrizes}

\subsection{Triagem de risco para hipercolesterolemia familiar}

Para a estratificação de risco de uma criança ou adolescente ser portador de HF monogênica, devem-se tomar em conta três aspectos: valores de LDL-c da criança ou do adolescente no diagnóstico; valores de LDL-c da criança ou do adolescente após seis meses de dieta; e se os pais utilizam ou não hipolipemiantes. Segundo essas três variáveis, os riscos estimados de o indivíduo ser portador de HF estão descritos nos Quadros 1 e $2^{173}$ :

Quadro 1 - Risco estimado de ser portador de hipercolesterolemia familiar em crianças e adolescentes, cujos pais utilizam hipolipemiantes, segundo LDL-c no diagnóstico e após seis meses de dieta

\begin{tabular}{|l|c|c|c|c|c|}
\hline & \multicolumn{5}{|c|}{ LDL-c após dieta } \\
\hline \multirow{4}{*}{$\begin{array}{l}\text { LDL-c no } \\
\text { diagnóstico }\end{array}$} & $\mathrm{mg} / \mathrm{dL}$ & $<140$ & $140-169$ & $170-229$ & $>230$ \\
\cline { 2 - 6 } & $130-169$ & $7 \%$ & $14 \%$ & $29 \%$ & $49 \%$ \\
\cline { 2 - 6 } & $170-209$ & $27 \%$ & $48 \%$ & $68 \%$ & $84 \%$ \\
\cline { 2 - 6 } & $210-259$ & $67 \%$ & $83 \%$ & $92 \%$ & $97 \%$ \\
\cline { 2 - 6 } & $>=260$ & $92 \%$ & $96 \%$ & $98 \%$ & $99 \%$ \\
\hline
\end{tabular}

Legenda: \% possivel \% provável \% definitivo

Quadro 2 - Risco estimado de ser portador de hipercolesterolemia familiar em crianças e adolescentes cujos pais não utilizam hipolipemiantes, segundo LDL-c no diagnóstico e após seis meses de dieta

\begin{tabular}{|l|c|c|c|c|c|}
\hline & \multicolumn{5}{|c|}{ LDL-c após dieta } \\
\hline \multirow{4}{*}{$\begin{array}{l}\text { LDL-c no } \\
\text { diagnóstico }\end{array}$} & $\mathrm{mg} / \mathrm{dL}$ & $<140$ & $140-169$ & $170-229$ & $>230$ \\
\cline { 2 - 6 } & $130-169$ & $1 \%$ & $3 \%$ & $7 \%$ & $15 \%$ \\
\cline { 2 - 6 } & $170-209$ & $7 \%$ & $14 \%$ & $29 \%$ & $49 \%$ \\
\cline { 2 - 6 } & $210-259$ & $28 \%$ & $48 \%$ & $69 \%$ & $84 \%$ \\
\cline { 2 - 6 } & $>=260$ & $67 \%$ & $83 \%$ & $92 \%$ & $97 \%$ \\
\hline
\end{tabular}

Legenda: \% possivel \% provável \% definitivo

Quando considerado o valor de LDL-c isolado, o ponto de corte com maior sensibilidade e especificidade para suspeita de hipercolesterolemia familiar na infância é de 150 mg/d ${ }^{174}$ (Classe Ilb, Nível B).

\subsection{Tratamento}

Recomenda-se que, seguindo rigorosamente os critérios descritos adiante e após mudança de estilo de vida, a terapia hipolipemiante seja iniciada após os dois anos de idade, salvo casos graves e com avaliação individualizada. Tem como objetivo alcançar a meta de valores de $110 \mathrm{mg} / \mathrm{dL}$ de LDL-c - ou no mínimo 130 mg/dL - e reduzir xantomatose, diminuir os risco de pancreatite e prevenir o aparecimento de doença arterial coronariana (Classe I, Nível A).

\subsubsection{Estatinas}

O uso de estatinas diminui significativamente colesterol total, LDL-c e apolipoproteína B, sem aparentemente ocorrência significativa de efeitos adversos, relacionados a desenvolvimento sexual, toxicidade muscular ou hepática, podendo ser utilizado a partir dos 8 anos de idade ${ }^{175}$. Podem diminuir o LDL-c em cerca de $30 \%$ e aumentar o HDL-c em $5 \%$, e consequentemente atenuar o espessamento médiointimal e melhorar a função endotelial| ${ }^{176-181}$ (Classe I, Nível A). Em que pesem essas considerações, não há evidências suficientes para consenso de quando começar estatinas na infância ou qual a meta de LDL-c a ser alcançada nessa faixa etária ${ }^{182}$ (Classe Ilb, Nível B).

As doses usualmente utilizadas dos hipolipemiantes em crianças e adolescentes são descrita no Quadro 3:

Quadro 3 - Doses de hipolipemiantes utilizados em crianças e adolescentes (Classe lla, Nível B)

\begin{tabular}{|l|c|}
\hline Fármaco & Doses $(\mathrm{mg} / \mathrm{d})$ \\
\hline Lovastatina & $10-40$ \\
\hline Pravastatina & $10-40$ \\
\hline Sinvastatina & $10-40$ \\
\hline Rosuvastatina & $5-40$ \\
\hline Atorvastatina & $10-40$ \\
\hline Colestiramina & $4-16^{*}$ \\
\hline Ezetimiba & 10 \\
\hline * gramas & \\
\hline
\end{tabular}

Doses maiores que as descritas podem ser utilizadas, após análise individual de risco em crianças. Em crianças e adolescentes, sugere-se a utilização inicial da menor dose possível de estatinas, preferencialmente associada a inibidores da absorção do colesterol (Classe Ila, Nível C).

\subsubsection{Monitoração do tratamento}

A figura 6 mostra o algoritmo da monitoração do uso de estatinas em crianças e adolescentes (Classe Ila, Nível C).

\subsection{Inibidores da absorção do colesterol}

O uso de ezetimibe como monoterapia diminui em cerca de $28 \%$ os valores de LDL-c em crianças com hipercolesterolemia familiar heterozigótica. Recomenda-se seu uso como monoterapia a partir dos 5 anos e em associação com estatina acima de 8 anos, diminuindo os efeitos colaterais dessas $^{185}$ (Classe Ilb, Nível C).

\subsection{Sequestrantes dos ácidos biliares}

Os sequestrantes dos ácidos biliares podem ser utilizados em qualquer idade. Diminuem em média, como monoterapia, cerca de 10\%-15\% dos níveis de LDL-c. Podem ser também utilizados de forma associada com estatinas, em horários de administração diferentes. Pelo risco de desnutrição relacionado às vitaminas lipossolúveis, recomenda-se monitoração nutricional e suplementação segundo critérios objetivos de deficiência ${ }^{186}$ (Classe I, Nível B). 


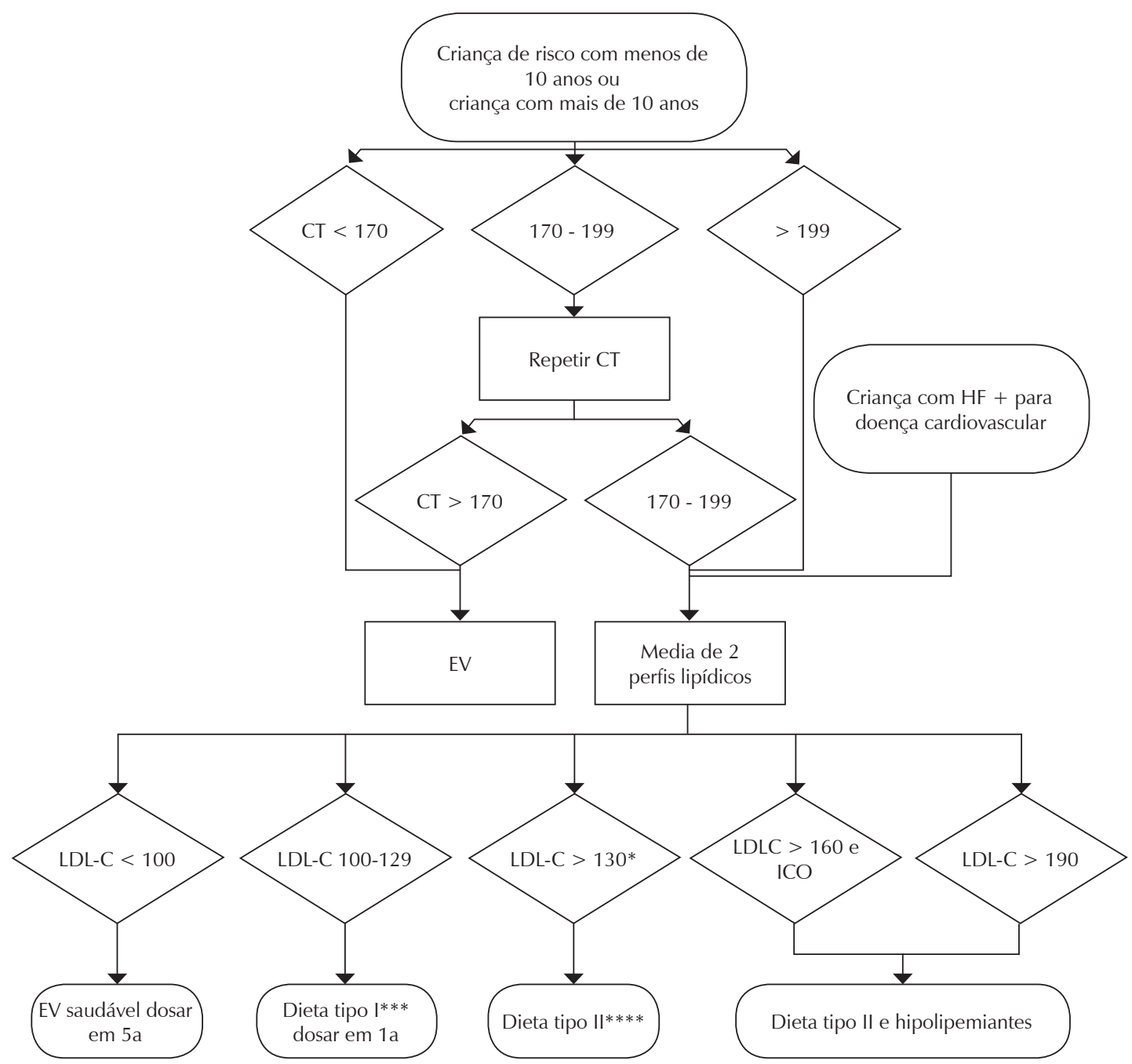

\section{Alvo Terapêutico}

CT: colesterol total, HF: história familiar, LDL-C: LDL-colesterol.

\section{Notas:}

* Na presença de diabete melito, infecção pelo HIV, doença de Kawasaki, síndrome nefrótica e lúpus eritematoso sistêmico, o tratamento medicamentoso deve ser instituído com valores de LDL-c acima de $130 \mathrm{mg} / \mathrm{dL}$, após mudanças do estilo de vida.

** A presença de fatores de risco emergentes - valores elevados de lipoproteína (a), homocisteína e proteína C-reativa - são considerados como determinantes do uso de hipolipemiantes em crianças com niveis de LDL-c acima de $160 \mathrm{mg} / \mathrm{dL}$, por alguns autores.

*** Dieta tipo I: até $30 \%$ de calorias de gorduras, até $10 \%$ de gorduras saturadas, até $100 \mathrm{mg} / 1000$ Cal de colesterol, no máximo $300 \mathrm{mg} / \mathrm{d}$.

**** Dieta tipo II: até $20 \%$ de calorias de gorduras, até 7\% de gorduras saturadas, até $60 \mathrm{mg} / 1000$ Cal de colesterol, no máximo $200 \mathrm{mg} / \mathrm{d}$.

***** Toda criança com diagnóstico de hipercolesterolemia deve ter afastada causa secundária para a dislipidemia e/ou a triagem lipídica de seus familiares de primeiro grau.

Fig. 5 - Algoritmo de diagnóstico e conduta na dislipidemia na infância, baseado em fatores de risco e níveis de lípides (em mg/dL) (adaptado de Caramelli, B e Giuliano, I. Dislipidemia na infância e na adolescência. Pediatria (São Paulo) 2008;29(4):275-285.) 


\section{Diretrizes}

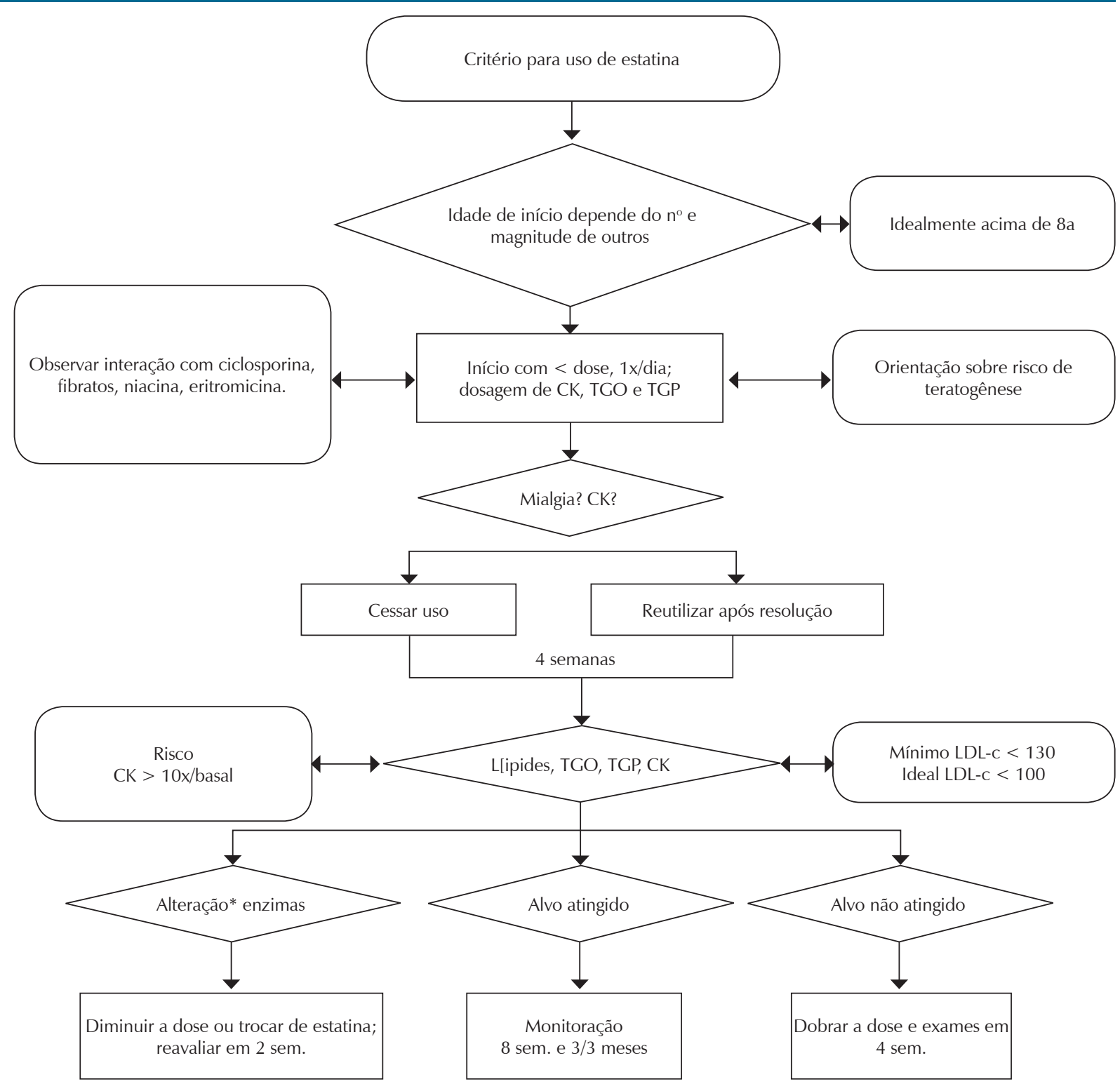

*CPK: sintomático +3 a $10 x$

Assintomático $>10 \mathrm{x}$

Fig. 6 - Algoritmo de monitoração do uso de estatinas em crianças e adolescentes. Adaptado de Caramelli, B e Giuliano, I. Dislipidemia na infância e na adolescência. Pediatria (São Paulo) 2008;29(4):275-285.)

\subsection{Suplementos}

A suplementação de 1,2 a 1,5 g de fitosteróis pode diminuir os níveis de colesterol total e LDL-c em crianças portadoras de hipercolesterolemia familiar heterozigótica em cerca de $10 \%{ }^{26,187}$ (Classe Ilb, Nível B).

\subsection{Indicações cirúrgicas}

Em adolescentes graves com aterosclerose clinicamente manifesta, há indicação de revascularização do miocárdio ${ }^{188,189}$. No caso de doença aórtica decorrente de dislipidemia severa, a troca por homoenxerto pulmonar (cirurgia de Ross-Konno) pode ser uma opção interessante para o adolescente, por sua durabilidade ${ }^{190}$.

O tratamento mais eficaz para a HF monozigótica é o transplante hepático, com bons resultados ${ }^{191,192}$ (Classe llb, Nível C).

\subsection{Aspectos psicológicos}

O tratamento farmacológico parece não impactar na qualidade de vida ou na ansiedade de crianças portadoras de hipercolesterolemia familiar. Cerca de $40 \%$ das crianças sofrem 
por serem portadores, mas utilizar hipolipemiantes os faz sentir mais seguros em cerca de $60 \%$. Mais de $50 \%$ fazem dieta e $79 \%$ dos pais sofrem porque os filhos têm hipercolesterolemia familiar ${ }^{193}$ (Classe Ilb, Nível B).

\section{Tratamento de hipercolesterolemia familiar na gravidez}

Durante a gravidez e a lactação, as opções terapêuticas da Hipercolesterolemia Familiar (HF) são bastante limitadas, já que estatinas, ezetimiba e ácido nicotínico não devem ser prescritos para evitar potenciais efeitos adversos no feto, associados ao uso desses agentes (respectivamente categorias $\mathrm{X}, \mathrm{Ce} \mathrm{C}$ ). Isso pode ser preocupante considerando-se o aumento dos níveis plasmáticos de lípides que ocorre usualmente durante a gravidez, de $25 \%$ a $50 \%$ de aumento dos níveis de colesterol e $150 \%$ a 300\% de aumento dos triglicérides, em adição a concentrações basais de colesterol já bastante elevadas em razão da $\mathrm{HF}^{194}$.

O uso de outras medicações hipolipemiantes, mais especificamente das resinas, é possível quando há necessidade clara da manutenção de terapêutica medicamentosa com provável benefício. As resinas, como o colesevelam e a colestiramina, são agentes da categoria B na gravidez e lactação, e portanto podem ser consideradas para tratamento da HF nessas condições, desde que sob supervisão médica ${ }^{15}$. A LDL-aférese é uma modalidade de tratamento que também pode ser utilizada em casos especiais, em que o risco cardiovascular da paciente, na ausência de tratamento, é muito alto, como em pacientes com HF homozigótica ou com HF heterozigótica e doença aterosclerótica grave ${ }^{195}$.

As mulheres portadoras de HF em idade fértil e que desejem engravidar devem receber aconselhamento prégravidez e suspender estatinas, ezetimiba e ácido nicotínico, pelo menos quatro semanas antes de interromperem o método contraceptivo utilizado. É importante destacar que o uso de anticoncepcional oral geralmente não é contraindicado para a maioria de mulheres com $\mathrm{HF}^{196}$, e não interfere na eficácia das estatinas ${ }^{197}$. Mulheres com risco aumentado de eventos cardiovasculares devem discutir outros métodos contraceptivos além do anticoncepcional oral ${ }^{196}$.

As pacientes que engravidaram de forma não programada devem suspender esses hipolipemiantes imediatamente e procurar acompanhamento obstétrico. Alguns poucos estudos avaliaram mulheres com hipercolesterolemia familiar que engravidaram em uso de estatinas, com resultados controversos, em relação à incidência de malformações fetais. Ofori e cols. ${ }^{198}$, por exemplo, não observaram aumento da frequência de anormalidades fetais em mulheres que conceberam em uso de estatina em estudo que incluiu mais de 100 mil gestantes, sendo 106 em uso de estatina ${ }^{198}$. Entretanto, uma série de casos relatados pelo FDA em 2004 avaliou 52 casos selecionados de exposição gestacional a estatinas, e encontrou 20 casos de defeitos estruturais fetais, especialmente defeitos neurológicos e esqueléticos ${ }^{199}$.

A escassez relativa de tratamentos seguros e eficazes para redução dos níveis de colesterol plasmático nessas pacientes se associa à preocupação em relação a efeitos adversos pela própria hiperlipidemia. De fato, alguns trabalhos sugerem um risco aumentado de prematuridade em grávidas com níveis elevados de colesterol ${ }^{200,201}$. Um trabalho recente realizado na Noruega, que avaliou 2.319 nascimentos de 1.093 mulheres com HF, não detectou diferença em relação à prematuridade entre mulheres com diagnóstico genético de HF e mulheres da população geral $^{194}$. Quanto ao baixo peso ao nascer, em geral também não parece haver diferença significativa entre recém-nascidos de mulheres com ou sem o diagnóstico de HF. A frequência de malformações congênitas em fetos de mulheres com HF também não parece maior em comparação a mulheres da população geral, respectivamente 3,3\% e 3,2\%. Toleikyte e cols. ${ }^{194}$ também não encontraram diferenças em prematuridade, baixo peso e malformações segundo diferentes tipos de mutação genética.

Embora a maioria dos estudos disponíveis não demonstre eventos adversos fetais significativos em associação à presença de hipercolesterolemia familiar, é recomendável o acompanhamento conjunto das gestantes portadoras de hipercolesterolemia familiar pelo especialista em lípides e pelo obstetra. Deve-se estar atento a possível presença de lesões valvares, em particular de estenose aórtica, e de doença coronariana prematura nessas pacientes ${ }^{202}$. Do ponto de vista obstétrico, também é importante a pesquisa de insuficiência vascular útero-placentária ${ }^{203,204}$.

\subsection{Recomendações}

Uso de medicações hipolipemiantes em gestantes com HF:

- Estatinas, ezetimiba, ácido nicotínico, fibratos: Classe III, Nível de evidência B.

- $\quad$ Resinas: Classe IIB, Nível de evidência B.

- $\quad$ Aférese: Classe IIB, Nível de evidência B.

10.2. Classificação dos agentes quanto a possíveis efeitos no feto segundo o FDA

- Categoria A: Estudos adequados e controlados não demonstraram risco ao feto no primeiro trimestre da gravidez (e não há evidência de risco nos trimestres seguintes).

- Categoria B: Estudos de reprodução em animais não demonstraram risco ao feto, e não há estudos adequados e controlados em mulheres grávidas.

- Categoria C: Estudos de reprodução em animais demonstraram efeito adverso ao feto, mas não há estudos adequados e controlados em mulheres grávidas.

- Categoria D: Existe evidência de risco ao feto humano baseada em dados de reação adversa provenientes de estudos em humanos ou experiência de marketing ou investigativa. Os benefícios do uso do agente em mulheres grávidas podem ser superiores ao seu risco em algumas situações.

- Categoria X: Estudos em animais ou humanos demonstraram anormalidades fetais e/ou existe evidência de risco fetal humano baseado em dados de efeitos adversos provenientes de experiência de marketing ou investigativa. Os riscos do uso do agente em mulheres grávidas superam claramente potenciais benefícios. 


\section{Diretrizes}

\section{Perspectivas futuras para o tratamento da hipercolesterolemia familiar}

Apesar do grande avanço no tratamento da hipercolesterolemia particularmente obtido com as estatinas, um número considerável de indivíduos permanece com níveis plasmáticos de LDL-c acima das metas. Nos pacientes com HF, essa realidade é ainda mais expressiva pela gravidade da hipercolesterolemia nesses indivíduos. Além das estatinas, resinas e ezetimiba, novas classes têm sido investigadas com a finalidade desenvolver a terapia múltipla nos pacientes fora das metas, particularmente aqueles com HF. As classes em estágios mais avançados de desenvolvimento são: (i) inibidor da MTP; (ii) inibidor da esqualeno sintase; (iii) inibidor da PCSK9; (iv) análogos do hormônio tireoidiano; e (v) oligonucleotídeos antissenso.

\subsection{Inibidor da Microsomal transfer protein}

A proteína de transferência microssomal de triglicerídeos (MTP) é responsável pela transferência de triglicerídeos para a apolipoproteína B nos hepatócitos, durante a síntese de VLDL. Na ausência ou disfunção da MTP, como na abetalipoproteinemia recessiva, não há produção de VLDL e, consequentemente, das demais lipoproteínas que contêm apolipoproteína B como a LDL, IDL, Lp(a). Assim, a inibição farmacológica da MTP é uma estratégia potencial como terapia complementar da hipercolesterolemia.

O lomitapide é um inibidor da MTP que em estudo preliminar em pacientes homozigotos para HF mostrou ser capaz de reduzir o LDL-C em até $50,9 \%$ após quatro ${ }^{4}$ semanas de tratamento ${ }^{205}$. No estudo fase III Long Term, Follow-on Study of Lomitapide in Patients With Homozygous Familial Hypercholesterolemia (ClinicalTrials.gov:NCT00943306), recentemente concluído, o lomitapide foi administrado na dose de até $60 \mathrm{mg} /$ dia, durante 56 semanas, a 29 pacientes com uma média de LDL-c de 336 $\mathrm{mg} / \mathrm{dL}$ em tratamento com uma variedade de hipolipemiantes. Em 26 semanas, observou-se uma redução de 50,2\% do LDL-C e de $56,1 \%$ dos triglicérides. Nesse período, três pacientes abandonaram o estudo por efeitos adversos gastrointestinais e três retiraram o consentimento.

Não existe até o presente estudo com tamanho amostral e desfechos clínicos que determinem a segurança e a eficácia na redução de eventos cardiovasculares.

\subsection{Inibidor da esqualeno sintase}

A cascata de biossíntese do colesterol possui várias enzimas de restrição, sendo a HMG CoA reductase uma das primeiras e a esqualeno sintase, a última. Alguns inibidores da esqualeno sintase foram descobertos ao longo do tempo. O laropipranto foi um dos inibidores que progrediram a estudos clínicos com redução de LDL-c de 23\% na dose máxima de 100 mg/dia ${ }^{206}$. Apesar de se tratar da inibição de uma mesma via metabólica, em estudos preliminares, observou-se efeito aditivo na combinação terapêutica de estatinas com lapaquistat ${ }^{207}$. O lapaquistat progrediu para fase de ensaios clínicos III, mas os estudos com dose elevada (100 mg/kg) foram interrompidos em razão da toxicidade hepática detectada pela elevação das transaminases. Ainda não é sabido se o evento adverso foi efeito de classe ou específico do fármaco. Inibição da esqualeno sintase pode acumular precursores do esqualeno que poderia ser responsável pela hepatotoxicidade.

\subsection{Inibidor do Proprotein convertase subtilisin kexin type 9 (PCSK9)}

PCSK9 regula as concentrações de colesterol plasmático por inibir a captação de LDL pelo seu receptor hepático. Indivíduos que apresentam mutações relacionadas à redução de função de PCSK9 apresentam concentrações mais baixas de LDL-c e menor risco de doença cardiovascular ${ }^{208}$. Estão sendo desenvolvidos anticorpos e moléculas antissenso para PCSK9 e estudos em fase II e III estão em andamento. Os inibidores de PCSK9 diminuem o LDL-c de $20 \%$ a $50 \%{ }^{208}$. Não existe, contudo, evidência de benefício clínico ou segurança até o momento.

\subsection{Análogos de hormônio tireoidiano}

Os análogos do hormônio tireoidiano reduzem LDL-c e outras lipoproteínas por ação seletiva sobre o receptor hepático da LDL, sem os efeitos adversos dos hormônios tireoidianos sobre o sistema cardiovascular. O eprotirome, por exemplo, liga-se ao receptor beta da triodotironina facilitando a expressão do receptor hepático para a LDL. Em um estudo aleatorizado controlado com placebo em pacientes dislipidêmicos em uso de doses máximas toleradas de estatinas, eprotirome $25-100 \mathrm{mcg} /$ dia por 12 semanas reduziu o LDL-C de $22 \%$ a $32 \% 209$. Houve reduções similares nas concentrações de triglicérides, apo B100 e Lp(a). Este estudo mostrou, ainda, queda de HDL-c em 5\% com a dose máxima de eprotirome. Houve queda nas concentrações de tiroxina livre com o uso do eprotirome; contudo, esses permaneceram dentro dos limites da normalidade. Não há estudos desse medicamento sobre a doença cardiovascular.

\subsection{Oligonucleotídios antissenso (ASO)}

Oligonucleotídeos antissenso são pequenas sequências de nucleotídeos (DNA ou RNA) que se ligam especialmente ao RNA mensageiro e inibem a síntese proteica por interferir na tradução da mensagem carregada por esse último. Injetadas no subcutâneo, essas moléculas inibem a síntese hepática de apolipoproteína B100 e, consequentemente, reduzem as concentrações plasmáticas de VLDL, LDL e Lp(a).

O mipomersen é um ASO de segunda geração já em fase avançada de desenvolvimento, devendo ser aprovado em breve para HF homozigótica. O medicamento é administrado por injeção subcutânea semanal na dose de 200 mg. Existem estudos fase III com seguimento de até 104 semanas de duração em portadores de HF hetero e homozigótica, além de portadores de hipercolesterolemia poligênica refratários ao tratamento convencional.

Na dose de 200 mg/semana, o mipomersen diminui em média o LDL-c em 25\% nas populações estudadas com respostas variáveis de paciente para paciente $(2 \% \text { a }-80 \%)^{210}$. Na maioria dos estudos, os pacientes faziam uso de doses máximas toleradas de estatinas e ou ezetimiba. As reduções de apo B100 e Lp(a) foram também de $25 \%-30 \%$. Os principais efeitos colaterais do mipomersen são reações no local de injeção, sintomas semelhantes a gripe e acúmulo de gordura hepática. Até o momento, não existe evidência de benefício cardiovascular.

\section{Errata}

$\mathrm{Na}$ "I Diretriz Brasileira de Hipercolesterolemia Familiar (HF)", publicada como suplemento dos Arquivos Brasileiros de Cardiologia [Arq Bras Cardiol. 2012; 99(2 Supl.2): 1-28], considerar correta a grafia Lottenberg AM para o nome da autora Ana Maria Lottenberg. 


\section{Referências}

1. Khachadurian AK. The inheritance of essential familial hypercholesterolemia. Am J Med. 1964;37:402-7.

2. Brown MS, Goldstein JL. A receptor-mediated pathway for cholesterol homeostasis. Science. 1986;232(4746):34-47

3. Soria LF, Ludwig EH, Clarke HR, Vega GL, Grundy SM, McCarthy BJ. Association between a specific apoprotein $B$ mutation and familial defective apo B 100. Proc Natl Acad Sci USA. 1989;86(2):587-91.

4. Abifadel M, Varret M, Rabès JP, Allard D, Ouguerram K, Devillers M, et al. Mutations in PCSK9 cause autosomal dominant hypercholesterolemia. Nat Genet. 2003;34(2):154-6.

5. Rauh G, Keller C, Schuster H, Wolfram G, Zöllner N. Familial defective apolipoprotein B-100: a common cause of primary hypercholesterolemia. Clin Investig. 1992;70(1):77-84.

6. Ose L. [Müller-Harbitz disease-familial hypercholesterolemia]. Tidsskr Nor Laegeforen. 2002;122(9):924-5.

7. Müller C. Xanthomata, hypercholesterolemia and angina pectoris. Acta Med Scand Suppl. 1938;89:75-84.

8. Brown MS, Goldstein JL. Analysis of a mutant strain of human fibroblasts with a defect in the internalization of receptor bound low density lipoprotein. Cell. 1976;9(4 Pt 2):663-74.

9. Brown MS, Goldstein JL. Receptor-mediated control of cholesterol metabolism. Science. 1976;191(4223):150-4

10. Goldstein JL, Brown MS. Regulation of the mevalonate pathway. Nature. 1990;343(6257):425-30.

11. Russell DW, Yamamoto T, Schneider WJ, Slaughter CJ, Brown MS Goldstein JL. C-DNA cloning of the bovine low density lipoprotein receptor: feedback regulation of a receptor mRNA. Proc Natl Acad Sci USA. 1983;80(24):7501-5.

12. Motulski AG. Genetic aspects of familial hypercholesterolemia and its diagnosis. Arteriosclerosis. 1989;9(1 Suppl):I3-7

13. Garcia CK, Wilund K, Arca M, Zuliani G, Fellin R, Maioli M, et al. Autosomal recessive hypercholesterolemia caused by mutations in a putative LDL receptor adaptor protein. Science. 2001;292(5520):1394-8.

14. Morganroth J, Levy RI, McMahon AE, Gotto AM Jr. Pseudohomozygous type II hyperlipoproteinemia. J Pediatr. 1974;85(5):639-43.

15. Moghadasian MH, Salen G, Frohlich JJ, Scudamore CH. Cerebrotendinous xanthomatosis: a rare disease with diverse manifestations. Arch Neurol. 2002;59(4):527-9.

16. Patel SB, Salen G, Hidaka H, Kwiterovich PO, Stalenhoef AF, Miettinen TA, et al. Mapping a gene involved in regulating dietary cholesterol absorption. The sitosterolemia locus is found at chromosome 2 p21. J Clin Invest. 1998;102(5):1041-4.

17. Civeira F; International Panel on Management of Familial Hypercholesterolemia. Guidelines for the diagnosis and management of heterozygous familial hypercholesterolemia. Atherosclerosis. 2004:173(1):55-68.

18. NICE clinical guideline on familial hypercholesterolaemia. [Cited in 2011 Oct 31]. Available from: http://guidance.nice.org.uk/CG71/NICEGuidance/ doc/English

19. Winder AF, Jolleys JC, Day LB, Butowski PF. Corneal arcus, case finding and definition of individual clinical risk in heterozygous familial hypercholesterolaemia. Clin Genet. 1998;54(6):497-502.

20. Koivunen-Niemelä T, Alanen A, Viikari J. Sonography of the Achilles tendon in hypercholesterolaemia. J Intern Med. 1993;234(4):401-5.

21. Goldstein JL, Brown MS. Familial hypercholesterolemia. In: Scriver CR, Beaudet AL, Sly WS, Valle D, (editors). The metabolic bases of inherited diseases. New York: McGraw-Hill; 1989. p. 1215-50.
22. Moorjani S, Roy M, Gagné C, Davignon J, Brun D, Toussaint M, et al. Homozygous familial hypercholesterolemia among French Canadians in Québec Province. Arteriosclerosis. 1989;9(2):211-6.

23. Kotze MJ, De Villiers WJ, Steyn K, Kriek JA, Marais AD, Langenhoven E, et al Phenotypic variation among familial hypercholesterolemics heterozygous for either one of two Afrikaner founder LDL receptor mutations. Arterioscler Thromb. 1993;13(10):1460-8.

24. Gylling H, Aalto-Setälä K, Kontula K, Miettinen TA. Serum low-density lipoprotein cholesterol level and cholesterol absorption efficiency are influenced by apolipoprotein $\mathrm{B}$ and $\mathrm{E}$ polymorphism and by the $\mathrm{FH}$ Helsinki mutation of the low-density lipoprotein receptor gene in familial hypercholesterolemia. Arterioscler Thromb. 1991;11(5):1368-75.

25. World Health Organization. Familial hypercholesterolemia (FH). Report of a WHO consultation. Paris: WHO: Human Genetic Programme; 1997 October. (Report No.WHO/HGN/FH/CONS/98.7)

26. Risk of fatal coronary heart disease in familial hypercholesterolemia Scientific Steering Committee (SSC) on behalf of the Simon Broome Register Group. BMJ. 1991;303(6807):893-6.

27. Burnett JR, Ravine D, van Bockxmeer FM, Watts GF. Familial hypercholesterolaemia: a look back, a look ahead. Med J Aust. 2005;182(11):552-3

28. Marks D, Wonderling D, Thorogood M, Lambert H, Humphries SE, Nei HA. Screening for hypercholesterolaemia versus case finding for familial hypercholesterolaemia: a systematic review and cost effectiveness analysis. Health Technol Assess. 2000;4(29):1-123.

29. Hill JS, Hayden MR, Frohlich J, Pritchard PH. Genetic and environmental factors affecting the incidence of coronary artery disease in heterozygous familial hypercholesterolemia. Arterioscler Thromb. 1991;11(2):290-7.

30. Ferrières J, Lambert J, Lussier-Cacan S, Davignon J. Coronary artery disease in heterozygous familial hypercholesterolemia patients with the same LDL receptor gene mutation. Circulation. 1995;92(3):290-5.

31. Miettinen TA, Gylling H. Mortality and cholesterol metabolism in familial hypercholesterolemia. Arteriosclerosis. 1988;8(2):163-7.

32. Versmissen J, Oosterveer DM, Yazdanpanah M, Defesche JC, Basart DC, Liem AH, et al. Efficacy of statins in familial hypercholesterolaemia: a long term cohort study. BMJ. 2008;337:a2423.

33. Koeijvoets KC, Rodenburg J, Hutten BA, Wiegman A, Kastelein JJ, Sijbrands EJ. Low-density lipoprotein receptor genotype and response to pravastatin in children with familial hypercholesterolemia: substudy of an intima-media thickness trial. Circulation. 2005;112(20):3168-73.

34. Raal FJ, Pilcher GJ, Panz VR, van Deventer HE, Brice BC, Blom DJ, et al. Reduction in mortality in subjects with homozygous familial hypercholesterolemia associated with advances in lipid-lowering therapy. Circulation. 2011;124(20):2202-7.

35. World Health Organization. WHO. Human Genetics Programme. Familial Hypercholesterolaemia (FH). Report of a second WHO Consultation. Geneva, 4 September, 1998. (Report No.: WHO/HGN/FH/CONS/99.2.)

36. Williams RR, Hunt SC, Schumacher MC, Hegele RA, Leppert MF, Ludwig EH Diagnosing heterozygous familial hypercholesterolemia using new practical criteria validated by molecular genetics. Am J Cardiol. 1993;72(2):171-6.

37. National Collaborating Centre for Primary Care (UK). Identification and management of familial hypercholesterolaemia (FH). London: Royal College of General Practitioners (UK); 2008 Aug. [Cited in 2011 Nov 07]. Available from: http://www.nice.org.uk/CG71.

38. Hopkins PN, Toth PP, Ballantyne CM, Rader DJ; National Lipid Association Expert Panel on Familial Hypercholesterolemia. Familia hypercholesterolemias: prevalence, genetics, diagnosis and screening recommendations from the National Lipid Association Expert Panel on Familial Hypercholesterolemia. J Clin Lipidol. 2011;5(3 Suppl):S9-17.

39. Leigh SE, Foster AH, Whittal RA, Hubbart CS, Humphries SE. Update an analysis of the University College London low density lipoprotein receptor familial hypercholesterolemia data base. Ann Hum Genet. 2008; 72 (PT 4):485-98 
40. Cooper DN, Ball EV, Stenson PD, Phillips AD, Shaw K, Mort ME. Institute of Medical Genetics in Cardiff. The human gene mutation database. [Cited in 2011 Nov 11]. Available from: http://www.hgmd.cf.ac.uk/ac/index.php

41. DNA Diagnostick voon Familiaire Hyper Cholesteromia. [Cited in 2011 Nov 12]. Available from: http://www.jojogenetics.nl

42. Horsthemke B, Dunning A, Humphries S. Identification of deletions inthe human low density lipoprotein receptor gene. J Med Genet. 1987;24(3):144-7.

43. Hobbs HH, Brown MS, Russell DW, Davignon J, Goldstein JL. Deletion in the gene for the low-density-lipoprotein receptor in a majority of French Canadians with familial hypercholesterolemia. N Engl J Med. 1987;317(12):734-7.

44. Hobbs HH, Leitersdorf E, Goldstein JL, Brown MS, Russell DW. Multiple crm-mutations in familial hypercholesterolemia: evidence for 13 alleles, including four deletions. J Clin Invest. 1988;81(3):909-17.

45. Hobbs HH, Russell DW, Brown MS, Goldstein JL. The LDL receptor locus in familial hypercholesterolemia: mutational analysis of a membrane protein. Annu Rev Genet. 1990;24:133-70.

46. Hobbs HH, Brown MS, Goldstein JL. Molecular genetics of the LDL receptor gene in familial hypercholesterolemia. Hum Mutat. 1992;1(6):445-66.

47. Langlois S, Kastelein JJ, Hayden MR. Characterization of six partial deletions in the low-density-lipoprotein (LDL) receptor gene causing familial hypercholesterolemia (FH). Am J Hum Genet. 1988;43(1):60-8.

48. Innerarity TL, Mahley RW, Weisgraber KH, Bersot TP, Krauss RM, Vega GL, et al. Familial defective apolipoprotein B-100: a mutation of apolipoprotein B that causes hypercholesterolemia. J Lipid Res. 1990;31(8):1337-49.

49. Whitfield AJ, Barrett PH, van Bockxmeer FM, Burnett JR. Lipid disorders and mutations in the $A P O B$ gene. Clin Chem. 2004;50(10):1725-32.

50. März W, Ruzicka C, Pohl T, Usadel KH, Gross W. Familial defective apolipoprotein B-100: mild hypercholesterolaemia without atherosclerosis in a homozygous patient [letter]. Lancet. 1992;340(8831):1362.

51. Ejarque I, Real JT, Martinez-Hervas S, Chaves FJ, Blesa S, Garcia-Garcia AB, et al. Evaluation of clinical diagnosis criteria of familial ligand defective $a p o B$ 100 and lipoprotein phenotype comparison between LDL receptor gene mutations affecting ligand-binding domain and the R3500Q mutation of the $a p o B$ gene in patients from a South European population. Transl Res. 2008; 151(3):162-7.

52. Varret $M$, Abifadel M, Rabès JP, Boileau C. Genetic heterogeneity of autosomal dominant hypercholesterolemia. Clin Genet. 2008;73(1):1-13.

53. Horton JD, Cohen JC, Hobbs HH. Molecular biology of PCSK9: its role in LDL metabolism. Trends Biochem Sci. 2007;32(2):71-7.

54. Horton JD, Cohen JC, Hobbs HH. PCSK9: a convertase that coordinates LDL catabolism. J Lipid Res. 2009;50 Suppl:S172-7.

55. He G, Gupta S, Yi M, Michaely P, Hobbs HH, Cohen JC. ARH is a modular adaptor protein that interacts with the LDL receptor, clathrin, and AP-2. J Biol Chem. 2002;277(46):44044-9.

56. Soutar AK, Naoumova RP. Mechanisms of disease: genetic causes of familial hypercholesterolemia. Nat Clin Pract Cardiovasc Med. 2007;4(4):214-25.

57. Wang J, Joy T, Mymin D, Frohlich J, Hegele RA. Phenotypic heterogeneity of sitosterolemia. J Lipid Res. 2004;45(12):2361-7.

58. Graham CA, Mcllhatton BP, Kirk CW, Beattie ED, Lyttle K, Hart P, et al. Genetic screening protocol for familial hypercholesterolemia which includes splicing defects gives an improved mutation detection rate. Atherosclerosis. 2005;182(2):331-40.

59. Ose L. An update on familial hypercholesterolaemia. Ann Med. 1999;31 Suppl 1:13-8.

60. Pollex RL, Hegele RA. Genomic copy number variation and its potential role in lipoprotein and metabolic phenotypes. Curr Opin Lipidol. 2007;18(2):174-80.
61. Watts GF, van Bockxmeer FM, Bates T, Burnett JR, Juniper A, O'Leary P. A new model of care for familial hypercholesterolaemia from Western Australia: closing a major gap in preventive cardiology. Heart Lung Circ. 2010;19(7):419-22.

62. Leren TP, Manshaus T, Skovholt U, Skodje T, Nossen IE, Teie C, et al. Application of molecular genetics for diagnosing familial hypercholesterolemia in Norway: results from a family-based screening program. Semin Vasc Med. 2004;4(1):75-85.

63. Wonderling D, Umans-Eckenhausen MA, Marks D, Defesche JC, Kastelein JJ, Thorogood M. Cost-effectiveness analysis of the genetic screening program for familial hypercholesterolemia in The Netherlands. Semin Vasc Med. 2004;4(1):97-104.

64. Johannesson M, Jönsson B, Kjekshus J, Olsson AG, Pedersen TR, Wedel $\mathrm{H}$. Cost effectiveness of simvastatin treatment to lower cholesterol levels in patients with coronary heart disease. Scandinavian Simvastatin Survival Study Group. N Engl J Med. 1997;336(5):332-6.

65. Marks D, Thorogood M, Neil HA, Humphries SE. A review on the diagnosis, natural history, and treatment of familial hypercholesterolaemia. Atherosclerosis. 2003;168(1):1-14.

66. Austin MA, Hutter CM, Zimmern RL, Humphries SE. Familial hypercholesterolemia and coronary heart disease: a HuGE association review. Am J Epidemiol. 2004;160(5):421-9.

67. Stone NJ, Levy RI, Fredrickson DS, Verter J. Coronary artery disease in 116 kindred with familial type II hyperlipoproteinemia. Circulation. 1974;49(3):476-88.

68. Slack J. Risks of ischaemic heart-disease in familial hyperlipoproteinaemic states. Lancet. 1969;2(7635):1380-2.

69. Mortality in treated heterozygous familial hypercholesterolaemia: implications for clinical management. Scientific Steering Committee on behalf of the Simon Broome Register Group. Atherosclerosis. 1999;142(1):105-12.

70. Mohrschladt MF, Westendorp RG, Gevers Leuven JA, Smelt AH. Cardiovascular disease and mortality in statin-treated patients with familial hypercholesterolemia. Atherosclerosis. 2004;172(2):329-35.

71. Risk of fatal coronary heart disease in familial hypercholesterolaemia. Scientific Steering Committee on behalf of the Simon Broome Register Group. Atherosclerosis. 1999;142(1):105-12.

72. Jansen AC, van Aalst-Cohen ES, Tanck MW, Trip MD, Lansberg PJ, Liem $\mathrm{AH}$, et al. The contribution of classical risk factors to cardiovascular disease in familial hypercholesterolaemia: data in 2400 patients. J Intern Med. 2004;256(6):482-90.

73. Alonso R, Mata N, Castillo S, Fuentes F, Saenz P, Muñiz O, etal. Cardiovascular disease in familial hypercholesterolaemia: influence of low-density lipoprotein receptor mutation type and classic risk factors. Atherosclerosis. 2008; 200(2):315-21.

74. Lloyd-Jones DM, Leip EP, Larson MG, D'Agostino RB, Beiser A, Wilson PW, et al. Prediction of lifetime risk for cardiovascular disease by risk factor burden at 50 years of age. Circulation. 2006;113(6):791-8.

75. Kastelein JJ, Akdim F, Stroes ES, Zwinderman AH, Bots ML, Stalenhoef AF, et al. Simvastatin with or without ezetimibe in familial hypercholesterolemia. N Engl J Med. 2008;358(14):1431-43.

76. Genser B, Dias KC, Siekmeier R, Stojakovic T, Grammer T, Maerz W. Lipoprotein (a) and risk of cardiovascular disease - a systematic review and meta analysis of prospective studies. Clin Lab. 2011;57(3-4):143-56.

77. Dahlén GH, Stenlund H. Lp(a) lipoprotein is a major risk factor for cardiovascular disease: pathogenic mechanisms and clinical significance. Clin Genet. 1997; 52(5):272-80.

78. Holmes DT, Schick BA, Humphries KH, Frohlich J. Lipoprotein (a) is an independent risk factor for cardiovascular disease in heterezygous familial hypercholesterolemia. Clin Chem. 2005;51(11):2067-73. 
79. Civeira F, Castillo S, Alonso R, Meriño-lbarra E, Cenarro A, Artied M, et al. Tendon xanthomas in familial hypercholesterolemia are associated with cardiovascular risk independently of the low-density lipoprotein receptor gene mutation. Arterioscler Thromb Vasc Biol. 2005;25(9):1960-5.

80. Oosterveer DM, Versmissen J, Yazdanpanah M, Hamza TH, Sijbrands EJ. Differences in characteristics and risk of cardiovascular disease in familial hypercholesterolemia patients with and without tendon xanthomas: a systematic review and meta-analysis. Atherosclerosis. 2009;207(2):311-7.

81. Martinez LR, Miname MH, Bortolotto LA, Chacra AP, Rochitte CE, Sposito $\mathrm{AC}$, et al. No correlation and low agreement of imaging and inflammatory atherosclerosis' markers in familial hypercholesterolemia. Atherosclerosis. 2008;200(1):83-8

82. Ye ZX, Cheng HM, Chiou KR, Huang PH, Lin SJ, Charng MJ. Relation of coronary artery calcium to flow-mediated dilation and C-reactive protein levels in asymptomatic patients with heterozygous familial hypercholesterolemia. Am J Cardiol. 2007;100(7):1119-23

83. Wilson PW, D'Agostino RB, Levy D, Belanger AM, Silbershatz H, Kannel WB. Prediction of coronary heart disease using risk factor categories. Circulation. 1998;97(18):1837-47.

84. Assmann G, Cullen P, Schulte H. Simple scoring scheme for calculating the risk of acute coronary events based on the 10-year follow-up of the prospective cardiovascular Munster (PROCAM) study. Circulation. 2002; 105(3):310-5.

85. Ridker PM, Buring JE, Rifai N, Cook NR. Development and validation of improved algorithms for the assessment of global cardiovascular risk in women: the Reynolds Risk Score. JAMA. 2007;297(6):611-9.

86. Ridker PM, Paynter NP, Rifai N, Gaziano JM, Cook NR. C-reactive protein and parental history improve global cardiovascular risk prediction: the Reynolds Risk Score for men. Circulation. 2008;118(22):2243-51.

87. Sposito AC, Caramelli B, Fonseca FA, Bertolami MC, Afiune Neto A, Souza AD, et al; Sociedade Brasileira de Cardiologia. IV Diretriz brasileira sobre dislipidemias e prevenção da aterosclerose. Arq Bras Cardiol. 2007;88(supl 1):1-18.

88. Robinson JG, Goldberg AC; National Lipid Association Expert Panel on Familial Hypercholesterolemia. Treatment of adults with Familial Hypercholesterolemia and evidence for treatment: recommendations from the national lipid association expert panel on Familial Hypercholesterolemia. J Clin Lipidol. 2011;5(3 Suppl):S18-29.

89. Raggi P, Cooil B, Callister TQ. Use of electron beam tomography data to develop models for prediction of hard coronary events. Am Heart J. 2001;141(3):375-82.

90. Kondos GT, Hoff JA, Sevrukov A, Daviglus ML, Garside DB, Devries SS, et al. Electron-beam tomography coronary artery calcium and cardiac events: a 37-month follow-up of 5635 initially asymptomatic low-to intermediate-risk adults. Circulation. 2003;107(20):2571-6.

91. Arad Y, Goodman KJ, Roth M, Newstein D, Guerci AD. Coronary calcification, coronary disease risk factors, C-reactive protein, and atherosclerotic cardiovascular disease events: the St. Francis Heart Study. J Am Coll Cardiol. 2005;46(1):158-65

92. Pletcher MJ, Tice JA, Pignone M, Browner WS. Using the coronary artery calcium score to predict coronary heart disease events: a systematic review and meta-analysis. Arch Intern Med. 2004;164(12):1285-92.

93. Greenland P, Bonow RO, Brundage BH, Budoff MJ, Eisenberg MJ, Grundy SM, et al. ACCF/AHA 2007 clinical expert consensus document on coronary artery calcium scoring by computed tomography in global cardiovascular risk assessment and in evaluation of patients with chest pain: a report of the American College of Cardiology Foundation Clinical Expert Consensus Task Force (ACCF/AHA Writing Committee to Update the 2000 Expert Consensus Document on Electron Beam Computed Tomography). Circulation. 2007;115(3):402-26.

94. Santos RD, Meneghelo RS, Chacra AP, Martinez TL, Ramires JA, Carvalho JA. Detection of subclinical atherosclerosis by electron beam tomography in females with heterozygous familial hypercholesterolaemia. Heart. 2004;90(1):92-4.
95. Caussin C, Ohanessian A, Ghostine S, Jacq L, Lancelin B, Dambrin G, et al Characterization of vulnerable nonstenotic plaque with 16 -slice computed tomography compared with intravascular ultrasound. Am J Cardiol. 2004:94(1):99-104

96. Leber AW, Knez A, White CW, Becker A, von Ziegler F, Muehling O, et al. Composition of coronary atherosclerotic plaques in patients with acute myocardial infarction and stable angina pectoris determined by contrast-enhanced multislice computed tomography. Am J Cardiol. 2003:91(6):714-8

97. Inoue F, Sato Y, Matsumoto N, Tani S, Uchiyama T. Evaluation of plaque texture by means of multislice computed tomography in patients with acute coronary syndrome and stable angina. Circ J. 2004;68(9):840-4.

98. Pundziute G, Schuiif JD, Jukema JW, Boersma E, de Roos A, van der Wal $\mathrm{EE}$, et al. Prognostic value of multislice computed tomography coronary angiography in patients with known or suspected coronary artery disease. I Am Coll Cardiol. 2007:49(1):62-70.

99. Alderman EL, Corley SD, Fisher LD, Chaitman BR, Faxon DP, Foster ED, et al. Five-year angiographic follow-up of factors associated with progression of coronary artery disease in the Coronary Artery Surgery Study (CASS). CASS Participating Investigators and Staff. J Am Coll Cardiol. 1993;22(4):1141-54.

100. Ambrose JA, Tannenbaum MA, Alexopoulos D, Hjemdahl-Monsen CE, Leavy I, Weiss $\mathrm{M}$, et al. Angiographic progression of coronary artery disease and the development of myocardial infarction. J Am Coll Cardiol. 1988;12(1):56-62.

101. Little WC, Constantinescu M, Applegate RJ, Kutcher MA, Burrows MT, Kahl FR, et al. Can coronary angiography predict the site of a subsequent myocardial infarction in patients with mild-to-moderate coronary artery disease? Circulation. 1988;78(5 Pt 1):1157-66.

102. Little WC. Angiographic assessment of the culprit coronary artery lesion before acute myocardial infarction. Am J Cardiol. 1990;66(16):44G-47G.

103. Miname MH, Ribeiro MS 2nd, Parga Filho J, Avila LF, Bortolotto LA, Martinez LR, et al. Evaluation of subclinical atherosclerosis by computed tomography coronary angiography and its association with risk factors in familial hypercholesterolemia. Atherosclerosis. 2010;213(2):486-91.

104. Hodis HN, Mack WJ, LaBree L, Selzer RH, Liu CR, Liu CH, et al. The role of carotid arterial intima-media thickness in predicting clinical coronary events. Ann Intern Med. 1998;128(4):262-9.

105. de Groot E, Hovingh GK, Wiegman A, Duriez P, Smit AJ, Fruchart JC, et al. Measurement of arterial wall thickness as a surrogate marker for atherosclerosis. Circulation. 2004;109(23 Suppl 1):III33-8.

106. Smilde TJ, van Wissen S, Wollersheim H, Trip MD, Kastelein IJ, Stalenhoe AF. Effect of aggressive versus conventional lipid lowering on atherosclerosis progression in familial hypercholesterolaemia (ASAP): a prospective, randomised, double-blind trial. Lancet. 2001:357(9256):577-81.

107. Mabuchi H, Koizumi J, Shimizu M, Takeda R. Development of coronary heart disease in familial hypercholesterolemia. Circulation. 1989;79(2):225-32.

108. Kwiterovich PO Jr. Recognition and management of dyslipidemia in children and adolescents. J Clin Endocrinol Metab. 2008;93(11):4200-9.

109. Williams CL, Hayman LL, Daniels SR, Robinson TN, Steinberger J, Paridon $\mathrm{S}$, et al. Cardiovascular health in childhood: A statement for health professionals from the Committee on Atherosclerosis, Hypertension, and Obesity in the Young (AHOY) of the Council on Cardiovascular Disease in the Young, American Heart Association. Circulation. 2002;106(1):143-60.

110. Kwiterovich PO Jr. Prevention of coronary disease starting in childhood: what risk factors should be identified and treated? Coron Artery Dis. 1993;4(7):611-30.

111. Mensink RP, Zock PL, Kester AD, Katan MB. Effects of dietary fatty acids and carbohydrates on the ratio of serum total to HDL cholesterol and on serum lipids and apolipoproteins: a meta-analysis of 60 controlled trials. Am J Clin Nutr. 2003;77(5):1146-55.

112. Mozaffarian D, Aro A, WillettWC. Health effects of trans-fatty acids: experimental and observational evidence. Eur J Clin Nutr. 2009;63(Suppl 2):S5-21. 
113. Task Force for the management of dyslipidaemias of the European Society of Cardiology (ESC) and the European Atherosclerosis Society (EAS), Catapano AL, Reiner Z, De Backer G, Graham I, Taskinen MR, et al. ESC/EAS Guidelines for the management of dyslipidaemias. The Task Force for the management of dyslipidaemias of the European Society of Cardiology (ESC) and the European Atherosclerosis Society (EAS). Atherosclerosis. 2011;217(Suppl 1):S1-44.

114. Van Horn L, McCoin M, Kris-Etherton PM, Burke F, Carson JA, Champagne $\mathrm{CM}$, et al. The evidence for dietary prevention and treatment of cardiovascular disease. J Am Diet Assoc. 2008;108(2):287-331.

115. Micha R, Mozaffarian D. Saturated fat and cardiometabolic risck factors, coronary heart disease, stroke and diabetes: a fresh look at the evidence. Lipids. 2010;45(10):893-905.

116. Hegsted DM, McGandy RB, Myers ML, Stare FJ. Quantitative effects of dietary fato n serum cholesterol in man. Am J Clin Nutr. 1965;17(5):281-95.

117. Kris-Etherton PM, Yu S. Individual fatty acids on plasma lipids and lipoprotein: human studies. Am J Clin Nutr. 1997;65(5 Suppl):1628S-1644S.

118. De Lorgeril M, Salen P, Martin JL, Mamelle N, Monjaud I, Touboul P, et al. Effect of a Mediterranean type of diet on the rate of cardiovascular complications in patients with coronary artery disease. J Am Coll Cardiol. 1996;28(5):1103-8.

119. Navarro JA, Caramelli B. Vegetarians from Latin America. Am J Cardiol. 2010;105(6):902.

120. Saravanan P, Davidson NC, Schmidt EB, Calder PC. Cardiovascular effects of marine omega-3 fatty acids. Lancet. 2010;376(9740):540-50.

121. Gagliardi AC, Mancini Filho J, Santos RD. [Nutritional profile of foods with zero trans fatty acids claim]. Rev Assoc Med Bras. 2009;55(1):50-3.

122. Larqué E, Zamora S, Gil A. Dietary trans fatty acids in early life: a review. Early Hum Dev. 2001;65 Suppl:S31-41.

123. Aro A, van Amelsvoort Becker W, van Erp-Baart MA, Kafatos A, Leth $T$, van Poppel, G. Trans fatty acids in dietary fats and oils from 14 European Countries: the TRANSFAIR study. J Food Comp Anal. 1998;11(2):137-49.

124. Dionisi F, Golay PA, Fay LB. Influence of milk fat presence on the determination of trans fatty acids in fats used for infant formulae. Anal Chim Acta. 2002;465(1):395-407.

125. Oomen CM, Ocké MC, Feskens EJ, van Erp-Baart MA, Kok FJ, Kromhout D. Association between trans fatty acid intake and 10-year risk of coronary heart disease in the Zutphen Elderly Study: a prospective population-based study. Lancet. 2001;357(9258):746-51.

126. Lairon D, Arnault N, Bertrais S, Planells R, Clero E, Hercberg S, et al. Dietary fiber intake and risk factors for cardiovascular disease in French adults. Am J Clin Nutr. 2005;82(6):1185-94.

127. Brown L, Rosner B, Willett WW, Sacks FM. Cholesterol-lowering effects of dietary fiber: a meta-analysis. Am J Clin Nutr. 1999;69(1):30-42.

128. Hollander JM, Mechanick JI. Complementary and alternative medicine and the management of the metabolic syndrome. J Am Diet Assoc. 2008;108(3):495-509.

129. Trautwein EA, Duchateau GS, Lin YG, Mel'nikov SM, Molhuizen HOF, Ntanios FY. Proposed mechanisms of cholesterol-lowering action of plant sterols. Eur J Lipid Sci Technol. 2003;105:171-85.

130. Gagliardi AC, Maranhão RC, de Sousa HP, Schaefer EJ, Santos RD. Effects of margarines and butter consumption on lipid profiles, inflammation markers and lipid transfer to HDL particles in free-living subjects with the metabolic syndrome. Eur J Clin Nutr. 2010;64(10):1141-9.

131. Demonty I, Ras RT, van der Knaap HC, Duchateau GS, Meijer L, Zock PL, et al. Continuous dose-response relationship of the LDL-cholesterol-lowering effect of phytosterol intake. J Nutr. 2009;139(2):271-84.

132. Amundsen AL, Ntanios F, Put N, Ose L. Long-term compliance and changes in plasma lipids, plant sterols and carotenoids in children and parents with FH consuming plant sterol ester-enriched spread. Eur J Clin Nutr. 2004;58(12):1612-20.
133. Obarzanek E, Sacks FM, Vollmer WM, Bray GA, Miller ER 3rd, Lin $\mathrm{PH}$, et al. Effects on blood lipids of a boold pressure-lowering diet: the Dietary Approaches to Stop Hypertension (DASH) Trial. Am J Clin Nutr. $2001 ; 74(1): 80-9$.

134. McVeigh BL, Dillingham BL, Lampe JW, Duncan AM. Effect of soy protein varying in isoflavone content on serum lipids in healthy young men. Am J Clin Nutr. 2006;83(2):244-51.

135. Høie LH, Morgenstern EC, Gruenwald J, Graubaum HJ, Busch R, Lüder W, et al. A double-blind placebo-controlled clinical trial compares the cholesterol-lowering effects of two different soy protein preparations in hypercholesterolemic subjects. Eur J Nutr. 2005;44(2):65-71.

136. McNamara DJ. The impact of egg limitations on coronary heart disease risk: do the numbers add up? J Am Coll Nutr. 2000;19(5 Suppl):540S-548S .

137. Hu FB, Stampfer MJ, Manson JE, Ascherio A, Colditz GA, Speizer FE. Dietary saturated fat and their food sources in relations to the risk of coronary heart disease in women. Am J Clin Nutr. 1999;70(6):1001-8.

138. Hopkins PN. Effects of dietary cholesterol on serum cholesterol: a metaanalysis and review. Am J Clin Nutr. 1992;55(6):1060-70.

139. Wang JF, Schramm DD, Holt RR, Ensunsa JL, Fraga CG, Schmitz HH, et al. A dose-response effect from chocolate consumption on plasma epicatechin and oxidative damage. J Nutr. 2000;130(8S Suppl):2115S-9S.

140. Tokede OA, Gaziano JM, Djoussé L. Effects of cocoa products/dark chocolate on serum lipids: a meta-analysis. Eur J Clin Nutr. 2011;65(8):879-86.

141. de Roos N, Schouten E, Katan M. Consumption of a solid fat rich in lauric acid results in a more favorable lipid profile in healthy men and women than consumption of a solid fat rich in trans-fatty acids. J Nutr. 2001;131(2):242-5.

142. Lipoeto NI, Agus Z, Oenzil F, Wahlqvist M, Wattanapenpaiboon N. Dietary intake and the risk of coronary heart disease among the coconutconsuming Minangkabau in West Sumatra, Indonesia. Asia Pac J Clin Nutr. 2004;13(4):377-84.

143. Kumar PD. The role of coconut and coconut oil in coronary heart disease in Kerala, south India. Trop Doct. 1997;27(4):215-7.

144. Assunção ML, Ferreira HS, dos Santos AF, Cabral CR Jr, Florêncio TM. Effects of dietary coconut oil on the biochemical and anthropometric profiles of women presenting abdominal obesity. Lipids. 2009;44(7):593-601.

145. Lecker JL, Matthan NR, Billheimer JT, Rader DJ, Lichtenstein AH. Impact of dietary fat type within the context of altered cholesterol homeostasis on cholesterol and lipoprotein metabolism in the F1B hamster. Metabolism. 2010;59(10):1491-501.

146. Grundy SM, Cleeman JI, Merz CN, Brewer HB Jr, Clark LT, Hunninghake DB, et al; Coordinating Committee of the National Cholesterol Education Program. Implications of recent clinical trials for the National Cholesterol Education Program Adult Treatment Panel III guidelines. Circulation. 2004;110(2):227-39.

147. Baigent C, Keech A, Kearney PM, Blackwell L, Buck G, Pollicino C, et al; Cholesterol Treatment Trialists' (CTT) Collaborators. Efficacy and safety of cholesterol-lowering treatment: prospective meta-analysis of data from 90,056 participants in 14 randomised trials of statins. Lancet. 2005;366(9493):1267-78.

148. Cholesterol Treatment Trialists' (CTT) Collaboration, Baigent C, Blackwell L, Emberson J, Holland LE, Reith C, et al. Efficacy and safety of more intensive lowering of $\mathrm{LDL}$ cholesterol: a meta-analysis of data from 170000 participants in 26 randomised trials. Lancet. 2010;376(9753):1670-81.

149. National Institute for Health and Clinical Excellence. [internet]. Clinical guidelines and evidence review for familial hypercholesterolemias: the identification and management of adults and children with familial hypercholesterolemia - 2008 (Clinical guidelines 71). [Cited in $2011 \mathrm{Nov}$ 21]. Available from: http://www.nice.org.uk/CG71.

150. Wierzbicki AS, Humphries SE, Minhas R; Guideline Development Group. Familial hypercholesterolemia: summary of NICE guidance. BMJ. 2008;337:a1095. 
151. Cohen DE, Anania FA, Chalasani N; National Lipid Association Statin Safety Task Force Liver Expert Panel. An assessment of statin safety by hepatologists. Am J Cardiol. 2006;97(8A):77C-81C.

152. Thompson PD, Clarkson PM, Rosenson RS; National Lipid Association Statin Safety Task Force Muscle Safety Expert Panel. An assessment of statin safety by muscle experts. Am J Cardiol. 2006;97(8A):69C-76C

153. McKenney JM, Davidson MH, Jacobson TA, Guyton JR; National Lipid Association Statin Safety Assessment Task Force. Final conclusions and recommendations of the National Lipid Association Statin Safety Assessment Task Force. Am J Cardiol. 2006;97(8A):89C-94C

154. Jones P, Kafonek S, Laurora I, Hunninghake D. Comparative dose efficacy study of atorvastatin versus simvastatin, pravastatin, lovastatin, and fluvastatin in patients with hypercholesterolemia (the CURVES study). Am J Cardiol. 1998;81(5):582-7.

155. Jones PH, Davidson MH, Stein EA, Bays HE, McKenney JM, Miller E, et al. Comparison of the efficacy and safety of rosuvastatin versus atorvastatin, simvastatin, and pravastatin across doses (STELLAR* Trial). Am J Cardiol. 2003:92(2):152-60

156. Backes JM, Venero CV, Gibson CA, Ruisinger JF, Howard PA, Thompson PD, et al. Effectiveness and tolerability of every-other-day rosuvastatin dosing in patients with prior statin intolerance. Ann Pharmacother. 2008;42(3):341-6.

157. Backes JM, Moriarty PM, Ruisinger JF, Gibson CA. Effects of once weekly rosuvastatin among patients with a prior statin intolerance. Am J Cardiol. 2007;100(3):554-5

158. Ito MK, McGowan MP, Moriarty PM; National Lipid Association Expert Panel on Familial Hypercholesterolemia. Management of familial hypercholesterolemias in adult patients: recommendations from the National Lipid Association Expert Panel on Familial Hypercholesterolemia. J Clin Lipidol. 2011;5(3 Suppl):S38-45.

159. The Lipid Research Clinics Coronary Primary Prevention Trial results. II. The relationship of reduction in incidence of coronary heart disease to cholesterol lowering. JAMA. 1984;251(3):365-74.

160. Baigent C, Landray MJ, Reith C, Emberson J, Wheeler DC, Tomson C, et al; The effects of lowering LDL cholesterol with simvastatin plus ezetimibe in patients with chronic kidney disease (Study of Heart and Renal Protection): a randomised placebo-controlled trial. Lancet. 2011;377(9784):2181-92.

161. Berge KG, Canner PL. Coronary drug project: experience with niacin. Coronary Drug Project Research Group. EurJ Clin Pharmacol. 1991;40(Suppl 1):S49-51.

162. Taylor AJ, Lee HJ, Sullenberger LE. The effect of 24 months of combination statin and extended-release niacin on carotid intima-media thickness: ARBITER 3. Curr Med Res Opin. 2006;22(11):2243-50.

163. Fazio S, Guyton JR, Polis AB, Adewale AJ, Tomassini JE, Ryan NW. Longterm safety and efficacy of triple combination ezetimibe/simvastatin plus extended-release niacin in patients with hyperlipidemia. Am J Cardiol. 2010;105(4):487-94.

164. Guyton JR. Effect of niacin on atherosclerotic cardiovascular disease. Am J Cardiol. 1998;82(12A):18U-23U.

165. Taylor AJ, Villines TC, Stanek EJ, Devine PJ, Griffen L, Miller M, et al. Extended-release niacin or ezetimibe and carotid intima-media thickness. N Engl J Med. 2009;361(22):2113-22.

166. McKenney J, Bays H, Koren M, Ballantyne CM, Paolini JF, Mitchel Y, et al. Safety of extended-release niacin/laropiprant in patients with dyslipidemia. J Clin Lipidol. 2010;4(2):105-112.e1.

167. Buchwald H, Varco RL, Matts JP, Long JM, Fitch LL, Campbell GS, et al. Effect of partial ileal bypass surgery on mortality and morbidity from coronary heart disease in patients with hypercholesterolemia. Report of the Program on the Surgical Control of the Hyperlipidemias (POSCH). N Engl J Med. 1990;323(14):946-55.

168. Ohri SK, Keane PF, Swift I, Sackier JM, Williamson RC, Thompson GR, et al. Reappraisal of partial ileal bypass for the treatment of familial hypercholesterolemia. Am J Gastroenterol. 1989;84(7):740-3.
169. Kroon AA, Aengevaeren WR, van der Werf T, Uijen GJ, Reiber JH, Bruschke AV, et al; LDL-Apheresis Atherosclerosis Regression Study (LAARS). Effect of aggressive versus conventional lipid lowering treatment on coronary atherosclerosis. Circulation. 1996;93(10):1826-35.

170. Nishimura S, Sekiguchi M, Kano T, Ishiwata S, Nagasaki F, Nishide $\mathrm{T}$, et al. Effects of intensive lipid lowering by low-density lipoprotein apheresis on regression of coronary atherosclerosis in patients with familial hypercholesterolemia: Japan Low-density Lipoprotein Apheresis Coronary Atherosclerosis Prospective Study (L-CAPS). Atherosclerosis. 1999;144(2):409-17.

171. Goldberg AC, Hopkins PN, Toth PP, Ballantyne CM, Rader DJ, Robinson $J G$, et al. Hypercholesterolemia: screening, diagnosis and management of pediatric and adult patients: clinical guidance from the National Lipid Association Expert Panel on Familial Hypercholesterolemia. J Clin Lipidol. 2011;5(3 Suppl):S1-8

172. Barbir M, Khaghani A, Kehely A, Tan KC, Mitchell A, Thompson GR, et al. Normal levels of lipoproteins including lipoprotein(a) after liver-heart transplantation in a patient with homozygous familial hypercholesterolaemia. Q J Med. 1992;85(307-308):807-12.

173. Benlian P, Turquet A, Carrat F, Amsellem S, Sanchez L, Briffaut D, et al. Diagnosis scoring for clinical identification of children with heterozygous familial hypercholesterolemia. J Pediatr Gastroenterol Nutr. 2009;48(4):45663.

174. Campagna F, Martino F, Bifolco M, Montali A, Martino E, Morrone F, et al. Detection of familial hypercholesterolemia in a cohort of children with hypercholesterolemia: results of a family and DNA-based screening. Atherosclerosis. 2008;196(1):356-64.

175. Avis HJ, Vissers MN, Stein EA, Wijburg FA, Trip MD, Kastelein JJ, et al. A systematic review and meta-analysis of statin therapy in children with familial hypercholesterolemia. Arterioscler Thromb Vasc Biol. 2007;27(8):1803-10

176. Arambepola C, Farmer AJ, Perera R, Neil HA. Statin treatment for children and adolescents with heterozygous familial hypercholesterolaemia: a systematic review and meta-analysis. Atherosclerosis. 2007;195(2):339-47.

177. Avis HJ, Hargreaves IP, Ruiter JP, Land JM, Wanders RJ, Wijburg FA Rosuvastatin lowers coenzyme Q10 levels, but not mitochondrial adenosine triphosphate synthesis, in children with familial hypercholesterolemia. J Pediatr. 2011;158(3):458-62.

178. Avis HJ, Hutten BA, Gagné C, Langslet G, McCrindle BW, Wiegman A, et al. Efficacy and safety of rosuvastatin therapy for children with familial hypercholesterolemia. J Am Coll Cardiol. 2010;55(11):1121-6.

179. Clauss SB, Holmes KW, Hopkins P, Stein E, Cho M, Tate A, et al. Efficacy and safety of lovastatin therapy in adolescent girls with heterozygous familial hypercholesterolemia. Pediatrics. 2005;116(3):682-8

180. Ferreira WP, Bertolami MC, Santos SN, Barros MR, de Matos Barretto RB, Pontes SC Jr, et al. One-month therapy with simvastatin restores endothelial function in hypercholesterolemic children and adolescents. Pediatr Cardiol. 2007;28(1):8-13.

181. Gandelman K, Glue P, Laskey R, Jones J, LaBadie R, Ose L. An eight-week trial investigating the efficacy and tolerability of atorvastatin for children and adolescents with heterozygous familial hypercholesterolemia. Pediatr Cardiol. 2011;32(4):433-41.

182. Lebenthal Y, Horvath A, Dziechciarz P, Szajewska H, Shamir R. Are treatment targets for hypercholesterolemia evidence based? Systematic review and meta-analysis of randomised controlled trials. Arch Dis Child. 2010;95(9):673-80

183. Daniels SR, Greer FR; Committee on Nutrition. Lipid screening and cardiovascular health in childhood. Pediatrics. 2008;122(1):198-208

184. Kavey RE, Allada V, Daniels SR, Hayman LL, McCrindle BW, Newburger JW, et al. Cardiovascular risk reduction in high-risk pediatric patients: a scientific statement from the American Heart Association Expert Panel on Population and Prevention Science; the Councils on Cardiovascular Disease in the Young, Epidemiology and Prevention, Nutrition, Physical Activity and 
Metabolism, High Blood Pressure Research, Cardiovascular Nursing, and the Kidney in Heart Disease; and the Interdisciplinary Working Group on Quality of Care and Outcomes Research: endorsed by the American Academy of Pediatrics. Circulation. 2006;114(24):2710-38.

185. Clauss S, Wai KM, Kavey RE, Kuehl K. Ezetimibe treatment of pediatric patients with hypercholesterolemia. J Pediatr. 2009;154(6):869-72.

186. Davidson MH. A systematic review of bile acid sequestrant therapy in children with familial hypercholesterolemia. J Clin Lipidol. 2011;5(2):76-81.

187. Amundsen AL, Ose L, Nenseter MS, Ntanios FY. Plant sterol ester-enriched spread lowers plasma total and LDL cholesterol in children with familial hypercholesterolemia. Am J Clin Nutr. 2002;76(2):338-44.

188. Bilal MS, Aydemir NA, Cine N, Celebi A, Kaplan M. Triple coronary bypass in a child with homozygous familial hypercholesterolemia. Heart Surg Forum. 2005;8(5):E351-3.

189. Göksel OS, Tireli E, El H, Oflaz H, Dayioğlu E. Coronary artery bypass grafting in a 12-year-old girl with familial hypercholesterolemia. Acta Chir Belg. 2009;109(1):117-8.

190. Bilal MS, Aydemir NA, Turan T. Ross-Konno procedure and ostial plasty in a child with homozygous hypercholesterolemia: case report. J Heart Valve Dis. 2005;14(6):855-8.

191. Kakaei F, Nikeghbalian S, Kazemi K, Salahi H, Bahador A, Dehghani SM, et al. Liver transplantation for homozygous familial hypercholesterolemia: two case reports. Transplant Proc. 2009;41(7):2939-41.

192. Khalifeh M, Faraj W, Heaton N, Rela M, Sharara Al. Successful living-related liver transplantation for familial hypercholesterolemia in the Middle East. Transpl Int. 2005;17(11):735-9.

193. de Jongh S, Kerckhoffs MC, Grootenhuis MA, Bakker HD, Heymans HS, Last BF. Quality of life, anxiety and concerns among statin-treated children with familial hypercholesterolaemia and their parents. Acta Paediatr. 2003;92(9):1096-101.

194. Toleikyte I, Retterstøl K, Leren TP, Iversen PO. Pregnancy outcomes in familial hypercholesterolemia: a registry-based study. Circulation. 2011;124(15):1606-14.

195. Klingel R, Göhlen B, Schwarting A, Himmelsbach F, Straube R. Differential indication of lipoprotein apheresis during pregnancy. Ther Apher Dial. 2003;7(3):359-64.

196. Thorogood M, Seed M, De Mott K; Guideline Development Group. Management of fertility in women with familial hypercholesterolaemia: summary of NICE guidance. BJOG. 2009;116(4):478-9.

197.Simonson SG, Martin PD, Warwick MJ, Mitchell PD, Schneck DW. The effect of rosuvastatin on oestrogen \& progestin pharmacokinetics in healthy women taking an oral contraceptive. Br J Clin Pharmacol. 2004;57(3):279-86.
198. Ofori B, Rey E, Bérard A. Risk of congenital anomalies in pregnant users of statin drugs. Br J Clin Pharmacol. 2007;64(4):496-509.

199. Kusters DM, Homsma SJ, Hutten BA, Twickler MT, Avis HJ, van der Post JA, et al. Dilemmas in treatment of women with familial hypercholesterolaemia during pregnancy. Neth J Med. 2010;68(1):299-303.

200. Catov JM, Bodnar LM, Kip KE, Hubel C, Ness RB, Harger G, et al. Early pregnancy lipid concentrations and spontaneous preterm birth. Am J Obstet Gynecol. 2007;197(6):610.e1-7.

201. Amundsen AL, Khoury], Iversen PO, Bergei C, Ose L, Tonstad S, et al. Marked changes in plasma lipids and lipoproteins during pregnancy in women with familial hypercholesterolemia. Atherosclerosis. 2006;189(2):451-7.

202. Hameed AB, Tummala PP, Goodwin TM, Nuno I, Wani OR, Karaalp IS, et al. Unstable angina during pregnancy in two patients with premature coronary atherosclerosis and aortic stenosis in association with familial hypercholesterolemia. Am J Obstet Gynecol. 2000;182(5):1152-5.

203. Khoury J, Amundsen AL, Tonstad S, Henriksen T, Ose L, Retterstøl K, et al. Evidence for impaired physiological decrease in the uteroplacental vascular resistance in pregnant women with familial hypercholesterolemia. Acta Obstet Gynecol Scand. 2009;88(2):222-6.

204. Liguori A, D'Armiento FP, Palagiano A, Balestrieri ML, Williams-Ignarro S, de Nigris F, et al. Effect of gestational hypercholesterolaemia on omental vasoreactivity, placental enzyme activity and transplacental passage of normal and oxidised fatty acids. BJOG. 2007;114(12):1547-56.

205. Cuchel M, Bloedon LT, Szapary PO, Kolansky DM, Wolfe ML, Sarkis A, et al. Inhibition of microsomal triglyceride transfer protein in familial hypercholesterolemia. N Engl J Med. 2007;356(2):148-56.

206. Stein EA, Bays H, O’Brien D, Pedicano J, Piper E, Spezzi A. Lapaquistat acetate: development of a squalene synthase inhibitor for the treatment of hypercholesterolemia. Circulation. 2011;123(18):1974-85.

207. Elsayed RK, Evans JD. Emerging lipid-lowering drugs: squalene synthase inhibitors. Expert Opin Emerg Drugs. 2008;13(2):309-22.

208. Ni YG, Di Marco S, Condra JH, Peterson LB, Wang W, Wang F, et al. APCSK9binding antibody that structurally mimics the EGF(A) domain of LDL-receptor reduces LDL cholesterol in vivo. J Lipid Res. 2011;52(1):78-86.

209. Ladenson PW, Kristensen JD, Ridgway EC, Olsson AG, Carlsson B, Klein I, et al. Use of the thyroid hormone analogue eprotirome in statin-treated dyslipidemia. N Engl J Med. 2010;362(10):906-16.

210. Raal FJ, Santos RD, Blom DJ, Marais AD, Charng MJ, Cromwell WC, et al. Mipomersen, an apolipoprotein B synthesis inhibitor, for lowering of LDL cholesterol concentrations in patients with homozygous familial hypercholesterolaemia: a randomised, double-blind, placebo-controlled trial. Lancet. 2010;375(9719):998-1006. 

